\title{
Systematics and phylogeny of Sitana (Reptilia: Agamidae) of Peninsular India, with the description of one new genus and five new species
}

\author{
V. Deepak ${ }^{1,6}$, Varad B. Giri², Mohammad Asif ${ }^{3}$, Sushil Kumar Dutta ${ }^{4}$, Raju Vyas ${ }^{5}$, Amod M. Zambre ${ }^{1}$, \\ Harshal Bhosale ${ }^{1}$, K. Praveen Karanth ${ }^{1}$ \\ ${ }^{1}$ Centre for Ecological Sciences, Indian Institute of Science, Bangalore 560012, India \\ ${ }^{2}$ National Centre for Biological Science, TIFR, GKVK, Bellari Road, Bangalore 560065, India \\ ${ }^{3}$ Department of Zoology, Aligarh Muslim University, Aligarh, Uttar Pradesh 202002, India \\ ${ }^{4}$ Nature Environment \& Wildlife Society (NEWS), Turang post, Angul, Odisha 759123, India \\ 5 505, Krishnadeep Tower, Mission road, Fatehgunj, Vadodara, Gujarat 390 002, India \\ ${ }^{6}$ E-mail:veerappandeepak@gmail.com
}

Key words: cryptic, dewlap, genetics, morphology, osteology, taxonomy

\begin{abstract}
We revise the taxonomy of the agamid genus Sitana Cuvier, 1829 , a widely distributed terrestrial lizard from the Indian subcontinent based on detailed comparative analyses of external morphology, osteology and molecular data. We sampled 81 locations spread over $160,000 \mathrm{~km}^{2}$ in Peninsular India including type localities, which represented two known and five previously undescribed species. Based on general similarity in body shape and dewlap all species were hitherto identified as members of the genus Sitana. However, Sitana deccanensis and two other morphotypes, which are endemic to north Karnataka and Maharashtra in Peninsular India, are very distinct from the rest of the known members of the genus Sitana based on their external morphology and osteology. Moreover, members of this distinct morphological group were monophyletic in the molecular tree, and this clade (clade 1) was sister to two well-supported clades ( 2 and 3 ) constituting the rest of the Sitana. The interclade genetic divergence in mtDNA between clade 1 and clades 2 and 3 was $21-23 \%$, whereas clade 2 and clade 3 exhibited 14$16 \%$ genetic divergence. Thus, we designate a new genus name "Sarada" gen. nov. for species represented in Clade 1, which also includes the recently resurrected Sitana deccanensis. We describe two new species in Sarada gen. nov. and three new species in Sitana. Similarity in the dewlap of Sitana and Sara$d a$ gen. nov. is attributed to similar function (sexual signaling) and similarity in body shape is attributed to a similar terrestrial life style and/or common ancestry.
\end{abstract}

\section{Contents}

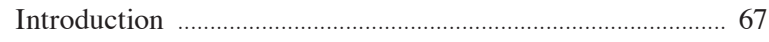

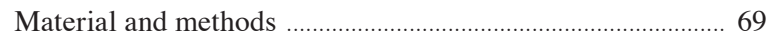

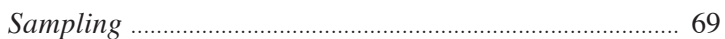

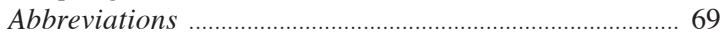

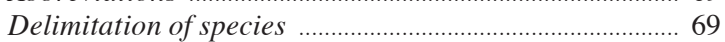

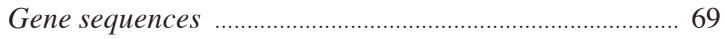

Characters used in this study ............................................. 70

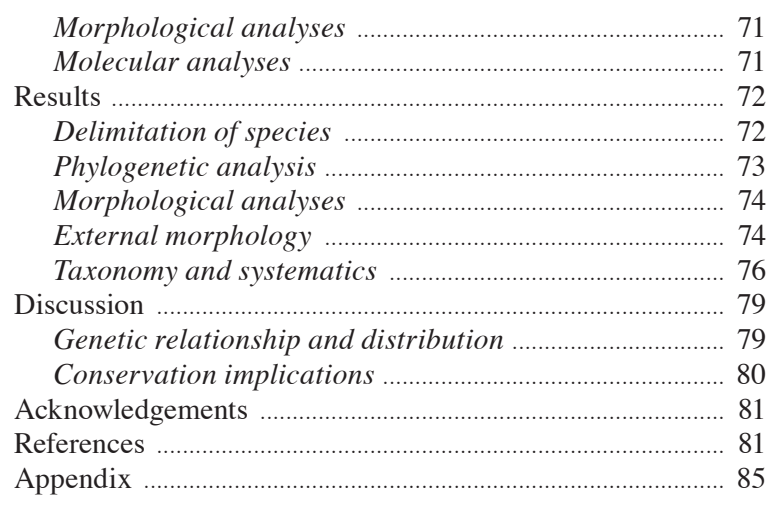

\section{Introduction}

Many widely distributed lizard species exhibit high intraspecific variation and often harbor cryptic diversity (e.g. Zamudio et al., 1997; Bergmann and Russell, 2007; Linkem et al., 2010; Smith et al., 2011; Ahmadzadeh et al., 2013; Oliver et al., 2014). These findings hint at the underestimated diversity of lizards across the world. The Indian subcontinent, a vast landscape, which is topologically and climatically heterogeneous, provides an ideal setting to further explore this issue. This large swathe of land harbors many widely distributed species and recent molecular studies indicate the presence of cryptic diversity among many lizard groups from India (Bansal and Karanth, 2010; Bauer et al., 2010; Agarwal et al., 2014a, b; Agarwal and Karanth, 2015). In this study, we attempt to better understand the diversity of one such widely distributed agamid genus, Sitana, which is endemic to the Indian subcontinent. 
Sitana are small ground dwelling agamid lizards found in diverse sets of habitats like scrublands, plateaus and sandy beaches with sparse vegetation (Pal et al., 2010; Subramanean and Reddy, 2010; Shanbhag et al., 2003; Trivedi, 2011). They primarily feed on insects but are also known to eat mollusks and plant seeds (Pal et al., 2007). In many parts of the country, they breed before the beginning of the south west monsoon (Pal et al., 2010; Subramanean and Reddy, 2010; Shanbhag et al., 2003; Trivedi, 2011). Males possess prominent dewlaps which are used in inter and intra-specific communication during the breeding season. Dewlaps are absent in female.

Cuvier (1829) described Sitana ponticeriana from Puducherry (then Pondicherry) in south India, which is the type species of the genus. Günther (1864) described a second species, Sitana minor. In his description, he mentioned that it is found in and around Madras (now Chennai). Jerdon (1870) described a third species, Sitana deccanensis, from Deccan. Boulenger (1885) synonymized both Sitana minor and Sitana deccanensis with Sitana ponticeriana. Amarasinghe et al. (2015) resurrected Sitana deccanensis, but agreed with Boulenger in considering Sitana minor a junior synonym of Sitana ponticeriana (Cuvier, 1829). Three species of Sitana (Sitana fusca Schleich and Kästle, 1998, Sitana sivalensis Schleich, Kästle and Shah, 1998, Sitana schleichi Anders and Kästle, 2002) were recently described from the Terai of Nepal. These three species are distinct from the Indian species of Sitana in having smaller dewlaps that do not extend beyond the forearm insertion, and no overlapping scales on the dewlaps (Schleich and Kästle, 2002). More recently, two new species of Sitana were described from Sri Lanka, Sitana bahiri Amarsinghe, Ineich, and Karunarathna, 2015 and Sitana devakai Amarsinghe, Ineich, and Karunarathna, 2015. Presently, only two species are known from India, though much of the range of the genus Sitana falls within this country. Given that Sitana is widely distributed in the various biogeographic subregions of India, we suspected that the Indian population might harbor various cryptic species. Furthermore, despite that many new Sitana species have been described in recent years, only one pub-

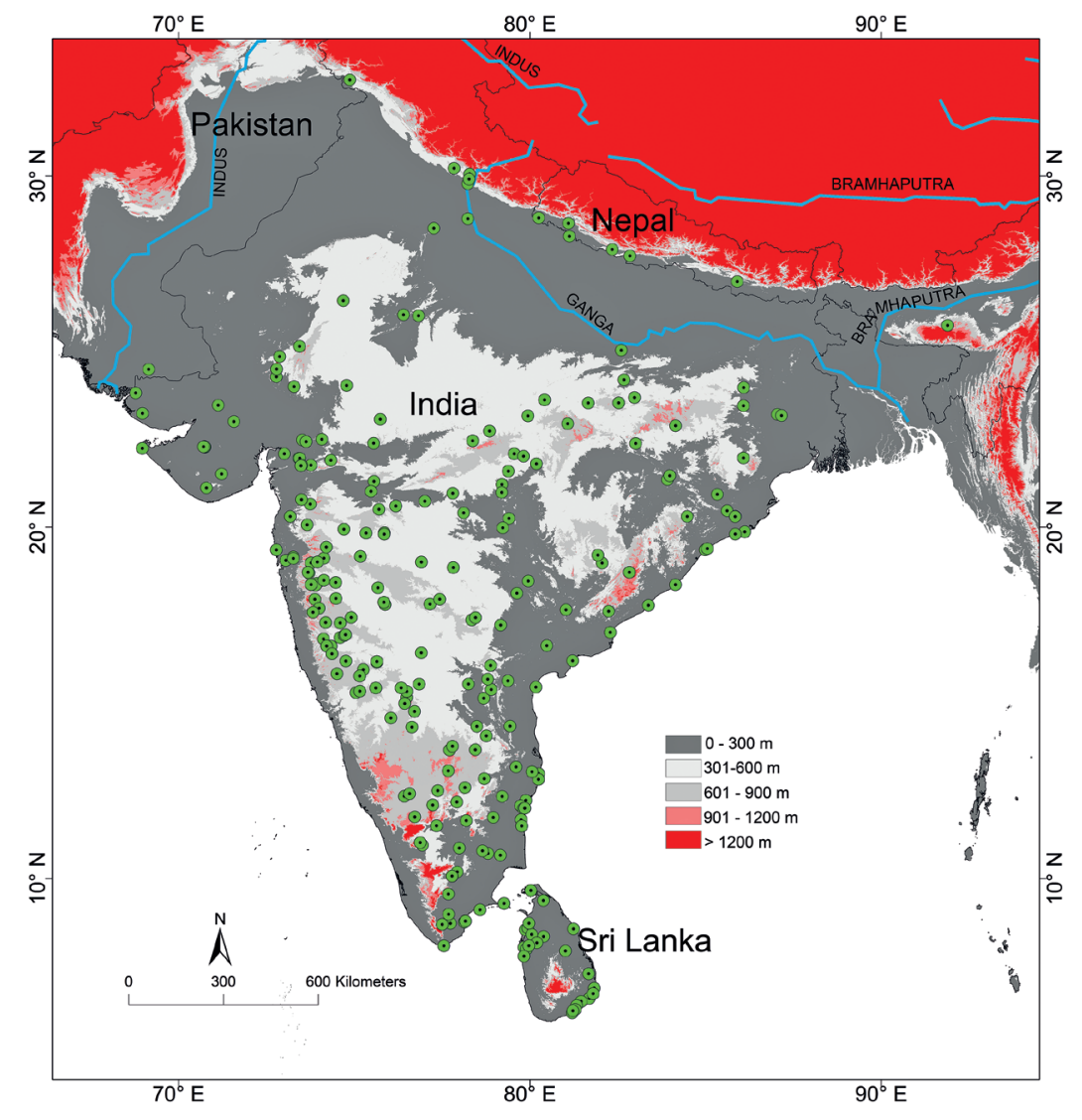

Fig. 1. Global distribution of Fan-throated lizards recorded between 1829 and 2014 (329 localities) based on museum records, published literature and our records. Major rivers in the northern part of the subcontinent are indicated in blue. Note: Umsning is the only locality record of Fan-throated lizard East of Bramhaputra River. 
lished nucleotide sequence is available in GenBank database (Macey et al., 2000), indicating that molecular data have not been recruited in an effort to identify cryptic lineages. The one available sequence was recently analyzed in the context of a dated phylogeny, suggested that the genus Sitana diverged from the genus Otocryptis (Wagler, 1830) around 12 million years ago in South Asia (Blankers et al., 2010).

Sitana ranges from the foothills of the Himalayas (Terai region of Jammu and Kashmir) in the north, to coastal Sri Lanka in the south, to Pakistan in the west, and into parts of West Bengal in the East. Stoliczka (1872), based on his experience collecting in the subcontinent and museum collections, suggested that Sitana is not found east of Brahmaputra River. However, the results of the German Indian Expedition of 1955-1958 (Hallermann et al., 2001) report a single specimen from Umsaw (Umsning), Mehalaya, West Khasi Hills, India, which is labelled as Sitana ponticeriana. This study aims to contribute to our understanding of Sitana taxonomy using morphology and support it with molecular data. We sampled in five different states in Peninsular India, including the type localities of Sitana ponticeriana and Sitana deccanensis. On the basis of these additional specimens to the museum collections, we describe one new genus and five new species of Fan-throated lizards: Sarada gen. nov., Sarada darwini sp. nov., Sarada superba sp. nov., Sitana visiri sp. nov., Sitana laticeps sp. nov. and Sitana spinaecephalus sp. nov. Additional descriptions are given for Sitana ponticeriana and Sarada deccanensis comb. nov.

\section{Material and methods}

\section{Sampling}

We carried out multiple surveys between March 2011 and November 2013, visiting 81 localities in five different states (Tamil Nadu, Karnataka, Maharashtra, Gujarat, and Rajasthan) and Puducherry union territory in India ( S1). Type localities of Sitana ponticeriana and Sitana deccanensis were also covered in the survey. Specimens were hand-collected. Sampling was carried out between 8.00-12.30 $\mathrm{h}$ in the morning and $16.00-17.30 \mathrm{~h}$ in the evening. Active search sessions involving 2-4 persons for about $2 \mathrm{~h}$ per locality were conducted. Our sampling and verification of literature records suggest that Sitana is distributed in 16 different states in India and two union territories (Fig. 1), the outer boundaries of the genus distribution is concurrent with Stoliczka's observations.

\section{Abbreviations}

Museum acronyms are as follows: NCBS (National Centre for Biological Sciences, Bangalore), BNHS (Bombay Natural History Society Museum, Mumbai), BMNH (Natural History Museum, London, UK), CES (Centre for Ecological Sciences, Indian Institute of Science, Bangalore), ZSIK (Zoological Survey of India, Kolkata), ZSIP (Zoological Survey of India, Pune), and MNHN (Muséum National d'Histoire Naturelle, Paris). Other abbreviations are as follows: meters above sea level (m.a.s.l.).

\section{Delimitation of species}

Field sampling and examination of museum specimens during the initial part of this study helped us identify specific characters for diagnosis of morphospecies. These characters were used in the field during our consecutive sampling to identify morpho-species. Morphological characters are thus distinct and used in the delimitation of the species. Molecular data was used to understand the evolutionary relationships of the species and their distinctiveness.

\section{Gene sequences}

Our sampling for molecular work was restricted to Peninsular India where we sampled type localities of two valid species and one synonym. Tissue samples from three individuals were collected from every sampling locality, and between two and seven samples per morpho-species from Peninsular India were used to generate molecular data. Specimens were fixed in $4 \%$ formaldehyde for 24 hours and subsequently preserved in $70 \%$ ethanol for long-term storage. Genomic DNA was extracted from tissue samples collected from the thigh region, liver, or tail of an individual. These samples were stored in $99.9 \%$ ethanol and refrigerated at $-20^{\circ} \mathrm{C}$. DNeasy (Qiagen ${ }^{\circledR}$ ) blood and tissue kits were used to extract DNA. Partial sequences of the NADH dehydrogenase subunit 2 (ND2) mitochondrial gene ( $\sim 1026$ bp) were obtained using the primers L4437b (forward) and H5540 (reverse) from Macey et al. (1997, 2000). Partial sequences were also obtained for three nuclear genes: Recombination activating gene 1 (RAG1), R35, and Phosducin (PDC). The 1026 bp fragment of RAG1 was amplified and sequenced using 
the R13 (forward) and R18 (reverse) primers (see Groth and Barrowclough, 1999). The 665 bp fragment of R35 was amplified and sequenced using the primers R-35 (forward) and R-35 (reverse) (see Leaché, 2009). The 424 bp fragment of Phosducin was amplified and sequenced using the primers PHOF2 (forward) and PHOR1 (reverse) as described in Bauer et al. (2007). Sequences were obtained using Sanger sequencing.

\section{Characters used in this study}

External morphology. We studied 231 specimens of Fan-throated lizard from across India, including 56 museum specimens and 175 from our own collection. One hundred and six out of the 231 specimens are males and 78 are female, with 39 subadults and 8 hatchlings. Twenty six of those specimens were damaged or badly preserved. Morphometric characters were measured from 158 specimens out of the 231 individuals. Most morphometric characters were measured following Zug et al. (2006), as described below. Most measurements (to the nearest $0.01 \mathrm{~mm}$ ) were taken with digital calipers (Mitutoyu ${ }^{\mathrm{TM}}$ ). Measurements from photographs were extracted using software ImageJ (Rasband, 2004). The following measurements were taken: snout-vent length (SVL, from tip of snout to anterior border of cloaca), head length (HL, from snout tip to posterior border of tympanum), head width (HW, distance from left to right outer edge of the head at its widest point), head height (HH, Dorsoventral distance from top of head to underside of jaw at transverse plane intersecting angle of jaws), snout-eye length (SE, from snout tip to anterior border of orbit), eye to tympanum (ET, from posterior border of orbit to anterior border of tympanum), jaw length (JL, from rostrum to corner of jaw), interorbital width (IO, transverse distance between anterodorsal corners of left and right orbits), naris to eye (NE, distance from the anterior edge of orbit to posterior edge of naris), snout width/internasal distance (IN, transverse distance between left and right nares), tympanum diameter (TD, greatest diameter of tympanum), orbit diameter (OD, distance between anterior and posterior margins of orbit), lower arm length (LAL, distance from elbow to distal end of wrist, or just underside of forefoot), upper arm length (UAL, distance from anterior insertion of forelimb to elbow), finger lengths (F1, F2, F3, F4, F5) (e.g. $\mathrm{F} 4=$ Distance from juncture of $3^{\text {rd }}$ and $4^{\text {th }}$ digits to distalmost extent of $4^{\text {th }}$ finger, femur length (FEL, length of femur from groin to knee), crus length (CL, length of crus (tibia) from knee to heel), hind foot length (HFL, distance from proximal end (heel) of hindfoot to distal most point of fourth toe), hind limb length (HLL, from groin to tip of fourth toe), toe lengths (T1, T2, T3, T4, T5) (e.g. T4 = Distance from juncture of 3rd and 4th digits to distal end of 4th digit on hindfoot), trunk length (TrL, from forelimb insertion to hind limb insertion), trunk height ( $\operatorname{TrH}$, depth midway between the fore- and hind limb insertions), trunk width (TrW, width midway between the fore- and hind limb insertions), tail length (TL, from posterior border of cloacal opening to tip of tail), tail height (TH) and tail width (TW) at tail base. Dewlap length (DWL, distance between posterior end of dewlap and tip of lower jaw). One morphometric character described by Amarasinghe et al. (2015) axillathroat-fan length is renamed as extent of dewlap in trunk (DWLT, measured from the axilla till the end of the dewlap).

Meristic characters were counted for multiple individuals per species. The following characters were scored: mid-body scale rows (MBS, number of scale rows around the trunk at midbody), ventral scales (VEN, number of scales from below mental to anterior border of cloaca), fourth toe lamellae (LAM4, number of $4^{\text {th }}$ toe lamellae, from $1^{\text {st }}$ lamella at the digit's cleft to the most distal lamella), dewlap scales (ESD, number of enlarged scale rows on the dewlap), supralabials (SL, posterior end defined by the last enlarged scale that touches infralabials at rear corner of mouth), infralabials (IL, posterior end defined by the posteriormost enlarged scales that contact the supralabials at the rear corner of the mouth).

Hemipenis morphology. For most specimens collected during the breeding season, we everted and prepared the hemipenes during specimen preparation. $4 \%$ formaldehyde was injected under the tail base in order to evert the hemipenes. Hemipenis morphology was documented using standard hemipenial nomenclature (Dowling and Savage, 1960). Hemipenis drawings were done under a camera lucida attached to the microscope (Leica M165C).

Osteology. One male and one female each of Sitana ponticeriana, Sitana spinaecephalus sp. nov., Sarada darwini sp. nov. and Sarada deccanensis comb. nov. were cleared and stained following protocols from Hanken and Wassersug (1981). Osteological descriptions were made from both sexes of a species. Skulls were prepared by maceration. Descriptions of skeletal characters followed Romer (1956), Oelrich (1956), Jollie (1960) and Moody (1980). 


\section{Morphological analyses}

All body size measurements were divided by SVL and DWLT was divided by TrL these ratios were compared and used to separate species. We first computed the ratios and then tested each variables for normality using the Shapiro-Wilk test of normality before performing the Principal Component Analysis (PCA). PCA was used to analyze the morphometric data in software R (R Core Team, 2013). Prior to analysis, all variables were square root transformed. The body ratios which we found to be different using exploratory analysis of the data for certain species were further tested using one way ANOVA and a pairwise comparison of means using the Tukey contrasts test. Prior to performing ANOVA, variables for each species were tested for normality. Due to our low sample size for females, only males were included in morphometric analyses.

\section{Molecular analyses}

We used maximum likelihood and Bayesian methods to analyze the molecular data. Based on the findings by Macey et al. (2000), Otocryptis wiegmanii and Calotes calotes were used as outgroups. ND2 sequences for these two genera and one sequence of Sitana bahiri were downloaded from GenBank (S1). Sequences were aligned using ClustalW and uncorrected genetic distances were calculated using MEGA 5 (Tamura et al., 2011). The combined dataset was partitioned into four genes (ND2, RAG1, R35, PDC). PartitionFinder v1.1.1 (Lanfear et al., 2012) was used to find the best partition scheme and model of sequence evolution for each partition. The optimal partitioning scheme included seven partitions (see S2). Likelihood analysis in RaxML takes only one model of sequence evolution, therefore we used GTR+G for all seven partitions. In case of Bayesian analysis seven partitions

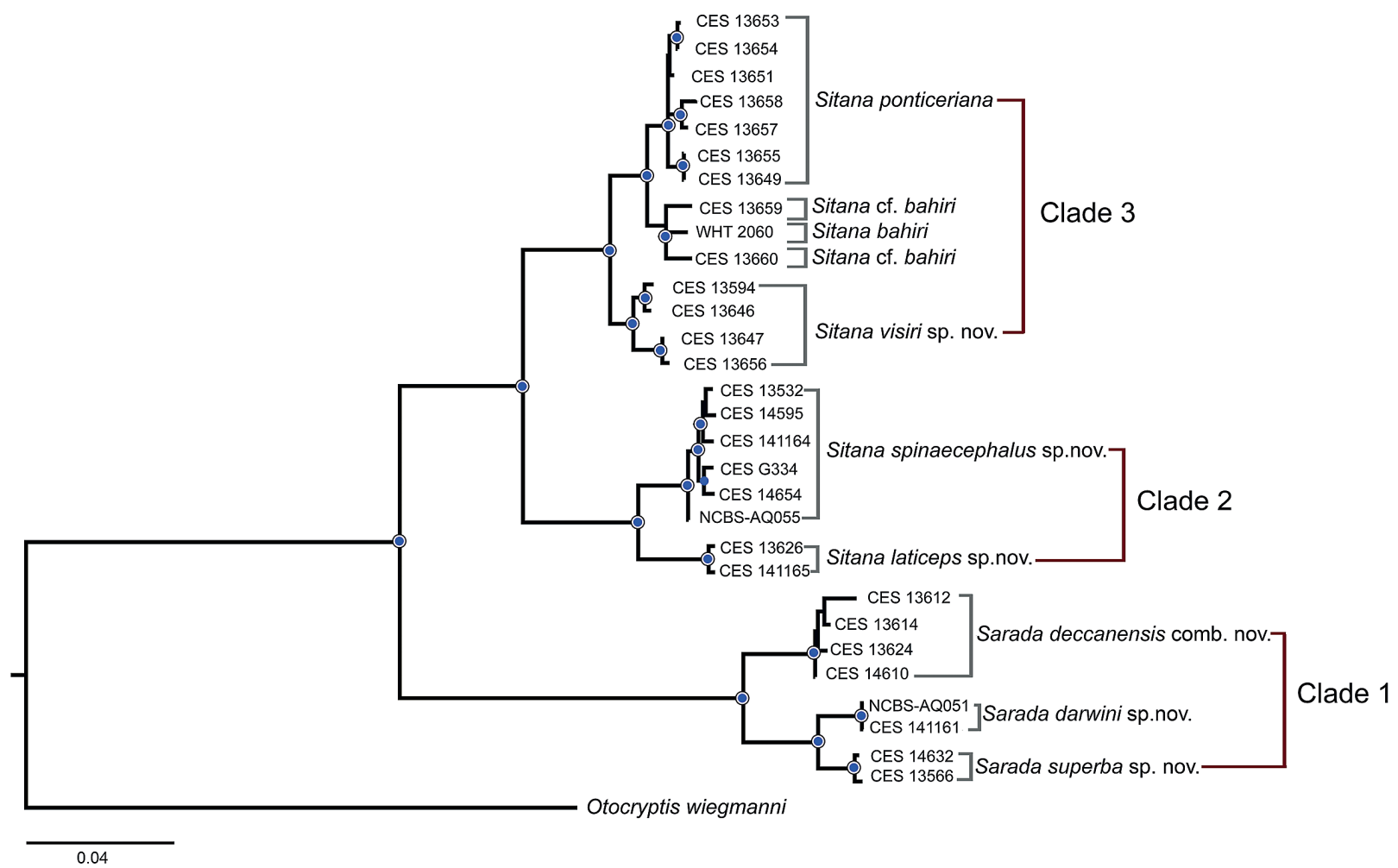

Fig. 2. Maximum likelihood phylogeny of Fan-throated lizards, showing the three different clades (Refer Fig. 3 for dewlap morphology and Fig. 4 for hemipenial morphology). Nodal support is indicated by the coloration of the circles at the nodes, with blue and white fill corresponding to ML bootstrap $\geq 75$ and pure blue fill indicating bootstrap support $>95 \%$. 


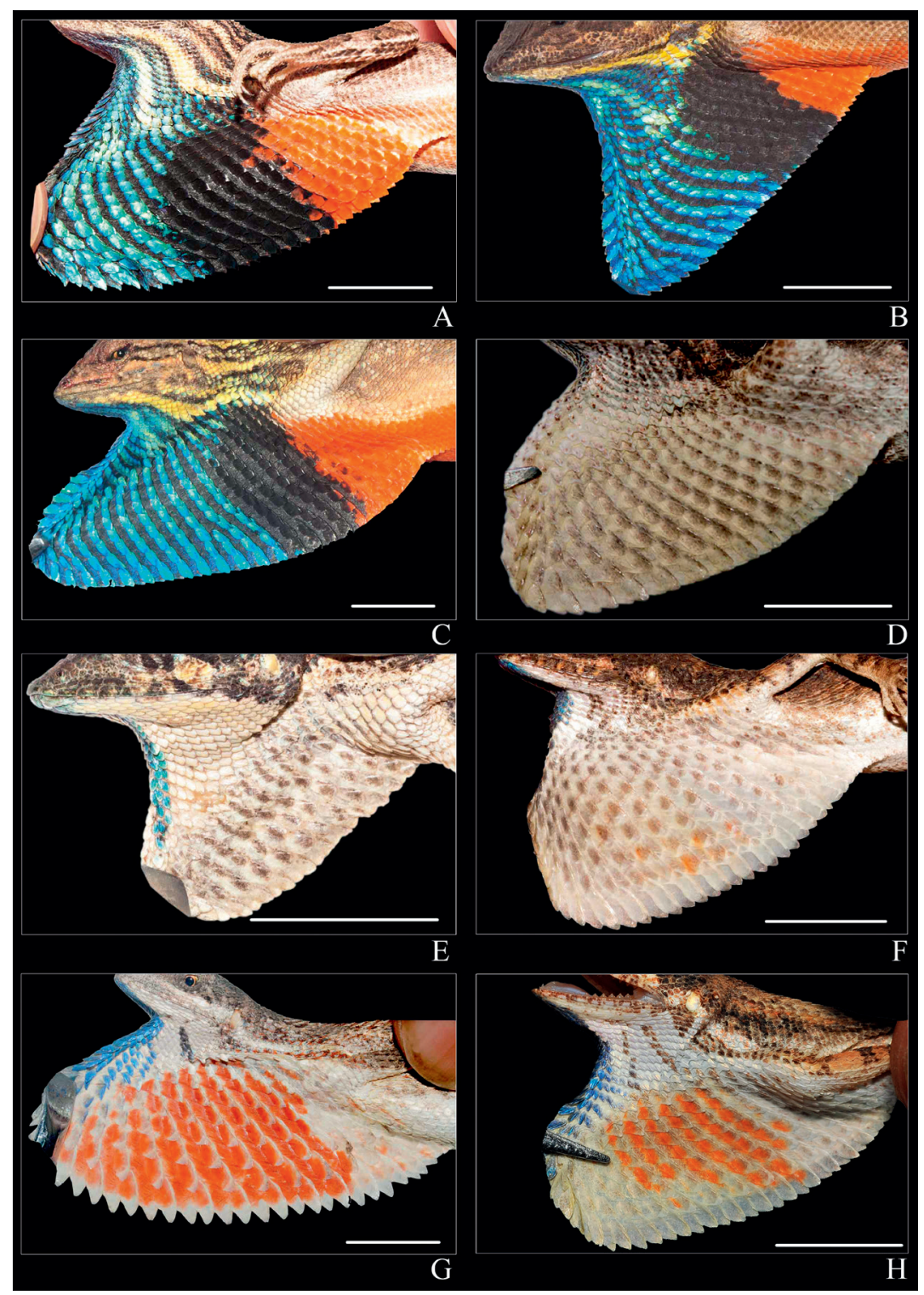

Fig. 3. Dewlap morphology and colouration of Fan-throated lizards. Clade 1: A. Sitana darwini sp. nov., B. Sarada deccanensis comb. nov., C. Sitana superba sp. nov.; Clade 2: D. Sitana spinaecephalus sp. nov., E. Sitana laticeps sp. nov.; Clade 3: F. Sitana ponticeriana, G. Sitana visiri sp. nov., H. Sitana cf. bahiri. Scale bar $=10 \mathrm{~mm}$ were assigned to different models (see S2). We employed the RAxML GUI (Silvestro and Michalak, 2012) to conduct a maximum likelihood phylogenetic analysis. This GUI implementation uses RAxML 1.3.1 (Stamatakis et al., 2005). We used the ML+ rapid bootstrap method to search for best scoring maximum likelihood tree, and assessed branch support using 1000 non-parametric bootstrap replicates. A Bayesian tree was also generated using the program MrBayes 3.2 (Ronquist et al., 2012). For this analysis, two Markov chains were initiated from random trees and allowed to run for 1,000,000 generations sampling every 100 generations. The analysis was terminated when the standard deviation of split frequencies was less than 0.005 , and the first 250,000 generations were discarded as "burn-in".

\section{Results}

\section{Delimitation of species}

Morphological characters including dewlap morphology, dewlap colour, body size ratios, and variations of 
the scales in flank and around head were used in species delimitation. Based on detailed morphological examination of museum specimens and fresh samples collected during this study we describe one new genus Sarada gen. nov. and five new species of Fanthroated lizards: Sarada gen. nov., Sarada darwini sp. nov., Sarada superba sp. nov., Sitana visiri sp. nov., Sitana laticeps sp. nov. and Sitana spinaecephalus sp. nov.

\section{Phylogenetic analysis}

The Maximum Likelihood (ML) and Bayesian analyses generated similar trees, and we have opted to base subsequent analysis and interpretation on the ML tree shown in Fig. 2. In both the ML and Bayesian trees, three major clades were recovered. Clade 1 is designated as the Sarada deccanensis clade, Clade 2 is the Sitana spinaecephalus clade, and Clade 3 is the Sitana ponticeriana clade. Additionally, when all the four genes where analyzed separately both ML and Bayesian methods recovered a well-supported monophyly of the Sarada deccanensis clade. The Sarada (gen. nov.) clade is sister to the two Sitana clades, and exhibited high mtDNA divergence from them (uncorrected $p$-distance $=21-24 \%$ ). The uncorrected $p$-distances between the Sitana ponticeriana and Sitana spinaecephalus clades was also quite high (14-16\%). Each species was found to be monophyletic and wellsupported with high bootstrap and Bayesian posterior probability support values despite that each was represented by specimens collected from across the species' range. The uncorrected $p$-distance in mtDNA among species varied from $5-11 \%$ for Sarada and 4-16\% for Sitana (Fig. 2, S4). Closely related species exhibit similar dewlap morphologies and colouration (Fig. 3). Hemipenial morphology, in contrast, exhibits substantial variation even among closely related species, with each species characterized by distinct morphologies. For example, both Sitana and Sarada include species exhibiting single and bilobed hemipenes (Fig. 4A-F).

\section{Morphological analyses}

Measurements were taken from 28 individual males representing the Sarada deccanensis clade, 25 individual males representing the Sitana ponticeriana clade, and 35 individual males representing the Sitana spinaecephalus clade. Twenty out of the 22 morphometric variables were highly correlated (Pearsons cor- relation > 0.70). Only TD, TW, DWLT and NE were normally distributed (Shapiro-Wilk test of normality $\mathrm{P}$ $<0.01$ ), while the remaining variables did not follow the assumptions of normality. The PC1 axis explained $86 \%$ of total variance and PC2 explained $4 \%$ of the variance. Sitana and Sarada are similar in their general body shape because there was low variation within loadings in PC1 (Table 1). There are higher negative loadings on SVL, LAL, HL and UAL in the first component (PC1) and TD in second component (PC2). There are higher positive loadings on DWLT, 4TL and HFL in the second component (PC2) (Table 1). The species in the genus Sarada are large lizards and separated in morphospace with minor overlap with that of the one large specimen in Sitana spinaecephalus sp. nov. and one Sitana visiri sp. nov. (Fig. 5). Sarada darwini sp. nov., Sarada superba sp. nov. and Sarada deccanensis comb. nov. have some amount of overlap in their body size (Fig. 5). The two species within the Sitana ponticeriana and Sitana spinaecephalus clades are clearly distinct in body size ratios (Fig. 5). In essence head length, snout-vent length, limb lengths and size of dewlap are some of the morphometric characters which separate different genera and species of Fan-throated lizards (Table 1), of which some are evident in our raw data (see Tables 2 and 3).

\section{External morphology}

Presence of enlarged scales on the body and thigh of Sitana is one of the key character in differentiating Sarada gen. nov. which lacks both these characters (Table 4, Fig. 6). There were no visible external morphological scale characters to differentiate species in the genus Sarada. Presence of enlarged spine like scales on the back of the head is a key character to differentiate Sitana spinaecephalus sp. nov. from the rest of the species in Sitana. Number of lamallae on the fourth toe, supralabials, infralabials, midbody scales, enlarged scales on the lateral side of body were all overlapping in Sitana (Table 5). Number of enlarged scale rows on the dewlap was relatively low in S. laticeps sp. nov. with marginal overlap with scale counts of S. visiri sp. nov. (Table 5). Ventral scale counts were also overlapping in $S$. ponticeriana, $S$. visiri sp. nov., Sitana spinaecephalus $\mathrm{sp}$. nov. and $S$. laticeps sp. nov. (Table 5). However ventral counts were useful in differentiating the species from Sri Lanka and India. (See key to the species). Details on the characters which were used to distinguish each species and genus are given in the taxonomy and systematics section below. 

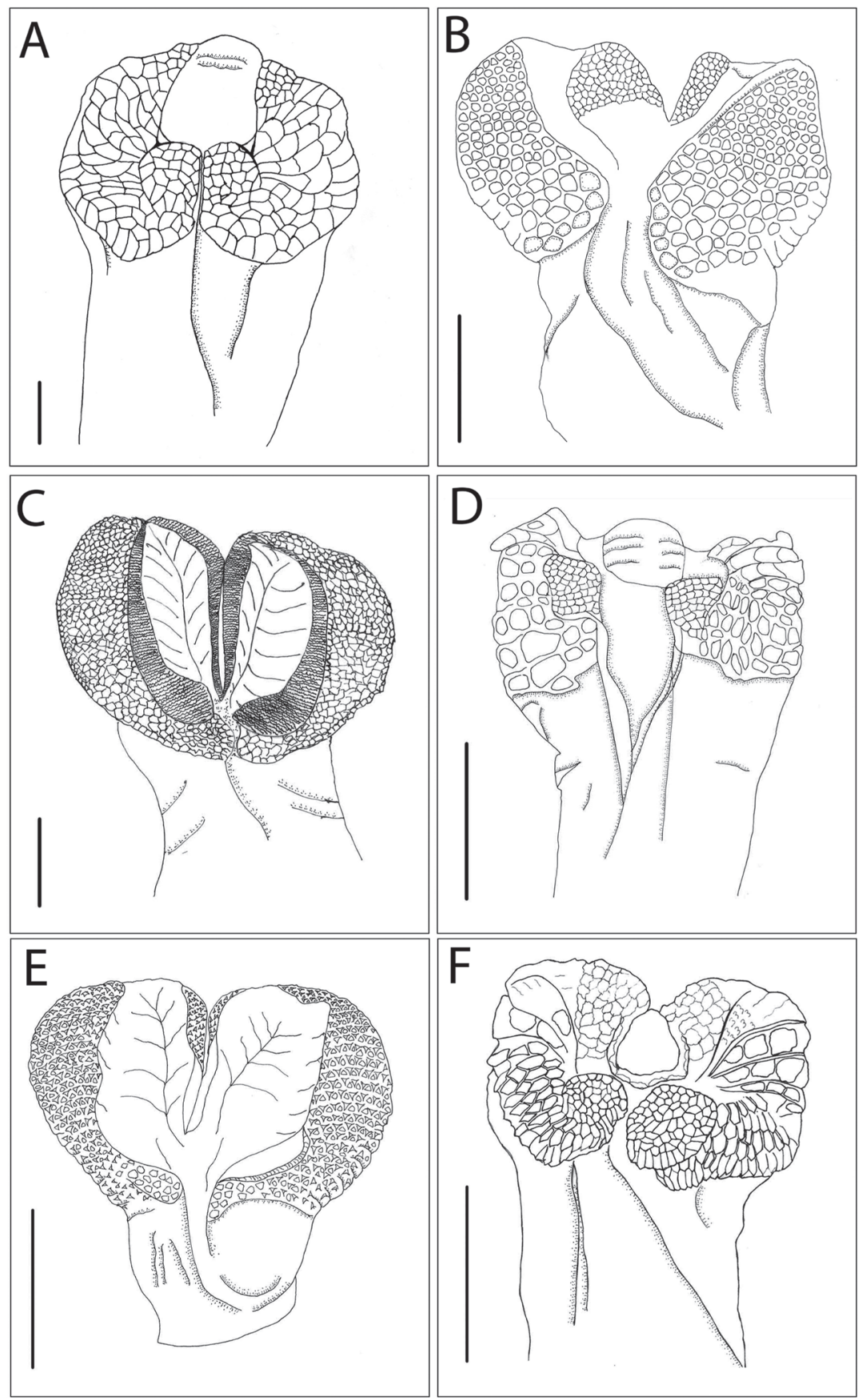

Fig. 4. Drawings of sulcal view of a representative hemipenis for different species of Fan-throated lizards. Clade 1: A. Sarada darwini sp. nov. B. Sarada superba sp. nov.; Clade 2: C. Sitana spinaecephalus sp. nov., D. Sitana laticeps sp. nov.; Clade 3: E. Sitana ponticeriana, F. Sitana visiri sp. nov. Scale bar $=2 \mathrm{~mm}$.
Hemipenis morphology. Sarada superba sp. nov., S. ponticeriana, S. spinaecephalus sp. nov. have a bilobed hemipenis (Fig. 4). However, they differ in their microornementations; $S$. superba sp. nov. have large calyces at the base of the sulcal side of the hemipenis compared to S. spinaecephalus sp. nov. and S. ponticeriana. Sitana spinaecephalus sp. nov. have a prominent grove on the asulcal side of the hemipenis which is absent in all other species (S2). Sarada darwini sp. nov., S. laticeps sp. nov. and $S$. visiri sp. nov. have a single lobed hemipenis (Fig. 4). They also differ considerably in their microornementation; Sarada darwi$n i$ sp. nov. have relatively less calyces on the asulcal side (only on the apex) compared to $S$. laticeps and $S$. 
visiri in which the calyces extend further down (S2). $S$. visiri have several smaller calyces on the center of the apical region on the asucal side whereas in S. laticeps and $S$. darwini they are more or less uniform (S2). More detailed descriptions of the hemipenies of each species is given in the species description section (appendix).

Osteology. In Sarada darwini sp. nov., S. deccanensis, Sitana ponticeriana and S. spinaecephalus the skull is subpentagonal in outline. Width of supratemporal fossa less than or equal to $60 \%$ of length. Splenial fused with the surrounding mandibular. The hyoid appears to be mostly bony, except the tip of the entoglossal process, tip of ceratobranchial I, tip of epibranchial I and the ceratohyals which are cartilaginous. The ceratobranchial is evidently longer in male than the female owing to the large dewlap in males. Several skeletal characters overlap between the four species (Table 6) except a few; Sitana ponticeriana and $S$. spinaecephalus $\mathrm{n} . \mathrm{sp}$. have 19 vertebrae excluding atlas and axis whereas $S$. darwini and $S$. deccanensis only have 18. Sitana ponticeriana and S. spinaecephalus $\mathrm{n} . \mathrm{sp}$. have four phalanges on the fourth toe whereas $S$. darwini and $S$. deccanensis have five.

\section{Taxonomy and systematics}

Generic level taxonomy. We describe the new genus Sarada gen. nov. based on specimens collected from throughout its distributional range. The absence of enlarged scales on the thigh and lateral body in combination with body ratios and dewlap color pattern can be used to differentiate Sarada gen. nov. from genus Sitana (Fig. 3, 6). The enlarged scales on the lateral body are shown in the description section (Figs 10b13b, Figs 15b-17b). Both Sitana and Sarada gen. nov. differ from Otocryptis (Wagler, 1830) in lacking the fifth toe (Smith, 1935). The skeletal characters of Sitana and Sarada gen. nov. are overall similar except two striking differences, an additional phalange on the fourth toe of manus and one reduced trunk vertebra in Sarada gen. nov., which is also observed in the other closely related sister genus and species Otocryptis beddomei (Boulenger, 1885) (Table 6, Fig. 7). Based on the body ratios and body size we identified three distinct morphotypes in the new genus Sarada gen. nov., which includes Sarada deccanensis comb. nov. and two undescribed species that are described here. Thus the nomen Sitana deccanensis become Sarada deccanensis comb. nov. Our molecular phylogenetic analysis suggests monophyly of the proposed genus containing the above mentioned three morphotypes collected from various localities in Maharashtra and Karnataka (Fig. 2, S1). Molecular analysis suggests that the Sarada gen. nov. is sister to Sitana with a deep divergence between these genera. Sarada gen. nov. is distributed predominantly in Maharashtra and north Karnataka (Fig. 8).

Species level taxonomy. Based on detailed examination of multiple specimens from different populations we provide detailed diagnostic characters for the species in the genus Sarada gen. nov. and Sitana (see key to the genus and species). Sarada deccanensis comb. nov. can be differentiated from Sarada superba sp. nov. in having relatively long hindlimb length (HLL) which exceeds SVL (df=1, F=32.37, p < 0.001; Table 2), relatively longer heel length (HFL) to SVL ratio $(\mathrm{df}=1, \mathrm{~F}=38.95, \mathrm{p}<0.001$; Table 2$)$ and smaller body size (SVL) $(\mathrm{df}=1, \mathrm{~F}=6.52, \mathrm{p}<0.05$; Table 2). Sarada deccanensis comb. nov. can be differentiated from Sarada darwini sp. nov. in having relatively long hindlimb length (HLL) which exceeds SVL (df=1, $\mathrm{F}=19.88, \mathrm{p}<0.001$; Table 2), relatively longer heel length (HFL) to SVL ratio (df=1, F=9.38, p < 0.01; Table 2) and larger body size (SVL) $(\mathrm{df}=1, \mathrm{~F}=5.52, \mathrm{p}<$ 0.05 ; Table. 3). Sarada superba sp. nov. can be differentiated from Sarada darwini sp. nov. in having shorter heel length (HFL) to $\mathrm{SVL}$ ratio $(\mathrm{df}=1, \mathrm{~F}=9.72, \mathrm{p}<$ 0.01 ; Table 2) and larger body size (SVL) (df=1, $\mathrm{F}=19.31, \mathrm{p}<0.001$; Table 2). All the above variables (HLL to SVL, HFL to SVL ratios and SVL) used in the analysis were normally distributed for different species (Shapiro-Wilk test of normality $\mathrm{P}<0.01$ ). There are several overlaps in the meristic characters between different species of Sarada gen. nov. (Table 4). All the scale counts except midbody scale counts are within the range of the two male syntypes (BMNH 1946.8.27.39 and BMNH 1946.8.27.40) of Sarada deccanensis comb. nov. There are minor variations in range of body measurements (SVL, TRL, DWL and DWLT) of our male specimens and the syntype (BMNH 1946.8.27.39). The type locality of Sarada deccanensis comb. nov. is "Deccan", which is a large area during British India. We assume Jerdon's (1853 and 1870) observations are from (Jalna, Maharashtra), where he was posted (Elliot, 1873), hence we assign the species name Sarada deccanensis comb. nov. to this population.

Sitana spinaecephalus sp. nov., and Sitana laticeps sp. nov. can be differentiated from all other Sitana species in having only a blue line on the throat extending in the dewlap. Sitana spinaecephalus sp. 


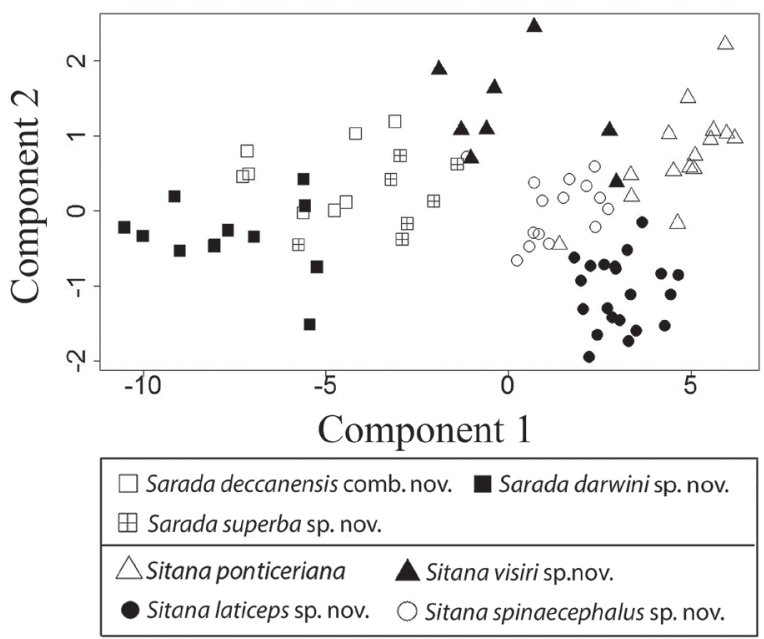

Fig. 5. PCA plot for Fan-throated lizards showing clear separation of Sitana from Sarada gen. nov.

nov. can be differentiated from Sitana laticeps sp. nov. in having a very large dewlap which extends far posteriorly along the trunk (up to $45 \%$ ) compared to dewlap up to $29 \%$. Sitana ponticeriana, Sitana visiri sp. nov., Sitana bahiri and Sitana devakai can be differentiated from all other Sitana species in having a strongly serrated dewlap margin. Sitana visiri sp. nov. can be differentiated from Sitana ponticeriana, Sitana bahiri and Sitana devakai in having a dewlap which extends far posteriorly along the trunk (up to 56\%) compared to dewlap up to $37 \%, 29 \%$ and $33 \%$ respectively. Sitana ponticeriana can be differentiated from Sitana devakai and Sitana bahiri in having a dewlap which extends far posteriorly along the trunk (up to 37\%). Sitana devakai can be differentiated from Sitana bahiri in having higher number of ventral scales (100-108) compared to 87-89, Sitana ponticeriana has a much lower ventral scale count (6476) which is an additional character for identification. The three subadult male specimens we collected from Rameshwaram Island and Karur in Tamil Nadu have overlapping characters with other species of Sitana spp in clade 3 . They are similar to Sitana bahiri and Sitana ponticeriana in having 47 and 51 around the body scales. They have a lower number (69 and 73) of ventral scales that falls within the range of Sitana ponticeriana and Sitana visiri sp. nov. counts, but they are lower than Sitana bahiri and Sitana devakai. Since we only have three specimens from this locality and the fact that they are all subadults it is difficult to identify the species. Due to
Table 1. Factor loadings on the principal components (PC) for each morphometric variable derived from PCA

\begin{tabular}{lrr}
\hline Variable & PC1 & PC2 \\
\hline SVL & -0.222 & -0.010 \\
HL & -0.222 & -0.079 \\
HW & -0.217 & -0.187 \\
HH & -0.218 & -0.065 \\
EE & -0.214 & -0.118 \\
IO & -0.216 & -0.156 \\
JL & -0.220 & -0.095 \\
NE & -0.200 & -0.199 \\
SE & -0.218 & -0.109 \\
IN & -0.202 & -0.042 \\
DEWL & -0.218 & 0.180 \\
DEWLT & -0.190 & 0.449 \\
TD & -0.162 & -0.506 \\
OD & -0.205 & -0.136 \\
LAL & -0.222 & 0.067 \\
UAL & -0.221 & 0.057 \\
FEL & -0.214 & 0.102 \\
CL & -0.217 & 0.101 \\
HFL & -0.209 & 0.337 \\
T1 & -0.186 & 0.156 \\
T4 & -0.196 & 0.391 \\
TW & -0.193 & -0.161 \\
TrL & -0.205 & -0.023 \\
\hline
\end{tabular}

their close genetic similarity to the sequence of the specimen from the type locality of Sitana bahiri (2\% uncorrected $p$-distance in ND2 mtDNA; Fig. 2) from here onwards we will refer them as Sitana cf. bahiri. There are several overlaps in the meristic characters (scale counts) between all the species of Sitana examined in this study (Table 5).

\section{Discussion}

Fan-throated lizards have undergone rapid diversification given that the dated tree of Blankers et al. (2012) indicates that Otocryptis and Sitana diverged beginning $\sim 12$ million years ago. In Peninsular India, the three Sitana clades are geographically separated with some overlap between the Sitana spinaecephalus clade and the Sarada clade. Each clade harbors multiple species that exhibit varying degrees of genetic divergence. Traditional morphological characters used in lizard taxonomy, such as the number of scales around the body, ventral scales, labials, and lamellae scales, were not useful for separating most species. This overlap in morphological characters may be due to their occupancy of similar open habitats in the sub- 
Table 2. Range of select measurements in adult Sarada specimens including the type series, mean in brackets. Abbreviations, all measurements in $\mathrm{mm} ;$ " "- = absent.

\begin{tabular}{|c|c|c|c|c|c|c|}
\hline & \multicolumn{2}{|c|}{ Sarada deccanensis comb. nov } & \multicolumn{2}{|c|}{ Sarada darwini sp. nov. } & \multicolumn{2}{|c|}{ Sarada superba sp. nov. } \\
\hline & $(\widehat{o} \mathrm{n}=8)$ & $(q \mathrm{n}=4)$ & $\left(\jmath^{\lambda} \mathrm{n}=8\right)$ & $(q \mathrm{n}=10)$ & $\left(0^{\pi} \mathrm{n}=12\right)$ & $(q \mathrm{n}=6)$ \\
\hline SVL & $56.1-66.2(62.2)$ & $49.0-58.4(52.2)$ & $52.9-63.4(58)$ & $41.6-61.8(54.47)$ & 59.5-75.7 (67.9) & $53.2-64.3(59.8)$ \\
\hline HW & $10.9-13.0(10.5)$ & $10.1-11.3(10.5)$ & $9.8-12.9(11.2)$ & $8.9-11.5(10.7)$ & $11.9-15.9(13.4)$ & $11.5-12.8(12.1)$ \\
\hline $\mathrm{IO}$ & $6.5-7.9(7.2)$ & $6.0-6.8(6.3)$ & $5.6-7.0(6.4)$ & $5.0-7.3(6.3)$ & $7.0-8.5(7.7)$ & $6.4-7.4(7.1)$ \\
\hline DWL & $38.9-46.5(42.3)$ & - & $33.6-50.0(40.0)$ & - & $38.9-55.0(45.8)$ & - \\
\hline DWLT & $9.1-12.8(11.1)$ & - & $8.2-11.8(9.6)$ & - & $10.2-17.1(13.4)$ & - \\
\hline FEL & $16.3-20.4(17.6)$ & 14.6-16.1(15.2) & $14.7-17.9(16.03)$ & $12.3-16.1(14.8)$ & $14.2-22.0(17.3)$ & $13.0-16.5(14.5)$ \\
\hline TRL & $19.3-25.4(23.4)$ & $18.1-24.9(21.2)$ & $19.5-33.8(22.8)$ & $17.3-26.6(23.7)$ & $24.0-35.1(28.2)$ & $23.9-28.7(26.7)$ \\
\hline HFL & $24.6-29.1(26.3)$ & $21.4-23.0(22.5)$ & 21.4-26.0 (23.9) & $19.7-22.7(21.3)$ & $22.9-28.4(25.5)$ & $20.3-21.8(21.3)$ \\
\hline
\end{tabular}

Table 3. Summary of select measurements in adult Sitana specimens including the type series. Abbreviations, all measurements in $\mathrm{mm} ; “$ ", = absent.

\begin{tabular}{|c|c|c|c|c|c|c|c|c|}
\hline & \multicolumn{2}{|c|}{ Sitana ponticeriana } & \multicolumn{2}{|c|}{ Sitana visiri sp. nov. } & \multicolumn{2}{|c|}{ Sitana spinaecephalus sp. nov. } & \multicolumn{2}{|c|}{ Sitana laticeps sp. nov. } \\
\hline & $(\hat{o} \mathrm{n}=16)$ & $(q \mathrm{n}=8)$ & $(\hat{o} \mathrm{n}=9)$ & $(q \mathrm{n}=10)$ & $(\hat{\mathrm{n}} \mathrm{n}=14)$ & $(q \mathrm{n}=10)$ & $($ to $\mathrm{n}=21)$ & $(q \mathrm{n}=22)$ \\
\hline SVL & $36.6-44.5(40.5)$ & $36.4-47.6(41.8)$ & $40.3-56.3(50)$ & $44.8-52.1(48.5)$ & $45.3-56.6(48.5)$ & $39.5-52.1(45.5)$ & $41.7-48.5(44.5)$ & $40.7-51.5(46.2)$ \\
\hline HL & $10.0-13.7(11.7)$ & $11.2-13.5(12.2)$ & $11.6-15.6(14.2)$ & $11.7-13.5(12.9)$ & $13.1-16.2(14.1)$ & $12.4-14.5(13.3)$ & $11.5-14.6(13.3)$ & $12.5-14.0(13.2)$ \\
\hline HW & $7.0-8.7(7.6)$ & $7.0-8.5(7.8)$ & $7.6-9.9(8.9)$ & 7.8-8.6 (8.4) & $8.7-10.4(9.4)$ & $8.1-9.9(9.0)$ & $8.2-10.0(9.1)$ & $8.6-9.9(9.2)$ \\
\hline $\mathrm{IO}$ & $3.9-5.0(4.4)$ & $4.0-4.6(4.3)$ & $4.5-5.8(5.2)$ & $4.1-4.9(4.5)$ & $4.6-5.8(5.1)$ & $4.1-5.5(5.0)$ & $4.7-5.9(5.2)$ & $4.8-5.7(5.2)$ \\
\hline DWL & $22.4-29.2(24.8)$ & - & $24.5-39.0(33.0)$ & - & $26.1-32.6(29.2)$ & - & $20.7-27.1(24.3)$ & - \\
\hline DWLT & $3.7-8.1(6.03)$ & - & $5.3-12.1(9.7)$ & - & $4.0-8.3(6.5)$ & - & $1.3-4.9(3.4)$ & - \\
\hline FEL & $9.3-11.7(10.7)$ & $9.8-11.5(10.7)$ & $11.4-15.2(13.5)$ & $10.1-13.0(11.6)$ & $10.8-15.3(12.8)$ & $9.7-13.4(12.2)$ & $10.4-12.3(11.5)$ & $10.2-12.5(11.3)$ \\
\hline HFL & $17.0-20.4(18.6)$ & $16.8-18.5(17.8)$ & $18.9-24.5(21.8)$ & $16.8-19.9(18.7)$ & $18.6-22.0(20.3)$ & $17.9-20.6(19.3)$ & $16.0-19.0(17.7)$ & $16.5-20.3(17.5)$ \\
\hline
\end{tabular}

continent and/or shared ancestry. However a combination of meristic and morphometric characters were useful to diagnose species.

\section{Genetic relationship and distribution}

It is already established that Sitana is the sister taxon of Otocryptis wiegmanni from Sri Lanka (Macey et al., 2000). The ND2 sequences compared with other genera from Peninsular India and Sri Lanka shows that the minimum sequence divergence (uncorrected distance) is between Lyriocephalus and Cophotis $(17.9 \%)$ and the maximum divergence is between Draco blanfordii and Sitana (38.1\%). The three species in the new genus Sarada gen. nov. are highly divergent (20-24\%) from all species in the genus Sitana. Species in Sarada gen. nov. are geographically restricted in distribution and are sympatric with members of Sitana spinaecephalus clade at multiple locations in their distribution (Fig. 8). Sitana spinaecephalus sp. nov. is the most widespread species, adapted to both lowland and high elevations in Gujarat and Maharashtra. Even though the Peninsular Indian landscape looks continuous, there are several hill ranges and rivers that could have played a significant role in the diversification of Sitana and Sarada. Based on the current distribution of the lineages, some of the hill ranges and rivers in Peninsular India seem to have served as a barrier to gene flow. For example, in the case of Sitana spinaecephalus sp. nov. and Sitana laticeps sp. nov., the Godavari river along with the mountain ranges (Trimbak Hills \& Balaghat Hill Range) may have served as a barrier for these species. The Krishna, Bhima and Godavari rivers along with the mountain ranges (Mahadeo Range) may have played a role in Sarada deccanensis comb. nov. and Sarada darwini sp. nov. distributions. Sarada superba sp. nov. appears to be a species restricted to the high elevation plateaus of Satara, Maharashtra. During our sampling, we only found this species on plateaus; searches at elevations below 1000 meters did not yield any individuals. Interestingly, and not surprisingly, species that are closely 
Table 4. Range of select scale counts Sarada gen. nov. specimens including the type series. Abbreviations, all measurements in mm, "_" = absent. Lam4 = Lamallae on fourth toe; SL = Supralabials; IL = infralabial; MBS = Mid body scales; ENL = enlarged scales on the flank region; ESD = enlarged scale rows in dewlap; VEN = number of ventral scales.

\begin{tabular}{|c|c|c|c|c|c|c|}
\hline & \multicolumn{2}{|c|}{ Sarada deccanensis comb.nov. } & \multicolumn{2}{|c|}{ Sarada darwini sp. nov. } & \multicolumn{2}{|c|}{ Sarada superba sp. nov. } \\
\hline & 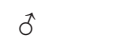 & q & $\hat{0}$ & q & $\hat{\sigma}$ & $q$ \\
\hline Lam4 & $22-24(5)$ & $21-24(4)$ & $21-24(4)$ & $22-24(4)$ & $21-22(4)$ & $18-22(5)$ \\
\hline SL & $12-14(4)$ & $13(3)$ & $11-12(5)$ & $11-12(7)$ & $12-13(6)$ & $12-13(3)$ \\
\hline IL & $12-14(4)$ & $14(3)$ & $12-13(5)$ & $12-13(7)$ & $12-13(6)$ & $11-13(3)$ \\
\hline MBS & $65-69(4)$ & $62-74(3)$ & $64-71(5)$ & $58-67(7)$ & $63-70(6)$ & $67-77(3)$ \\
\hline ESD & $22-24(4)$ & - & $18-23(5)$ & - & $17-22(6)$ & - \\
\hline VEN & $79-93(4)$ & 79-90 & $81-90(5)$ & $73-86(7)$ & $81-91(6)$ & $73-81(3)$ \\
\hline ENL & - & - & - & - & - & - \\
\hline
\end{tabular}

Table 5. Range of select scale counts of Sitana specimens including the type series, sample size in brackets.. Abbreviations, all measurements in mm, "_" = absent. Lam4 = Lamellae on fourth toe; SL = Supralabials; IL = infralabial; MBS = Mid body scales; ENL = enlarged scales on the flank region; ESD = enlarged scale rows in dewlap; VEN = number of ventral scales.

\begin{tabular}{|c|c|c|c|c|c|c|c|c|}
\hline & \multicolumn{2}{|c|}{ Sitana ponticeriana } & \multicolumn{2}{|c|}{ Sitana visiri sp. nov. } & \multicolumn{2}{|c|}{ Sitana spinaecephalus sp. nov. } & \multicolumn{2}{|c|}{ Sitana laticeps sp. nov. } \\
\hline & $\hat{0}$ & q & $\hat{0}$ & q & $\hat{0}$ & $q$ & $\hat{0}$ & $q$ \\
\hline Lam4 & $21-23(5)$ & $20-23(5)$ & $24-28(5)$ & $21-25(5)$ & $23(5)$ & $20-22(5)$ & $19-20(2)$ & $19-20(2)$ \\
\hline SL & $8-9(6)$ & $8-9(8)$ & $8-9(5)$ & $8-9(5)$ & $9-11(6)$ & $8-10(6)$ & $9-11(7)$ & $9-10(3)$ \\
\hline IL & $8-9(6)$ & $8-9(8)$ & $8-10(5)$ & $8-9(5)$ & $9-11(5)$ & $9-11(6)$ & $9-11(7)$ & $9-11(2)$ \\
\hline MBS & $49-55(7)$ & $50-56(7)$ & $52-59(7)$ & $51-60(8)$ & $53-60(11)$ & $55-59(7)$ & $51-61(6)$ & $58-65(2)$ \\
\hline ESD & $16-18(6)$ & - & $15-20(7)$ & - & $17-21(11)$ & - & $12-15(5)$ & - \\
\hline VEN & $64-76(6)$ & $58-67(6)$ & $65-85(7)$ & $61-70(7)$ & $70-88(12)$ & $61-77(8)$ & $75-81(6)$ & $67-75(3)$ \\
\hline ENL & $9-10(1)$ & $10-12(2)$ & $14-16(4)$ & $12-13(3)$ & $17-18(2)$ & $16(1)$ & $11-13(2)$ & $12(1) 13(1)$ \\
\hline
\end{tabular}

Table 6. Select osteological characters \& measurements of representative species from the genus Sitana \& Sarada gen. nov.

\begin{tabular}{|c|c|c|c|c|}
\hline \multirow[t]{2}{*}{ Characters } & \multicolumn{2}{|l|}{ Sitana } & \multicolumn{2}{|l|}{ Sarada } \\
\hline & ponticeriana & $\begin{array}{l}\text { spinaecephalus } \\
\text { sp. nov. }\end{array}$ & $\begin{array}{l}\text { deccanensis } \\
\text { comb. nov. }\end{array}$ & darwini sp. nov. \\
\hline Fenestra exonaria & $\begin{array}{l}\text { face upwards } \\
\text { and posteriorly } \\
\text { extended }\end{array}$ & $\begin{array}{l}\text { face upwards } \\
\text { and posteriorly } \\
\text { extended }\end{array}$ & $\begin{array}{l}\text { face upwards } \\
\text { and posteriorly } \\
\text { extended }\end{array}$ & $\begin{array}{l}\text { face upwards and } \\
\text { posteriorly } \\
\text { extended }\end{array}$ \\
\hline Orbits and supratemporal fenestra & large & large & large & large \\
\hline Teeth on premaxilla & 3 & 3 & 3 & 3 \\
\hline Acrodont teeth on maxilla & 2 & 2 & 2 & 2 \\
\hline Pleurodont teeth on maxilla & 15 & 14 & 15 & 15 \\
\hline Medial edges of the palatal portion of pterygoid & remain parallel & remain parallel & remain parallel & remain parallel \\
\hline Number of trunk vertebrae excluding atlas and axis & 19 & 19 & 18 & 18 \\
\hline Phalangeal formula of manus & $2-3-4-4-3$ & $2-3-4-4-3$ & $2-3-4-5-3$ & $2-3-4-5-3$ \\
\hline Phalangeal formula of pes & $2-3-4-5$ & $2-3-4-5$ & $2-3-4-5$ & $2-3-4-5$ \\
\hline
\end{tabular}

related to Sitana bahiri from Sri Lanka are found on Rameshwaram Island and one inland location in Tamil Nadu. These locations are just across the narrow Gulf of Mannar that separates Tamil Nadu from Sri Lanka.
Studies show that India and Sri Lanka had terrestrial connections in the recent past (most recently ca. 17,000 years ago) (see Voris 2000), which may have allowed these species share genes until quite recently (e.g. 

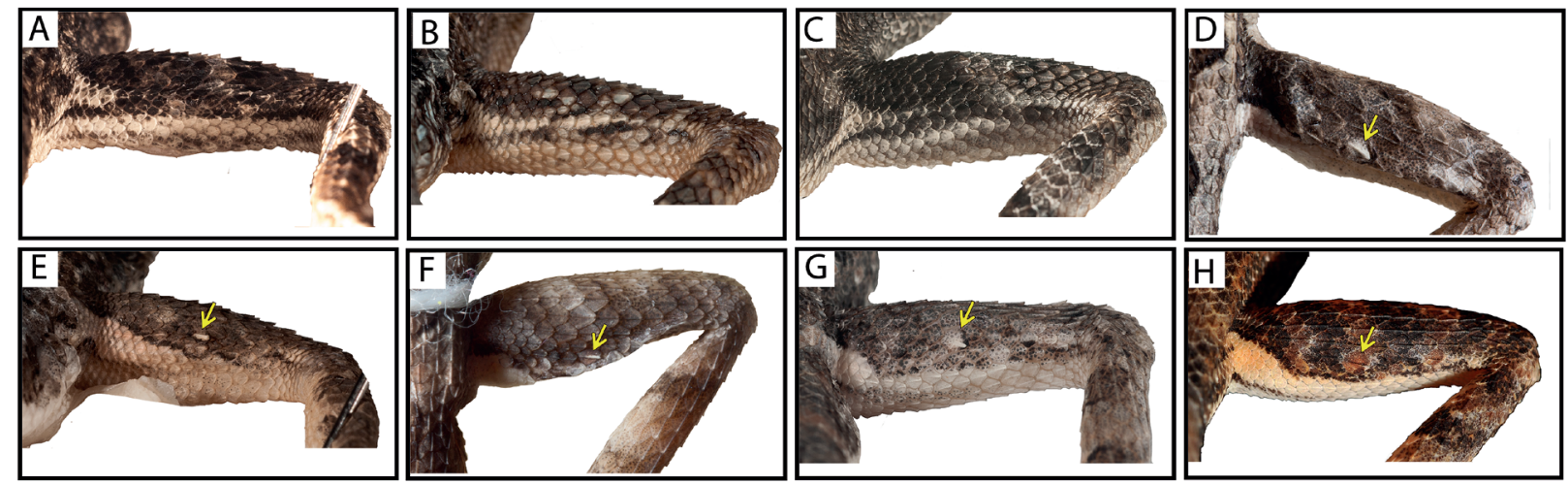

Fig. 6. The position and structure of the enlarged projecting scale on the thigh of Sitana. Note the complete absence of this scale in Sarada gen. nov. Clade 1: A. Sarada darwini sp. nov., B. Sarada deccanensis comb. nov., C. Sarada superba sp. nov.; Clade 2: D. Sitana spinaecephalus sp. nov., E. Sitana laticeps sp. nov.; Clade 3: F. Sitana ponticeriana, G. Sitana visiri sp. nov., H. Sitana cf. bahiri. Image not to scale.

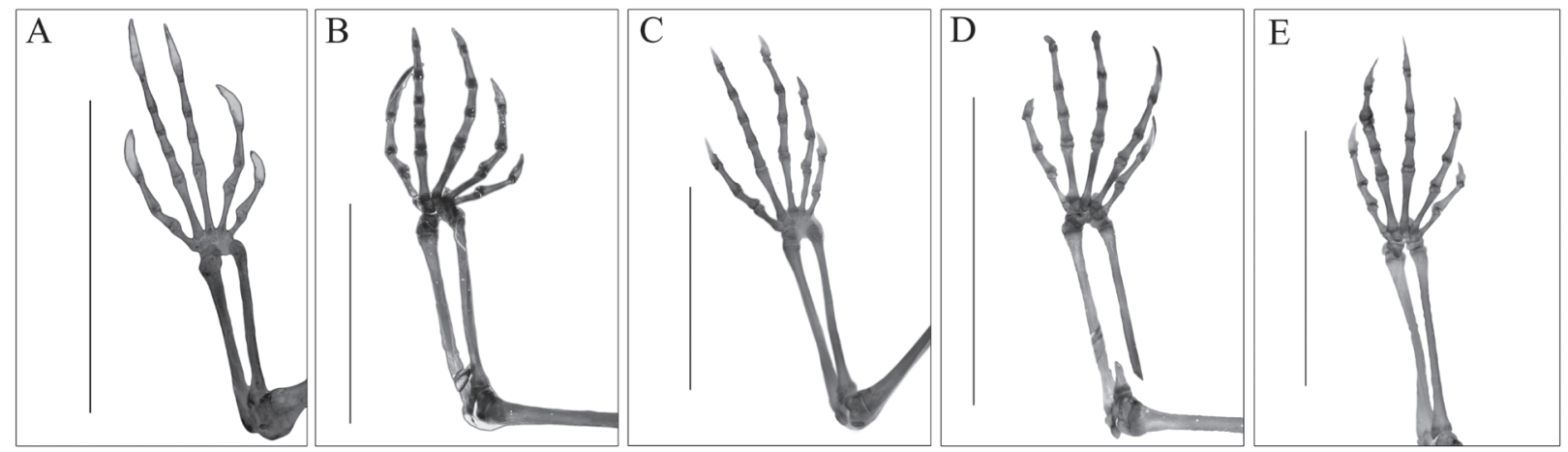

Fig. 7. Clear stained images of left forelimbs showing finger formulae in: (A) Otocryptis beddomei, (B) Sarada darwini sp. nov. (C) Sarada deccanensis comb. nov. (D) Sitana ponticeriana (E) Sitana spinaecephalus sp. nov. Scale bar $=10 \mathrm{~mm}$. Note the differing numbers of phalanges on the fourth digit of Sarada (6) versus Sitana (5).

Guptha et al.,2015). Although we sampled extensively in peninsular India we did not cover the entire range of Sitana distribution. The genetic relationship of species from the Sitana sivalensis complex with the other Sitana spp. needs to be investigated. The only fine scale phylogeographic study in Peninsular India is on Geckoella, a predominantly forest dwelling lizard, which suggests that there are several undescribed species from the hills in the dry zones of Peninsular India (Agarwal and Karanth, 2015). Sitana and Sarada gen. nov. predominantly occur in open habitats in the dry zones of Peninsular India. Even though the Peninsular Indian landscape looks continuous, there are several hill ranges and rivers that could have played a significant role in the diversification of Sitana and Sarada.

Osteology. Baig et al. (2012) noted that generic or suprageneric level variation is observed in various bony elements of agamids. However, he reported that variation within genera is low. The majority of agamids have 21 or 22 trunk vertebrae (Moody, 1980). Reduction of the trunk vertebrae to 18,19 or 20 has occurred in phenotypically different agamids viz. the slow moving (terrestrial) Moloch, fast moving facultative bipeds (terrestrial) Sitana and Otocryptis and the slow moving short-limbed (arboreal) Cophotis ceylanica and Ceratophora stoddartii (Moody, 1980). Interestingly our results shows that the new genus Sara$d a$ gen. nov. also has one reduced trunk vertebra compared to the genus Sitana. Additionally, all the examined skeletons of Sitana and Sarada in this study lacked the fifth toe. The function of hooked fifth metatarsal as a 'heel bone' is discussed in detail by Russell and Rewcastle (1979). This trait seems to have been 


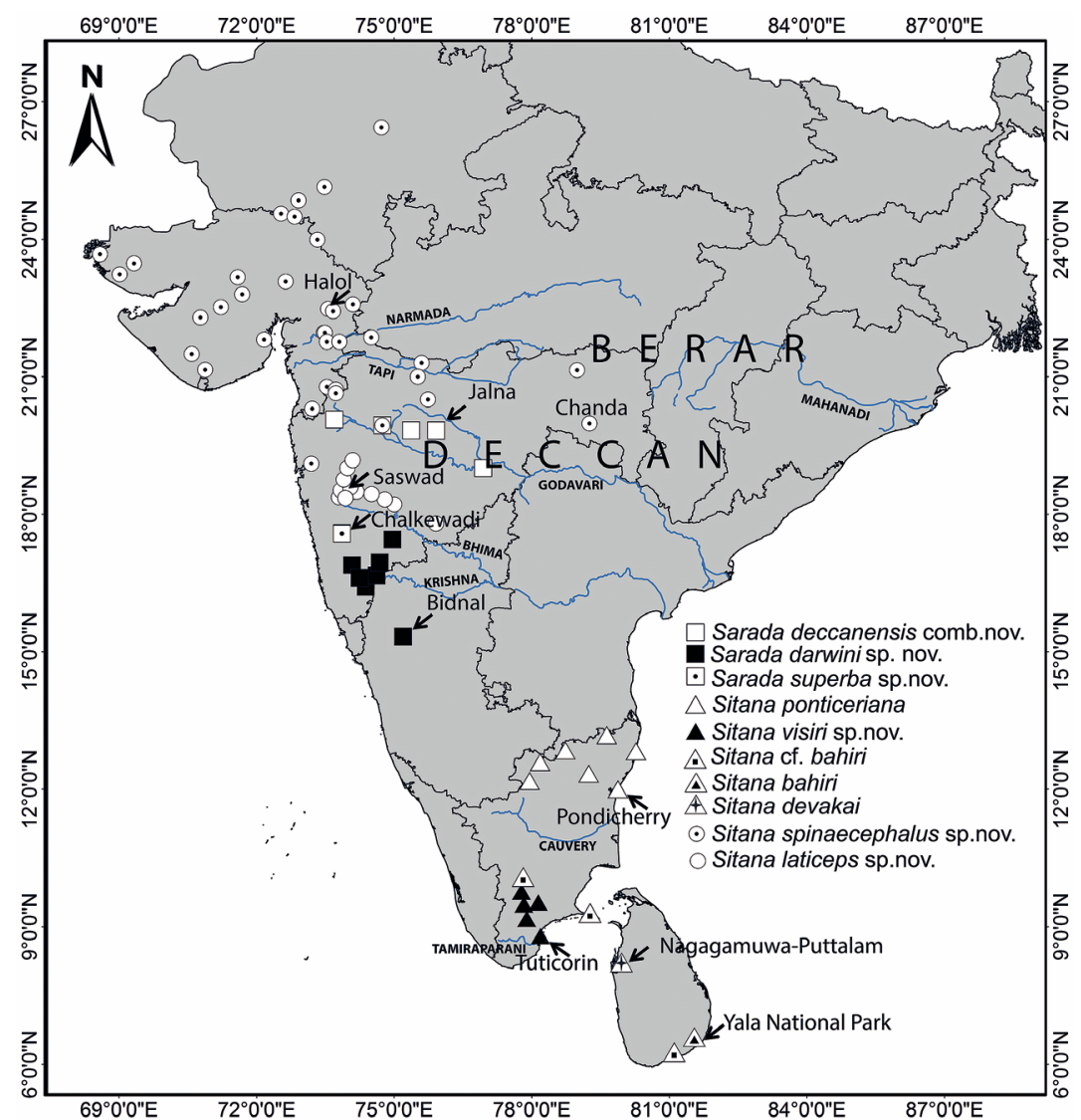

Fig. 8. Map showing our sampling in Peninsular India and the distribution of the previously known species of Sitana from India and Sri Lanka. Type localities of different species are marked with arrows. Major rivers are marked by a blue line and capitalized bold text. Based on Johnson (1867) and Colton and Colton (1855), the approximate limits of Berar and Deccan during the 1870 s is indicated. Chanda is now called Chandrapur in Eastern Maharashtra. conserved in both Sitana and Sarada gen. nov. All of the species in the genus Sitana and Sarada gen. nov. are terrestrial and are facultative bipeds which may be one of the reasons this trait is conserved in all known Fan-throated lizards. Drastic reduction in finger phalanges (formula 2:2:3:3:2) is found in Moloch (Moody, 1980). In the case of Sitana spinaecephalus sp. nov. and Sitana ponticeriana the formula is 2:3:4:4:3 and in Sarada deccanensis comb. nov. and in Sarada darwini sp. nov. there is an additional phalange in the fourth finger (2:3:4:5:3).

Hemipenial morphology and external morphology. Hemipenial morphology may be a useful character in Sitana taxonomy as some species have unique micro ornamentation. Hemipenial morphology has been identified as a useful line of evidence for species delimitation in many lizards (e.g. Arnold 1986; Glaw et al., 2012; Nunes et al., 2012). Iguanian and anguimorphan lizard taxa with visual communication and sexually dimorphic epigamic characters usually have less diverse genital structures (Böhme and Ziegler, 2009). On the other hand, taxa with less developed visually epigamic characters and highly developed chemical intersexual communications usually have diverse genital structures (Böhme and Ziegler, 2009). Interestingly, this hypothesis does not seem to hold true in the case of Sitana, which have one of the most elaborate epigamic characters along with remarkable hemipenial diversity. Recent studies on hemipenial morphology of agamid lizards from Sri Lanka suggests that there is low variation in the shape of hemipenis among genera (Maduwage et al., 2008; Maduwage and Silva, 2012) and most of the Sri Lankan agamids have epigamic characters. Sitana bahiri from Sri Lanka has a bilobed hemipenis which has very different micro-ornamentation compared to its sister species Sitana ponticeriana and Sitana visiri sp. nov. (See Fig. 3 in Maduwage and Silva, 2012).

Variations in dewlap size are an important key in identification of Sitana, which is also evident in the raw data and PCA results. The members of Sarada deccanensis clade are not only genetically very distinct from other Sitana species but also morphologically distinct. 


\section{Conservation implications}

Understanding species diversity is an essential step for conservation planning, especially when cryptic species exhibit narrow distributions. Herpetofaunal studies in Peninsular India have been largely focused on the global Biodiversity Hotspot, the Western Ghats, a mountain chain running along the west coast of India (Das, 2002). However, recent explorations of areas outside the Western Ghats of Peninsular India have resulted in the discovery of many species new to science (Bauer and Das, 2000; Agarwal et al., 2012, 2013; Datta-Roy et al., 2013). Similarly, our study of Sitana also uncovered many new species from the dryer parts of Peninsular India. We thus suggest that there is an urgent need to document biodiversity in these ignored landscapes of Peninsular India. Since Sitana in most of India were considered to be a single species, it is currently placed in the category 'Least Concern' by IUCN (2015). Species with restricted distributions are likely to be more vulnerable to extinction than the widespread ones. Therefore, developing a better understanding of the diversity and distribution of Peninsular Indian lizards is necessary to plan any successful conservation efforts in the dry zones. Our study, which reveals hitherto unknown diversity of Sitana across India, is a step towards understanding this poorly studied group of agamids. Although our sampling efforts were quite robust covering most of the biogeographic regions of India, due to time constraints there is poor fine scale data on the distribution of the species diversity. Focused and long-term studies are essential to address this problem. Although the taxonomy of Fanthroated lizards is much improved, due to the lack of proper distribution data and other natural history observations, we consider all the species as 'Data Deficient' regarding IUCN status.

\section{Acknowledgements}

We thank the Department of Biotechnology for the funding to carry out this research. VD thanks Department of Biotechnology for DBT-RA fellowship. We thank the Ministry of Environment forest and Climate Change for their funds which covered field work in this study. Rufford Small Grants supported parts of the field work during this study. VD thanks Ulrich Manthey for sharing photographs of the lectotype of Sitana ponticeriana housed at Museum of Natural History, Paris. Jakob Hallermann for providing photographs of specimens housed in Zoologisches Museum Hamburg, Germany. Kaushik Deuti for the measurements of the lectotypes. We also thank Rahul Khot, BNHS for his support. Kartik Upadhay, Madhu Kannan, Chetan, Dha- wal Mehta, Pratik Talwad, Pratyush Patankar, Bopanna Ittira Ponnappa, Sutirtha Dutta, Kunal Arekar, Arumugam, Akshay Khandekar, Kiran Rahalkar, Ashish Ranjan, Avinash Babu, Vaibhav naik, Omkar Yadav, Ravindra Sonwane, Prasad Shinde, Varun Vaze, Zeeshan Mirza and all the other members of Fan throated lizards - Citizen Science Initiative (Facebook group) for their assistance in field and additional location data. Dharmendra Khandal, Hemant Singh, Yadav Tarte Patil, Raman Upadhye, Shyam Soni, Atul, Daya, Anand Patki, Harshil Patel, Kartik Sunagar, Kartik Upadhay, Shantanu Kundu, Achyuthan Srikanthan, Janani Sooriya and Kulbhushan suryawanshi and their family for their assistance in field and logistics. Staff at Atree base camp in Kallidaikurichi for helping with the logistics and support. Aaranya Gayathri for her help in verifying morphological characters. Director of the Zoological Survey of India (ZSI) for granting VD permission to examine specimens in their collection. P.S. Bhatnagar and Sameer Kumar Pati Scientists from ZSI, Pune. We thank Bombay Natural History Society for their support, Aaron Bauer for partial funds for field work in Tamil Nadu, and Rohini Balakrishnan for allowing us to use their camera-Lucida facility in her lab. VG is supported by DAE Outstanding Scientist Grant to Uma.VG thanks Uma Ramakrishnan and Krushnamegh Kunte, NCBS for constant support and encouragement. VG also thanks the Maharashtra Forest Department for their support. RV thanks the Gujarat forest Department for their support. MA thanks Indian Academy of Sciences for the summer research fellowship, and Amnion Biosciences for sequencing the samples. AZ and HB thanks Maria Thaker for the logistical support during the field work in Satara. Abhijit Das, B.H.C.K. Murthy, Prathyush Mahopatra, Niladri B. Kar are thanked for their constant support of this study, Ishan Agarwal, Saunak Pal, Kalai Mani, Aparna Lajmi, Aniruddha Datta-Roy and Eleni Foui for their help during sampling and photo documentation, Kartik Upadhay, Rounak Khare, Jitedra Katre for providing additional records of Sitana and photographs, and Harikrishnan Surendran and Ishan Aggarwal for critical comments on the manuscript. We also thank Jimmy A. McGuire and an anonymous reviewer for their efforts to improve this manuscript.

\section{References}

Agarwal I, Karanth KP. 2015. A phylogeny of the only grounddwelling radiation of Cyrtodactylus (Squamata, Gekkonidae): diversification of Geckoella across peninsular India and Sri Lanka. Molecular Phylogenetics and Evolution 82: 193-199. http://dx.doi.org/10.1016/j.ympev.2014.09.016

Agarwal I, Datta-Roy A, Bauer AM, Giri VB. 2012. Rediscovery of Geckoella jeyporensis (Squamata: Gekkonidae), with notes on morphology, coloration and habitat. Hamadryad 36: 17-24.

Agarwal I, Wilkinson M, Mohapatra P, Dutta SK, Giri VB, Gower D. 2013. The first teresomatan caecilian (Amphibia: Gymnophiona) from the Eastern Ghats of India - a new species of Gegeneophis Peters, 1880. Zootaxa 3696: 534-546.

Agarwal I, Bauer AM, Jackman TR, Karanth P. 2014a. Cryptic species and Miocene diversification of Palaeartic naked toed geckos (Squamata: Gekkonidae) in the Indian dry zone. Zoologica Scripta 43: 1-17. http://dx.doi.org/10.1111/zsc.12062 
Agarwal I, Bauer AM, Jackman TR, Karanth P. 2014b. Insights into Himalayan biogeography from geckos: A molecular phylogeny of Cyrtodactylus (Squamata: Gekkonidae). Molecular Phylogenetics and Evolution 80: 145-155. http://dx. doi.org/10.1016/j.ympev.2014.07.018

Ahmadzadeh F, Flecks M, Carretero MA, Mozaffari O, Böhme W, Harris DJ, Freitas S, Rödder D. 2013. Cryptic speciation patterns in Iranian rock lizards uncovered by integrative taxonomy. PLoS ONE 8: e80563.

Amarasinghe AAT, Ineich I, Karunarathna DMS, Botejue WMS, Campbell PD. 2015. Two new species of agamid lizard of the genus Sitana Cuvier from Sri Lanka, with a taxonomic revision of Indian species. Zootaxa 3915: 67-98.

Anders C, Kästle W. 2002. Sitana schleichi spec. nov. Pp 39 in: Schleich HH, Kästle W. eds, Amphibians and Reptiles of Nepal: Lizards and Crocodiles. Koeltz Scientific Books, Königstein.

Arnold EN. 1986. Why copulatory organs provide so many useful taxonomic characters: the origin and maintenance of hemipenial differences in lacertid lizards (Reptilia: Lacertidae). Biological Journal of the Linnean Society 29: 263-281.

Baig KJ, Wagner P, Ananjeva NB, Böhme W. 2012. A morphology-based taxonomic revision of Laudakia Gray, 1845 (Squamata: Agamidae). Vertebrate Zoology 62: 213-260.

Bansal R, Karanth P. 2010. Molecular phylogeny of Hemidactylus geckos (Squamata: Gekkonidae) of the Indian subcontinent reveals a unique Indian radiation and an Indian origin of Asian house geckos. Molecular Phylogenetics and Evolution 57: 459-465. http://dx.doi.org/10.1016/j.ympev.2010.06. 008

Bauer AM, Das I. 2000. Two new species of Cnemaspis (Sauria: Gekkonidae) from Tamil Nadu, Southern India. Russian Journal of Herpetology 7: 17-28.

Bauer AM, de Silva A, Greenbaum E, Jackman TR. 2007. A new species of day gecko from high elevation in SriLanka, with a preliminary phylogeny of Sri Lankan Cnemaspis (Reptilia: Squamata: Gekkonidae). Mitteilungen aus dem Museum für Naturkunde in Berlin. Zoologische Reihe 83 Sonderheft: 22-32.

Bauer AM, Jackman TR, Greenbaum E, Giri VB, de Silva A. 2010. South Asia supports a major endemic radiation of Hemidactylus geckos. Molecular Phylogenetics and Evolution 57: 343-352. http://dx.doi.org/10.1016/j.ympev.2010.06. 014

Bergmann PJ, Russell AP. 2007. Systematics and biogeography of the widespread Neotropical gekkonid genus Thecadactylus (Squamata), with the description of a new cryptic species. Zoological Journal of Linnean Society 149: 339-370. http://dx.doi.org/10.1111/j.1096-3642.2007.00251.x

Blanford WT. 1870. Notes on some Reptilia and Amphibia from Central India. Journal of Asiatic Society of Bengal 39: 335376.

Blankers T, Townsend TM, Pepe K, Reeder TW, Wiens JJ. 2013. Contrasting global-scale evolutionary radiations: phylogeny, diversification, and morphological evolution in the major clades of iguanian lizards. Biological Journal of the Linnean Society 108: 127-143. http://dx.doi.org/10.1111/j.10958312.2012.01988.x

Böhme W, Ziegler T. 2009. A review of iguanian and anguimorph lizard genitalia (Squamata: Chamaeleonidae; Varanoidea, Shinisauridae, Xenosauridae, Anguidae) and their phylogenetic significance: comparisons with molecular data sets. Journal of Zoological Systematics and Evolutionary
Research 47: 189-202. http://dx.doi.org/10.1111/j.1439-0469. 2008.00495.x

Boulenger GA. 1890. The Fauna of British India, including Ceylon and Burma. Reptilia and Batrachia. London: Taylor and Francis 541.

Boulenger GA. 1885. Catalogue of the lizards in the British Museum. Volume 1, London: Stechert-Hafner Service Agency 436.

Colton GW, Colton CB. 1855. Colton's hindostan or British India. Published by G. W. and C.B. Colton, \& Co. No. 172. William's New York.

Cuvier G. 1829. Le Régne animal distribué d'aprèsson organisation, pour servir de base a l'histoire naturelle des animaux et d'introduction a l'anatomie comparée. Nouvelle édition, revue et augmentée, Tome II. Déterville \& Crochard, Paris: $\mathrm{xv}+406$.

Das I. 1997. Checklist of the reptiles of India with English common names. Hamadryad 22: 32-45.

Das I. 2002. A photographic guide to snakes and other reptiles of India. New Holland Publishers.

Datta-roy A, Mohapatra PP, Dutta SK, Giri VB, Veerappan D, Maddock ST, Raj P, Agarwal I, Karanth P. 2013. Long-lost relic from the Eastern Ghats: Morphology, distribution and habitat of Sepsophis punctatus Beddome, 1870 (Squamata: Scincidae). Zootaxa 3670: 55-62.

Deraniyagala PEP. 1953. A coloured atlas of some vertebrates from Ceylon. Volume 2, Tetrapod Reptilia. Govt. Press, Colombo.

Dowling HG, Savage JM. 1960. A guide to the snake hemipenis: a survey of basic structure and systematic characteristics. Zoologica 45: 17-28.

Duméril AMC, Bibron G. 1837. Erpétologie Général ou Histoire Naturelle compléte des Reptiles. Librairie Encyclopédique de Roret, Paris.

Elliot W. 1873. Memoir of Dr. T. C. Jerdon. History of the Berwickshire Naturalists' club. Alnwick 7: 143-151.

Glaw F, Köhler J, Townsend TM, Vences M. 2012. Rivaling the World's Smallest Reptiles: Discovery of Miniaturized and Microendemic New Species of Leaf Chameleons (Brookesia) from Northern Madagascar. PLoS ONE 7: e31314.

Groth JG, Barrowclough GF. 1999. Basal divergences in birds and the phylogenetic utility of the nuclear RAG-1 Gene. Molecular Phylogenetics and Evolution 12: 115-123. http://dx. doi.org/10.1006/mpev.1998.0603

Günther A. 1864. The Reptiles of British India. The Ray Society, London: xxvii+452.

Guptha B, Prasad NVS, Maddock ST, Deepak V. 2015. First record of Chrysopelea taprobanica Smith, 1943 (Squamata: Colubridae) from India. Check List 11: 1523. http://dx.doi. org/10.15560/11.1.1523

Hallermann J, Ananjeva NB, Orlov N. 2001. On a remarkable collection of reptiles and amphibians collected by the German Indian expedition 1955-1958. Russian Journal of Herpetology 8: 25-34.

Hanken J, Wassersug R. 1981. The visible skeleton: a new double-stain technique reveals the nature of the "hard" tissues. Functional photography 16: 22-44.

IUCN. 2015. Sitana ponticeriana. In: IUCN Red List of threatened Species.

Jerdon TC. 1853. Catalogue of the reptiles inhabiting the peninsula of India. Journal of Asiatic Society of Bengal 22: 462-479. 
Jerdon TC. 1870. Notes on Indian Herpetology. Proceedings of the Asiatic Society of Bengal 1870: 66-85.

Johnson AJ. 1867. Johnson's Hindoostan and farther India. A.J. Johnson, New York.

Jollie MT. 1960. The head skeleton of the lizard. Acta Zoologica 41: 1-64.

Kelaart EF. 1854. Catalogue of reptiles collected in Ceylon. Annals and Magazine of Natural History 13: 137-140.

Lanfear R, Calcott B, Ho SYW, Guindon S. 2012. Partitionfinder: combined selection of partitioning schemes and substitution models for phylogenetic analyses. Molecular Biology and Evolution 29: 1695-1701.

Leaché AD. 2009. Species tree discordance traces to phylogeographic clade boundaries in 132 North American fence lizards (Sceloporus). Systematic Biology 58: 547-559. http:// dx.doi.org/10.1093/sysbio/syp057

Linkem CW, Hesed KM, Diesmos AC, Brown RM. 2010. Species boundaries and cryptic lineage diversity in a Philippine forest skink complex (Reptilia; Squamata; Scincidae: Lygosominae). Molecular Phylogenetics and Evolution 56: 572-585. http://dx.doi.org/10.1016/j.ympev.2010.03.043

Macey RJ, Larson A, Ananjeva NB, Fang Z, Papenfuss T. 1997. Two novel gene orders and the role of light-strand replication in rearrangement of the vertebrate mitochondrial genome. Molecular biology and evolution 14: 91-104.

Macey RJ, Schulte II JA, Larson A, Ananjeva NB, Wang Y, Pethiyagoda R, Rastegar-Pouyani N, Papenfuss TJ. 2000. Evaluvating Trans-Tethys migration: An example using acrodont lizard phylogentics. Systematic Biology 49: 233-256. http://dx.doi.org/10.1093/sysbio/49.2.233

Maduwage K, Meegaskumbara M, Silva A, Pethiyagoda R. 2008. Phylogenetic implications of hemipenial morphology in Sri Lankan agamid lizards. Current Science 95: 838-840.

Maduwage K, Anjana S. 2012. Hemipenial morphology of Sri Lankan dragon lizards (Sauria: Agamidae). Ceylon Journal of Science 41: 111-123.

Moody SM. 1980. Phylogenatic and historical biogeographical relationship of the genera in the family Agamidae (Reptilia: Lacertilia). Unpublished Ph.D. thesis 373.

Murray JA. 1886. The Reptiles of Sind: A systematic account with description of all the species inhabiting the Province and a Table of their Geographical Distribution in Persia, Beloochstan, and Afghanistan; Punjab, North-west Province, and Peninsula of India generally, with woodcut, lithographs, and colored illustrations. Education Society's Press, Byculla, Bombay, and Richardson and Co., London 92.

Nunes PMS, Fouquet A, Curcio FF, Kok PJR, Rodrigues MT. 2012. Cryptic species in Iphisa elegans Gray, 1851 (Squamata: Gymnophthalmidae) revealed by hemipenial morphology and molecular data. Zoological Journal of the Linnean Society 166: 361-376. http://dx.doi.org/10.1111/j.10963642.2012.00846.x

Oelrich TM. 1956. The anatomy of the head of Ctenosaura pectinate (Iguanidae). University of Michigan Museum of Zoology. Miscellaneous Publications 94: 1-122.

Oliver PM, Adams M, Lee MSY, Hutchinson MN, Doughty P. 2014. Cryptic diversity in vertebrates: molecular data double estimates of species diversity in a radiation of Australian lizards (Diplodactylus, Gekkota). Proceedings of the royal society B 276: 2001-2007. http://dx.doi.org/10.1098/rspb. 2008.1881
Pal A, Swain MM, Rath S. 2010. Observations on microhabitat use and activity patterns in Sitana ponticeriana (Sauria: Agamidae). Russian Journal of Herpetology 17: 22-30.

Pal A, Swain MM, Rath S. 2007. Seasonal variation in the diet of the fan-throated lizard, Sitana ponticeriana (Sauria: Agamidae). Herpetological Conservation and Biology 2: 145148.

R Core Team (2013). R: A language and environment for statistical computing. R Foundation for Statistical Computing, software accessible at http://www.R-project.org/. Vienna, Austria.

Rao MV, Rajabai BS. 1972. Reproduction in the ground lizard, Sitana ponticeriana and the garden lizard, Calotes nemoricola. British Journal of Herpetology 4: 245-251.

Rasband WS. 2004. ImageJ, U.S. National institutes of health, software accessible at http://rsb.info.nih.gov/ij/. Bethesda, Maryland, USA.

Romer AS. 1956. The osteology of the reptiles. The University of Chicago press, Chicago \& London. 772.

Ronquist F, Teslenko M, van der Mark P, Ayres D, Darling A, Höhna S, Larget B, Liu L, Suchard MA, Huelsenbeck JP. 2012. MrBayes 3.2: efficient Bayesian phylogenetic inference and model choice across a large model space. Systematic Biology 61: 539-542.

Russell AP, Rewcastle SC. 1979. Digital reduction in Sitana (Reptilia: Agamidae) and the dual roles of the fifth metatarsal in lizards. Canadian Journal of Zoology 57: 1129-1135.

Sahi DN, Duda PL. 1981. Notes on little known lizards from Jammu \& Kashmir state. Journal of Bombay Natural History Society 80: 227-229.

Schleich HH, Kästle W. 2002. Amphibians and Reptiles of Nepal-Lizards and Crocodiles, Koeltz Scientific Books. Königstein, 39.

Schleich HH, Kästle W, Shah KB. 1998. Description of Sitana sivalensis spec. nov., (Sauria: Agamidae) from south Nepal. Pp. 87-100 in: Schleich HH, Kästle W. eds, Contributions to the herpetology of south-Asia (Nepal, India). FuhlrottMuseum, Wuppertal.

Schleich HH, Kästle W. 1998. Sitana fusca spec. nov., a further species from the Sitana sivalensis- complex. Pp. 207-226 in: Schleich HH, Kästle W. eds, Contributions to the herpetology of south-Asia (Nepal, India). Fuhlrott-Museum, Wuppertal.

Shanbhag BA, Radder RS, Gramapurohit NP, Dheeraj KV, Ammanna VH, Pandav BN, Saidapur SK. 2003. Demography of fan-throated lizard Sitana ponticeriana (Cuvier) in a cotton field in Dharwad district of Karnataka state, India. Current Science 85: 1363-1366.

Silvestro D, Michalak I. 2012. raxmlGUI: a graphical front-end for RAxML. Organisms Diversity and Evolution. 12: 335337. http://dx.doi.org/10.1007/s13127-011-0056-0

Smith SA. 1935. The Fauna of British India including Ceylon \& Burma. Vol II. - Today \& Tomorrow Publishing, New Delhi, India. 440.

Smith KL, Harmon LJ, Shoo LP, Melville J. 2011. Evidence of constrained phenotypic evolution in a cryptic species complex of agamid lizards. Evolution 65: 976-992.

Stamatakis A, Ludwig T, Meier H. (2005). RAxML-III: a fast program for maximum likelihood-based inference of large phylogenetic trees. Bioinformatics 21: 456-463.

Stoliczka F. 1872. Notes on various new or little known Indian lizards. Journal of the Asiatic Society of Bengal 41: 86-116. 
Subramanean J, Reddy MV. 2010. Seasonal variations in population densities of three lizard species along the Coromandel Coast, India. Hamadryad 35: 37-45.

Tamura K, Peterson D, Peterson N, Stecher G, Nei M Kumar S. 2011. MEGA 5: Molecular Evolutionary Genetics Analysis version 5.1. Molecular Biology and Evolution 30: 2725-2729. http://dx.doi.org/10.1093/molbev/mst197

Theobald W.Jr. 1876. Descriptive catalogue of the reptiles of British India. Thacker, Spink and Co., Calcutta.

Trivedi JN, Bayani AS, Pratyush P, Suresh B. 2011. Environmental factors do influence the nesting behavior of Fanthroated lizard Sitana ponticeriana (Cuvier). The Bioscan 6: 593-595.

Voris HK. 2000. Maps of Pleistocene sea levels in Southeast Asia: shorelines, river systems and time durations. Journal of Biogeography 27: 1153-1167. http://dx.doi.org/10.1046/j. 1365-2699.2000.00489.x

Wagler J. 1830. Natürliches System der Amphibien: mit vorangehender Classification der Säugethiere und Vögel. Ein Beitrag zur vergleichenden Zoologie. J.G. Cotta'schen Buchhandlung, München, Stuttgart and Tübingen.
Wiegmann AFA. 1834. Herpetologia Mexicana, seu descriptio amphibiorum novae hispaniae, quae itineribus comitis de Sack, Ferdinandi Deppe et Chr. Guil. Schiede im Museum Zoologicum Berolinense Pervenerunt. Pars prima, saurorum species. Berlin, Lüderitz.

Zamudio KR. Jones KB, Ward RH. 1997. Molecular Systematics of Short-Horned Lizards: Biogeography and Taxonomy of a Widespread Species Complex. Systematic Biology 46: 284-305. http://dx.doi.org/10.1093/sysbio/46.2.284

Zug GR, Brown HHK, Schulte II JA, Vindum JV. 2006. Systematics of the garden lizards, Calotes versicolor group (Reptilia, Squamata, Agamidae), in Myanmar: Central dry zone populations. Proceedings of the California Academy of Sciences 57: 35-68.

Received: 2 March 2015

Revised and accepted: 27 October 2015

Published online: 9 March 2016

Editor: J. van Rooijen

\section{Online Supplementary Information}

S1. Sitana samples used in this study with tissue sample number, locality and GenBank accession numbers. I = India, $\mathrm{SL}=$ Sri Lanka, $\mathrm{WHT}=$ Wildlife Heritage Trust, $\mathrm{CES}=$ Centre for Ecological Sciences, BNHS = Bombay Natural History Society. "-" = not sequenced/not available.

S2. Partitions and models of sequence evolution used in the Maximum Likelihood (ML) and Bayesian (MB) analysis.

S3. Drawings of both sulcal and asulcal view of hemipenis of two different species in Sarada gen. nov. and four species of Sitana. Scale $=2 \mathrm{~mm}$.

S4. Uncorrected p sequence divergence (ND2 data set) for genetic samples included in this study. Names arranged after the new taxonomic concept.

S5. Morphometric data for the paratypes of the five newly described species, as well as Sitana ponticeriana and Sarada deccanensis comb. nov. Abbreviations as in materials and methods, all measurements in $\mathrm{mm}$. Measurements extracted from photograph with scale are included in brackets. 


\section{Appendix}

New classification of Fan-throated lizards from India

We provide taxonomic accounts for all the presently known Sitana species from India, including the formal description of five new species. Species are classified into four groups: 1- the $S$. ponticeriana clade, found in coastal and Inland Tamil Nadu and coastal Sri Lanka; 2- the S. spinaecephalus clade, found from the Mysore Plateau to Ajmer in Rajasthan; 3- the Sarada deccanensis clade, found on the Deccan Plains and Plateau; 4- the Sitana sivalensis complex, comprising Sitana sivalensis, Sitana schleichi, and Sitana fusca, found in the Terai region of Nepal. External morphological diagnosis is only possible for males of different populations, therefore most of the diagnoses are based on males. However, we have provided details of morphometric measurements and scale counts for both sexes. All morphometric measurements in the text are reported as (mean $\pm \mathrm{SD}$ ). We only compare the mitochondrial sequences (ND2 gene) to show genetic divergence. The dewlap to trunk ratio is variable for different species and is one of the key characters for identifying Sitana spp. (Amarasinghe et al., 2015). For ease of identification, dewlap sizes were classified into four groups which are used in the key to the genus and species of Sitana and Sarada gen. nov. 1. Small: dewlap extending only to the forearm insertion, 2. Medium: dewlap extends beyond the forearm insertion up to $30 \%$ of trunk length, 3. Large: dewlap extends 31 to $50 \%$ of the trunk length. 4 . Very large: dewlap extends more than $50 \%$ of the length of the trunk.

\section{Family Agamidae Gray, 1827 Genus Sitana Cuvier, 1829}

Sitana Cuvier, 1829. Le Regne Animal Distribué, d'apres son Organisation, pur servir de base à l'Histoire naturelle des Animaux et d'introduction à l'Anatomie Comparé. 43. Type species: Sitana ponticeriana.

Semiophorus Wagler, 1830. Natürliches System der Amphibien: mit vorangehender Classification der Säugethiere und Vögel: ein Beitrag zur vergleichenden Zoologie. 152. Type species: Sitana ponticeriana (named as pondicerianus)

Litana Kelaart, 1854. Catalogue of reptiles collected in Ceylon. The Annals and magazine of natural history (2) 13: 138. Litana ponticereana.
Content. Sitana ponticeriana Cuvier, 1829; Sitana fusca Schleich and Kästle, 1998; Sitana sivalensis Schleich, Kästle and Shah, 1998; Sitana schleichi Anders and Kästle, 2002; Sitana bahiri Amarsinghe, Ineich, and Karunarathna, 2015; Sitana devakai Amarsinghe, Ineich, and Karunarathna, 2015.

English name. Fan-throated lizards (Das, 1997).

Etymology. Cuvier (1829) in his description did not mention anything about the generic name. Jerdon (1853) mentioned that Sitana is the name that it was known by at Puducherry, with the genus name a Latin termination of the word "Shaitan" or Devil. Jerdon also notes that the name was sometimes applied to it by the Musulmans of South India. More recently Schleich and Kästle (2002), without any reference, suggested that the generic name is derived from the Tamil language sit wona, small lizard. Sit wona does not translate to small lizard in Tamil: it is either siriyawona or chinnawona. There is no mention about the etymology of the genus by past herpetologists (Günther, 1864, Boulenger, 1890, Smith, 1935). Since Jerdon's information was published during the same century, we suggest his version of the genus etymology is more likely to be accurate.

Diagnosis. Small to medium-sized lizards, male SVL 36.6-56.6 mm, females 36.4-52.1 mm; headscales unequal, strongly keeled; supraciliary edge sharp; fourth toe extending well beyond third, fifth toe absent; exposed tympanum, no preanal or femoral pores, no prominent dorsal crest; presence of enlarged scales on the lateral side of the trunk and a single enlarged keeled scale on the thigh region. Scales on the dorsum within the dark brown line marking are relatively larger than the adjoining smaller scales on the lateral side of the body. Dewlap size varies from small to large depending on the species. Sitana can be differentiated from their closest living genus Otocryptis by the absence of fifth toe and an exposed tympanum.

Distribution and habit. Widely distributed in the Indian Subcontinent from Jammu and Kashmir in the north, the Sind region of Pakistan in the west, West Bengal in the east, and Sri Lanka in the south. (Stoliczka, 1872; Murray, 1886; Sahi and Duda, 1981). Sitana are primarily terrestrial, but also climb onto low bushes, herbs and small rocks (Fig. 9). Breeding starts approximately a month and a half before the monsoon (Rao and Rajabai, 1972; Subramanean and Reddy, 2010; Pal et al., 2010; Trivedi et al., 2011). 

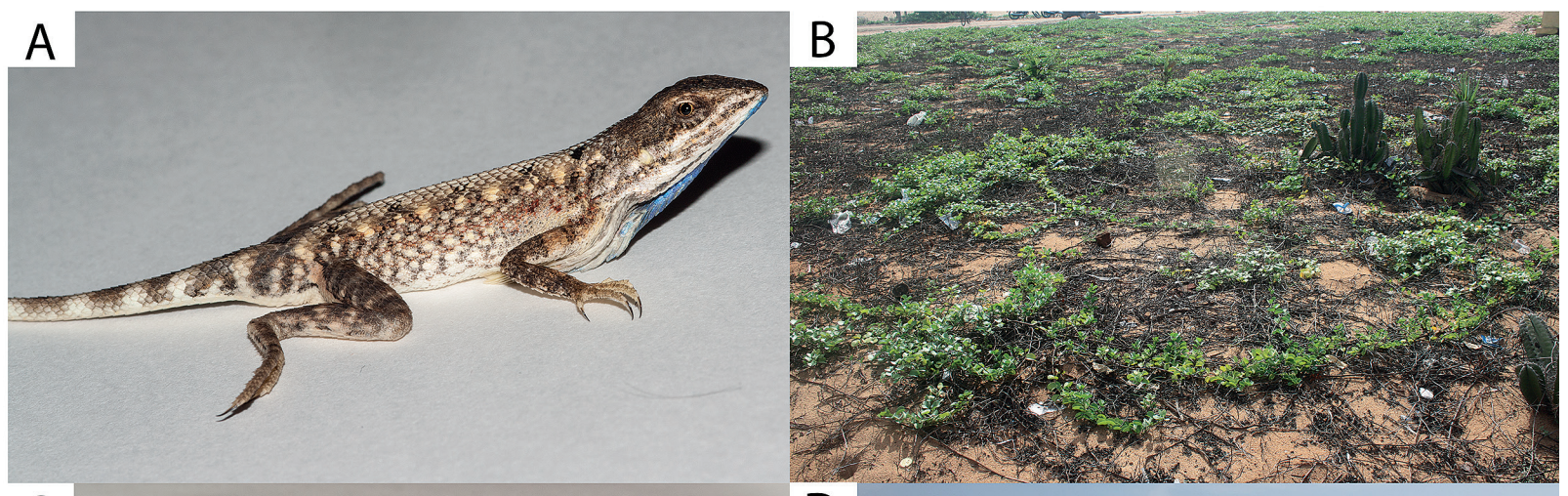

\section{C}

D
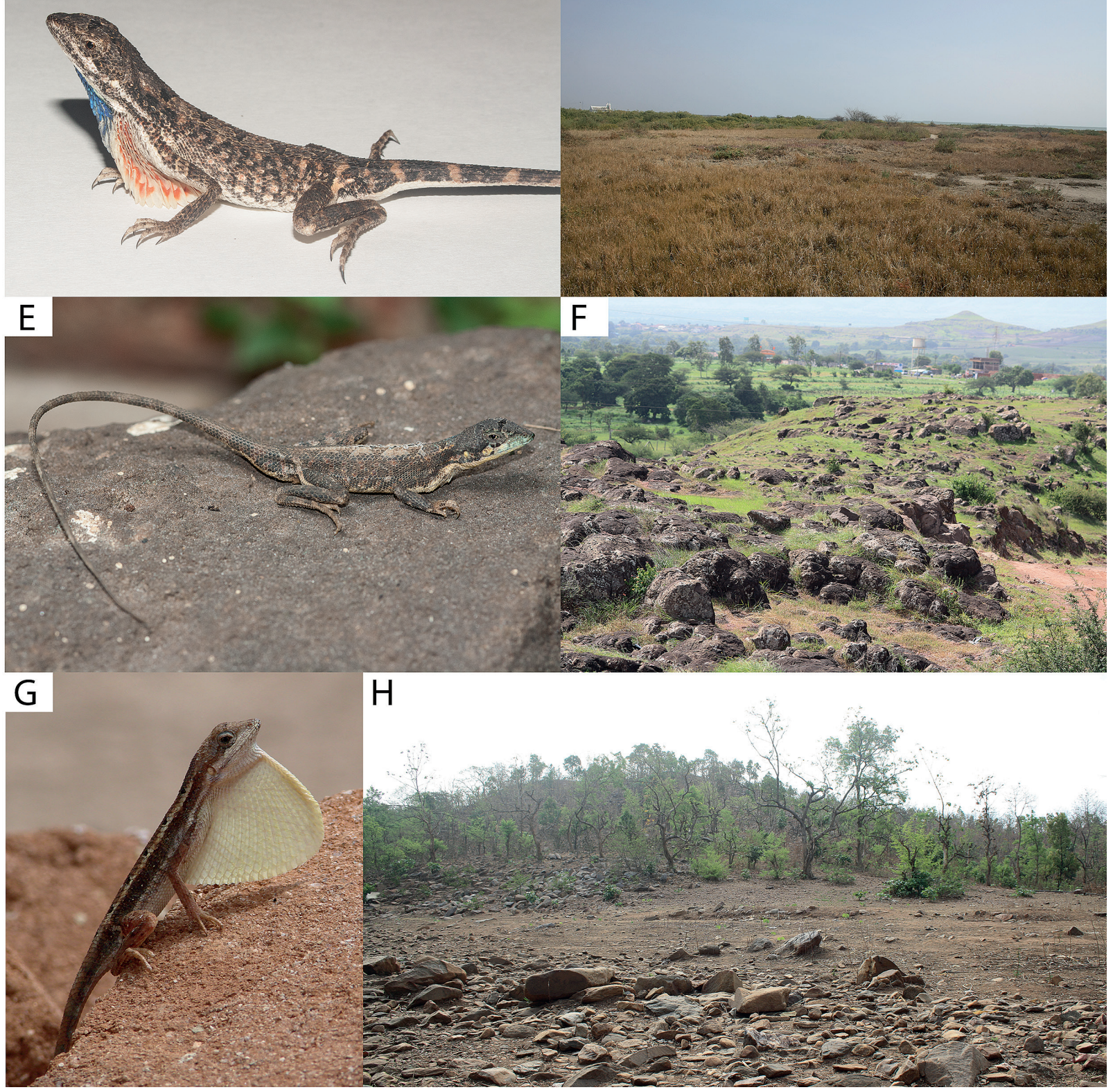


\section{Sitana ponticeriana (Cuvier, 1829)}

(Figs 9A, 10A-D; Table 3, 5, 7, 8)

Semiophorus pondiceriana, Wagler, 1830

Semiophorus pondicerianus, Wiegmann, 1834

Sitana minor, Günther, 1864

Sitana ponticeriana ponticeriana, Deraniyagala, 1953

Sitana ponticeriana Amarsinghe, Ineich, Karunarathna, Botejue and Campbell, 2015

Lectotype. Male, MNHN 6901, SVL $47.43 \mathrm{~mm}$, presented by Jean-Baptiste Leschenault de La Tour.

Type locality. "Indes orientales", restricted to "Pondicherry" (now Puducherry) by Smith (1935).

Referred specimens. Lectotype. MNHN 6901. (1 adult male), Pondichéry (now Puducherry), Puducherry Union Territory, collected by Leschenault between 1816 and 1822. Topotype. NCBS-AQ053 (1 adult male), Kuilapalayam, Puducherry Union Territory georeferenced latitude 11.98936 longitude 79.84823 , collected by V. Deepak and R. Arumugam on 16 June 2013. CES 13661-13665 (4 subadult males, 2 subadult females), Kuilapalayam, Puducherry Union Territory, collected by V. Deepak and R. Arumugam on 5 May 2011. CES 13555-13558, CES 13559-13565 (7 adult males, 4 adult females), Kuilapalayam, Puducherry Union Territory, collected by V. Deepak and R. Arumugam on 16 June 2013. CES 13607, CES 13660 (subadult male) Karur, Karur District, Tamil Nadu state, collected by V. Deepak and Ishan Agarwal on 26 May 2012. CES 13676-13677 (2 subadult males), Akkamadam, Rameshwaram, Ramanathapuram District, Tamil Nadu state, collected by V. Deepak and Ishan Agarwal on 24 May 2012. CES 13679 (1 subadult male) Muttukad, Kanchipuram District, Tamil Nadu state, collected by V. Deepak on 19 October 2013. CES 13591 (1 adult male) Vadanamelli, Kanchipuram District, Tamil Nadu state, collected by V. Deepak on 15 September 2013. CES 13666-13668 (1 hatchling, 1 subadult female, 1 subadult male), Kuilapalayam, Puducherry Union Territory, collected by V. Deepak and R. Arumugam on 23 April 2011. CES 13669-13675 (1 adult male, 2 adult females, 1 subadult female, 4 subadult males), Kuilapalayam, Puducherry Union Territory, collected by V. Deepak and R. Arumugam on 22 May 2012. CES 13649 (1 hatchling), Bodupatti, Dharma- puri District, Tamil Nadu state collected by V. Deepak on 26 January 2014. CES 13651 (1 hatchling), Kothandavadi lake, Tiruvannamalai District, Tamil Nadu state, collected by Kalai Mani on 29 November 2013. CES 13653 (1 hatchling), Kailasagiri hill, Vellore District, Tamil Nadu state, collected by Kalai Mani on 1 January 2014. CES 13654 (1 hatchling), Tiruthani hill, Tiruvallur District, Tamil Nadu state, collected by Kalai Mani on 6 January 2014. CES 13655 (1 hatchling), Bantharapalli, Krishnagiri District, Tamil Nadu state, collected by Kalai Mani on 24 January 2014.

Comments. The taxonomic history of this species and a detailed description of the lectotype are given in Amarasinghe et al. (2015). Because two new species have recently been described from this clade along with a third new species described herein, for clarification purposes we opt to assign a topotype and diagnose the species. The scale counts of the lectotype match with the topotype collections. The three subadult male specimens of Sitana cf. bahiri we collected from Rameshwaram Island (CES 13676 and CES 13677) and Karur (CES 13660) in Tamil Nadu state has overlapping scale count characters with Sitana ponticeriana. Sitana cf. bahiri have 47-51 around the body scales. Sitana cf. bahiri also has lesser number (69-73) of ventral scales that falls within the range of Sitana ponticeriana and Sitana visiri sp. nov. counts, and are lower than Sitana bahiri and Sitana devakai ventral scale counts.

Diagnosis. Sitana ponticeriana can be distinguished from all the members of Sitana spinaecephalus clade in having a strongly serrated dewlap with extensive blue colouration and a large orange spot vs a weaklyserrated dewlap with only a single blue line (Fig. 3 \& 9A). Sitana ponticeriana can be easily distinguished from the three species in Sitana sivalensis complex by having a dewlap that extends posteriorly beyond the forearm insertion. Sitana ponticeriana can be distinguished from Sitana visiri sp. nov. in having a proportionally smaller dewlap that only extends up to $46 \%$ of the trunk length vs up to $56 \%$. Sitana ponticeriana can be differentiated from the other members of the $S$. ponticeriana Clade, Sitana devakai and Sitana bahiri, in having a dewlap that extends far posteriorly along the trunk (up to $46 \%$ vs $29 \%$ and $33 \%$, respectively).

Fig. 9. Sitana (Cuvier, 1829) in life and their habitat: Sitana ponticeriana. A. Adult male from type locality, B. Habitat type in the type locality, Puducherry. Sitana visiri sp. nov. C. Adult male, D. Habitat type in the type locality, Tuticorin. Sitana laticeps sp. nov. E. Adult male in breeding display, F. Habitat type in the type locality, Bopdev Ghat. Sitana spinaecephalus sp. nov. G. Adult male H. Habitat type in the type locality, Halol. 

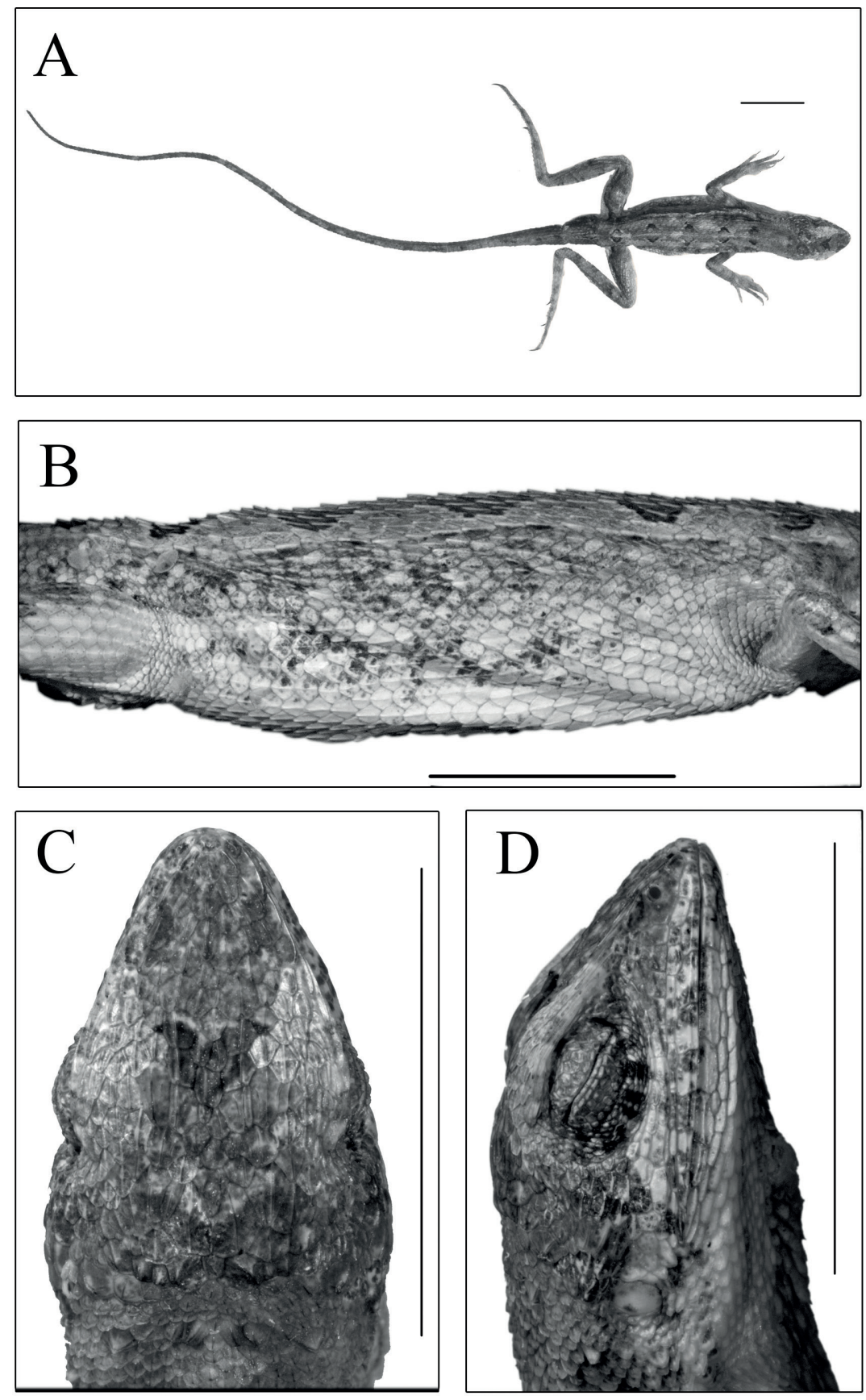

Fig. 10. Sitana ponticeriana collected from Puducherry, Tamil Nadu. (A) full body dorsal (B) flank region (C) head dorsal (D) head lateral. Scale bar is equal to $10 \mathrm{~mm}$.
Sitana ponticeriana are medium-sized lizards; males $(40.5 \pm 2.5)$, females $(41.8 \pm 4.6)$. Details on morphometric data, scale counts and body ratios of select characters for multiple samples are given in Table 3, 7 and 8 . The dewlap is large, extending posteriorly up to $46 \%$ of the length of the trunk.

Genetic divergence. Sitana ponticeriana, Sitana vi- siri sp. nov., and Sitana cf. bahiri have 14-16\% genetic divergence from the two species in the Sitana spinaecephalus clade. Between populations of Sitana ponticeriana, the genetic divergences were 0-1\%. Sitana ponticeriana had 5-6\% genetic divergence from that of Sitana visiri sp. nov. and $4 \%$ genetic divergence from that of Sitana bahiri and Sitana cf. bahiri (S4). 
Colour in life. Dorsum light to dark brown with a black patch on the neck, brown rhomboidal markings on the trunk. A black patch between the eyes. Limbs and tail with dark brown or black bands of variable widths. A cream-coloured streak begins below the eye, behind the nostril and extends into flank region. Belly pale white (iridescent) in color. Both forelimbs, hind limbs, and tail have dark brown bars of variable widths. dark blue colour from the mentum extending up to the middle to the whole length of dewlap when folded (Fig. 9a), brown and orange patches or spots develop on the plain (iridescent white) dewlap; parallel to the blue shade there is one brown line on the throat (Fig. 3F).

Colour in preservation. Dorsum buff to light brown with a dark brown patch on neck, three indistinct rhomboidal markings on the dorsum. Flank dark brown. Dark brown bars on limbs and tail faintly visible. The dewlap colouration is faint.

Hemipenial morphology. One specimen from $\mathrm{Pu}-$ ducherry was examined (NCBS-AQ053). The hemipenis is bilobed, relatively small, as wide as long, and shallowly-forked. The sulcus spermaticus is bifurcated and the fork continues to the apical lobes (Fig. 4E and S3). Sulcal lips are raised and papillate, the sulcus smooth originating from the side of the base. Apex with small deep polygonal calyces and the sulcal region of the apex unornamented, a medial projection absent. Ornamentation includes a combination of flounces and calyces. Papillae are present between the apical lobes. The calyces are deep irregular polygonal pits on the medial region of the organ and become shallow basally. Size of the calyces smaller in apical region. Ridges between the calyces are thin and show scalloped micro-ornamentation. Seven flounces are present, three of which are prominent and the basalmost flounce unornamented.

Suggested English name. Cuvier's fan-throated lizard.

Distribution. Sitana ponticeriana is found in Kuilapalayam, Puducherry union territory, Muttukad, Kanchipuram District, Vadanamelli, Kanchipuram District, Bodupatti, Dharmapuri District, Kothandavadi Lake, Tiruvannamalai District, Kailasagiri Hill, Vellore District, Tiruthani Hill, Tiruvallur District, Bantharapalli, Krishnagiri District, Tamil Nadu state. Sitana ponticeriana is a widespread species in the northern plains of Tamil Nadu state (Fig. 8). The altitudinal distribution of the species is between 6 and 520 m.a.s.l.

Habitat and natural history. Sitana ponticeriana is widely distributed on the east coast of Peninsular India, and are mostly seen on coastal sand dunes, grass- land habitats, Salai habitats (Subramanean and Reddy, 2010), and grassland plains in the inlands of Tamil Nadu state. Other diurnal lizard species found in these habitats include Ophisops sp. Eutropis carinata, Eutropis bibroni, and Calotes versicolor. Breeding males were observed during the months of May, July and September. One of the female specimens that we dissected had four undeveloped eggs.

\section{Sitana visiri Deepak sp. nov.}

(Figs 9C, 11A-D; Table 3, 5, 7, 8)

Holotype. NCBS-AQ054, adult male, Tuticorin, georeferenced latitude $\mathrm{N} 8.784993^{\circ}$, longitude E78.156341 ${ }^{\circ}$, Thoothukudi, Tamil Nadu state, collected by V. Deepak and M. Kannan on 17 October 2013.

Paratypes. CES 141163, adult male, BNHS 2310 adult female, Tuticorin, georeferenced latitude N8.784993 ${ }^{\circ}$, longitude E78.156341 ${ }^{\circ}$, Thoothukudi, Tamil Nadu state, collected by V. Deepak and M. Kannan on 17 October 2013.

Referred specimens. CES 13592-13605 (9 adult males, 9 adult females), Tuticorin, Thoothukudi District, Tamil Nadu state, collected by V. Deepak and M. Kannan on 17 October 2013. CES 13678 (1 adult female) Batlagundu, Dindigul District, collected by V. Deepak and Sandeep Varma on 15 October 2010. CES 13646 (1 hatchling), Kovilpatti, Thoothukudi District, collected by V. Deepak on 11 January 2014. CES 13647 (1 hatchling), Aruppukottai, Virudhunagar District, collected by V. Deepak on 12 January 2014.

Diagnosis. Sitana visiri sp. nov. can be distinguished from all the members of Sitana spinaecephalus clade in having a strongly serrated dewlap with extensive blue colouration and a large orange spot (Fig. 3G). Sitana visiri sp. nov. can be distinguished from Sitana ponticeriana, S. bahiri, and S. devakai in having proportionally larger dewlap that extends up to $56 \%$ of the length of the trunk (vs 46\%,29\%, and 33\%, respectively). Additionally Sitana visiri sp. nov. can be distinguished from the other four members of S. ponticeriana clade in having a large SVL; males $(50.0 \pm$ 5.2), females $(48.5 \pm 2.5)$ vs. S. ponticeriana males $(40.5 \pm 2.5)$, females $(41.8 \pm 4.6)$; S. bahiri males (40.545.0), females (44.1-46.9) ; $S$. devakai males (40.045.6), females (42.0-44.9). Details on morphometric data, scale counts and body ratios of select characters for multiple samples are given in Table 3,7 and 8 .

Genetic divergence. Genetic divergences between populations of Sitana visiri sp. nov. ranged from 0-1\%. 
Table 7. Mensural data for the holotypes of the five described species. Sitana ponticeriana Lectotype. and the male holotype of Sarada deccanensis comb. nov. Abbreviations as in materials and methods. all measurements in $\mathrm{mm}$. Measurements extracted from photograph with scale are included in brackets.

\begin{tabular}{|c|c|c|c|c|c|c|c|}
\hline & Sarada & & & Sitana & & & \\
\hline & $\begin{array}{l}\text { deccanensis } \\
\text { comb. nov. }\end{array}$ & $\begin{array}{l}\text { darwini } \\
\text { sp. nov. }\end{array}$ & $\begin{array}{l}\text { superba } \\
\text { sp. nov. }\end{array}$ & $\begin{array}{l}\text { visiri } \\
\text { sp. nov. }\end{array}$ & ponticeriana & $\begin{array}{l}\text { spinaecephalus } \\
\text { sp. nov. }\end{array}$ & $\begin{array}{l}\text { laticeps } \\
\text { sp. nov. }\end{array}$ \\
\hline & NCBS-AQ050 & NCBS-AQ052 & NCBS-AQ051 & NCBS-AQ054 & MNHN 6901 & NCBS-AQ055 & NCBS-AQ056 \\
\hline SVL & 65.68 & 75.71 & 59.8 & 52.65 & $47.43(44.5)$ & 48.13 & 43.05 \\
\hline HL & 18.7 & 22.06 & 17.22 & 14.91 & $10.92(13.7)$ & 14.2 & 12.8 \\
\hline HW & 13.02 & 15.9 & 10.51 & 9.43 & $8.33(8.68)$ & 9.31 & 8.88 \\
\hline $\mathrm{HH}$ & 11.37 & 14.14 & 9.08 & 7.97 & $7.31(7.60)$ & 7.02 & 6.45 \\
\hline ET & 5.63 & 6.41 & 4.75 & 3.85 & 4.14 (4.11) & 3.87 & 3.16 \\
\hline IO & 7.24 & 8.11 & 6.82 & 5.21 & $1.80(4.95)$ & 5.58 & 5.09 \\
\hline JL & 14.95 & 16.2 & 13.36 & 11.67 & $-(11.73)$ & 11.22 & 11.09 \\
\hline $\mathrm{NE}$ & 4.57 & 4.62 & 3.94 & 3.21 & $3.40(3.66)$ & 3.46 & 3.41 \\
\hline SE & 7.31 & 8.05 & 6.23 & 5.24 & $5.60(5.67)$ & 5.33 & 5.43 \\
\hline IN & 3.6 & 4.19 & 3.35 & 3.18 & $-(2.51)$ & 2.66 & 2.69 \\
\hline DEWL & 46.46 & 54.96 & 41.12 & 35.03 & $-(29.15)$ & 32.63 & 23.48 \\
\hline TD & 1.69 & 2.17 & 1.31 & 1.1 & $1.36(1.32)$ & 1.79 & 1.31 \\
\hline OD & 5.49 & 5.45 & 4.41 & 4.08 & $3.26(3.52)$ & 3.35 & 3.15 \\
\hline LAL & 12.24 & 14.16 & 10.28 & 9.39 & $9.65(8.95)$ & 9.08 & 6.96 \\
\hline UAL & 12.51 & 14.13 & 10.2 & 9.03 & $8.96(8.69)$ & 8.12 & 6.93 \\
\hline F1 & 3.28 & 3.45 & 2.13 & 2.14 & - $(1.90)$ & 2.11 & 1.85 \\
\hline $\mathrm{F} 2$ & 4.99 & 5.62 & 3.99 & 3.52 & - $(2.99)$ & 3.86 & 3.06 \\
\hline F3 & 7.34 & 7.95 & 6.38 & 5.52 & - $(4.62)$ & 5.21 & 4.81 \\
\hline F4 & 7.34 & 8.37 & 6.44 & 4.73 & $-(-)$ & 4.58 & 4.52 \\
\hline F5 & 4.46 & 4.9 & 3.73 & 3.09 & $-(-)$ & 3.15 & 2.72 \\
\hline FEL & 17.77 & 20.73 & 15.18 & 13.85 & 14.45 (11.74) & 12.93 & 12.33 \\
\hline CL & 21.35 & 23.55 & 18.34 & 18.24 & $17.37(15.27)$ & 14.83 & 13.72 \\
\hline HFL & 27.24 & 28.17 & 22.41 & 21.99 & - (20.36) & 20.38 & 16.76 \\
\hline $\mathrm{T} 1$ & 3.34 & 2.85 & 2.66 & 2.46 & $-(1.64)$ & 2.08 & 2.19 \\
\hline T2 & 5.46 & 5.53 & 4.35 & 5.09 & - $(3.77)$ & 3.46 & 3.51 \\
\hline $\mathrm{T} 3$ & 7.56 & 8.41 & 6.32 & 5.88 & $-(8.58)$ & 5.18 & 4.49 \\
\hline $\mathrm{T} 4$ & 14.97 & 14.86 & 12.54 & 11.7 & $-(8.85)$ & 11.14 & 9.72 \\
\hline TL & 133.34 & & & 149.02 & $-(-)$ & 123 & 106.84 \\
\hline TW & 7.09 & 7.94 & 5.37 & 5.38 & $4.65(6.16)$ & 5.46 & 5.08 \\
\hline TH & 6.63 & 8.21 & 5.55 & 4.99 & $-(-)$ & 5.6 & 4.29 \\
\hline TrL & 24.93 & 26.91 & 19.6 & 20.39 & $20.19(19.2)$ & 17.84 & 18.86 \\
\hline TrW & 17.34 & 16.78 & 11.2 & 11.99 & $-(-)$ & 11.76 & 10.54 \\
\hline $\operatorname{TrH}$ & 12.8 & 12.27 & 7.59 & 9.99 & $-(-)$ & 7.19 & 6.25 \\
\hline
\end{tabular}

Table 8. Mean range of body ratios in adult male Sitana \& Sarada gen.nov. specimens. Standard deviation are in given brackets.

\begin{tabular}{llllllll}
\hline \multicolumn{1}{l}{ Sarada } & \multicolumn{7}{c}{ Sitana } \\
\hline & $\begin{array}{l}\text { deccanensis } \\
\text { comb. nov. }\end{array}$ & $\begin{array}{l}\text { darwini } \\
\text { sp. nov. }\end{array}$ & $\begin{array}{l}\text { superba } \\
\text { sp. nov. }\end{array}$ & ponticeriana & $\begin{array}{l}\text { visiri } \\
\text { sp. nov. }\end{array}$ & $\begin{array}{l}\text { spinaecephalus } \\
\text { sp. nov. }\end{array}$ & $\begin{array}{l}\text { laticeps } \\
\text { sp. nov. }\end{array}$ \\
\hline & $(\mathrm{n}=8)$ & $(\mathrm{n}=8)$ & $(\mathrm{n}=11)$ & $(\mathrm{n}=16)$ & $(\mathrm{n}=9)$ & $(\mathrm{n}=15)$ & $(\mathrm{n}=21)$ \\
\hline HL/SVL & $0.29(0.01)$ & $0.29(0.01)$ & $0.29(0.01)$ & $0.29(0.01)$ & $0.28(0.01)$ & $0.29(0.01)$ & $0.30(0.01)$ \\
JW/SVL & $0.24(0.01)$ & $0.23(0.01)$ & $0.23(0.01)$ & $0.23(0.02)$ & $0.22(0.01)$ & $0.24(0.01)$ & $0.23(0.01)$ \\
HFL/SVL & $0.42(0.02)$ & $0.40(0.02)$ & $0.37(0.02)$ & $0.46(0.04)$ & $0.43(0.03)$ & $0.42(0.01)$ & $0.40(0.02)$ \\
HLL/SVL & $1.04(0.02)$ & $0.97(0.03)$ & $0.93(0.04)$ & $1.05(0.06)$ & $1.04(0.04)$ & $1.0(0.03)$ & $0.98(0.03)$ \\
DEW/SVL & $0.68(0.02)$ & $0.67(0.02)$ & $0.68(0.04)$ & $0.61(0.02)$ & $0.66(0.04)$ & $0.60(0.03)$ & $0.55(0.03)$ \\
DWLT/TrL & $0.48(0.06)$ & $0.46(0.05)$ & $0.48(0.06)$ & $0.36(0.06)$ & $0.49(0.05)$ & $0.35(0.07)$ & $19(0.05)$ \\
\hline
\end{tabular}


Sitana visiri sp. nov. are 6-7\% genetically divergent from S. bahiri and S. cf. bahiri (S4).

Description of holotype NCBS-AQ054 (Fig. 11A$\mathrm{D}$; Table 7). The holotype is in a good condition, hemipenis exposed and seen on both sides when viewed dorsally, tail broken. An adult male, SVL $52.65 \mathrm{~mm}$. Head relatively long (HL/SVL ratio 0.28 ), wide (HW/ HL ratio 0.63 ), not depressed (HH/HL ratio 0.53 ), distinct from neck. Snout short (SE/HL ratio 0.35), pointed; longer than eye diameter (OD/SE ratio 0.78). Eye large (ED/HL ratio 0.27); pupil rounded, eyelids covered with small pentagonal scales, supraciliaries short. Snout obtusely pointed in profile when viewed dorsally, rostral much wider than deep, contacted laterally by first supralabials, a large prenasal and dorsally by three small scales. Canthus rostralis and supraciliary edge sharp. Nostril subcircular, laterally positioned and placed in the centre of a large, undivided and roughly pentagonal nasal plate, which is bordered by six scales (right side), including one prenasal, two postnasals and one supranasal, separated from rostral by prenasal and supralabials by two enlarged scales. Eight rectangular, strongly keeled supralabials, bordered above by a single row of slightly smaller, rectangular, keeled scales, which terminate above seventh supralabial. Loreal region concave, scales of the loreal region heterogenous in size, flat, keeled, some of which roughly hexagonal. Scales on postorbital and temporal region homogenous, imbricate, strongly keeled, and directed backward and upwards. Orbital scales small but not granular. Tympanum naked. Canthals enlarged, overlapping, becoming slightly smaller along subimbricate supraciliaries, protrude slightly laterally on supraorbital ridge. Scales on dorsal surface of snout, forehead, interorbital and occipital region heterogenous in size, shape; mostly elongate, imbricate, strongly keeled longitudinally; those on snout smaller, rhomboidal, those on forehead largest, much elongate; supraorbital scales increase in size becoming more elongate from supraciliaries to inner edges of orbits, of which the enlarged scales follow the curvature of the orbit posterolaterally; occipital region with slightly smaller, less elongate, imbricate and keeled scales. Parietal plate with pineal eye, slightly larger than adjacent scales. Mental shield narrower than rostral; scales on the gular region keeled. Dewlap large, extends posteriorly over $50 \%$ of trunk length, with posterior scales extending slightly beyond axila, not extending to mid venter, about four to five rows of anteriodorsal dewlap scales (blue in colour) smaller, elongate, pointed, keeled, remainder of scales much enlarged, keeled, lanceolate, bluntly pointed, gradually increasing in size towards margin, single marginal row largest with many more pointed scales. 17 enlarged rows of scales on dewlap. Nuchal and dorsal crest absent. Scales on nuchal region smaller, less than half the size of those on interorbital region, imbricate, strongly keeled. Body slender, 54 rows of scales around midbody, of these 10 to 12 rows of scales on back, starting from back of neck to pectoral region homogenous in size, shape, slightly larger than those on neck, imbricate, pointed, keeled, these scales directed backwards forming regularly arranged longitudinal rows; those on flanks heterogenous in size, shape, smaller than those on back, obtusely pointed, keeled, with irregularly scattered, slightly larger, pointed, keeled scales, scales of upper rows directed backwards and upwards, ventral rows backwards and downwards; ventral scales subimbricate, keeled, homogenous in size, shape, arranged in 67 rows; no precloacal or femoral pores.

Fore and hindlimbs relatively slender, tibia short (CL/SVL ratio 0.35); digits moderately long, ending in strong, elongate, slightly recurved claw; inter-digital webbing absent; subdigital lamellae entire, tri-mucronate, 25 subdigital lamellae on toe IV; relative length of fingers $4>3>2>5>1$, toes $4>3>2>1$. Fore and hindlimbs covered above and below with regularly arranged, enlarged, pointed, strongly keeled, scales.

Tail entire but broken; tail base swollen; tail uniformly covered with similar sized, keeled, weakly pointed, regularly arranged, backwardly directed imbricate scales, no enlarged subcaudal row.

Colour in life. Dorsum light to dark brown with a black patch on the neck, three brown rhomboidal markings on the trunk, relatively lighter than the one on the neck. A black patch between the eyes. Limbs and tail with dark brown or black bands of variable widths. A cream-coloured streak begins below the eye, behind the nostril and extends into flank region. Belly pale white (iridescent) in color. Both forelimbs, hind limbs, and tail have dark brown bars of variable widths. Dewlap with dark blue colouration from the mental extending up to the anterior half margin of the dewlap, bright orange patches or spots present on the plain iridescent white dewlap; one black line on the throat.

Colour in preservation. Dorsum buff to light brown with a dark brown patch on neck, three indistinct rhomboidal markings on the dorsum. Flank with much darker marking with orange coloured markings mostly on enlarged scales. Dark brown bars on limbs and tail faintly visible. The dewlap colouration is faint. 

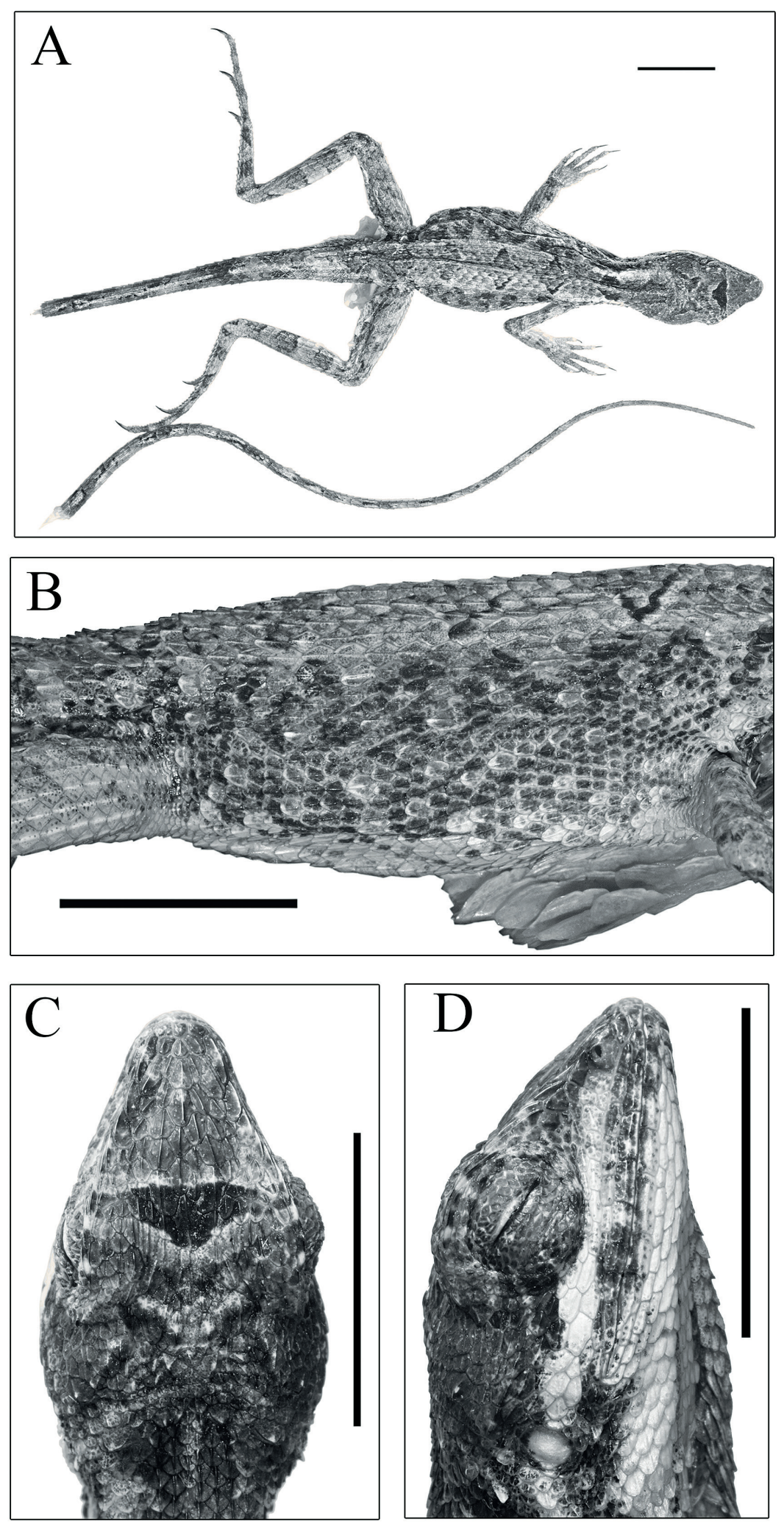

Fig. 11. Holotype of Sitana visiri sp. nov. from Tuticorin, Tamil Nadu. (A) full body dorsal (B) flank region (C) dorsal view of head (D) lateral view of head. Scale bar is equal to $10 \mathrm{~mm}$. 
Variation in paratypes. The paratypes agree with the holotype in overall scalation except CES 141163 , which has 68 ventral scales and 19 enlarged rows of scales on the dewlap and 51 scales around the body. BNHS 2310has 52 scales around the body and 67 ventrals. Morphometric data for the paratypes are summarized in S5. Morphological characters of females also mostly agree with males except absence of dewlap, tail base not swollen, and head narrower.

Hemipenial morphology. Hemipenes were examined for nine samples collected from Tuticorin (CES 13593, CES 13594, CES 13601, CES 13602, CES 13603, CES 13604, CES 13605, NCBS-AQ054, BNHS 2310). Hemipenis single, shallowly divided in the apical region, and longer than wide (Fig. 4F, S3). Sulcus spermaticus single, originating basally. Apex capitate, asulcal surface with calyces forming deep polygonal pits, ridges between the calyces thick and without micro-ornamentation. Sulcal surface differentiated and smooth, the size of the calyces varying greatly; medium sized calyces found around the medial projection, large, deep, smooth calyces with petal-like edges medially, small and medium sized calyces present near the point where sulcus spermaticus enters the ornamented region of hemipenis. Flounces not prominent. Papillae present near the sulcus spermaticus, the base unornamented.

Etymology. The species epithet is derived from the regional Tamil language for a palm leaf fan, a hand crafted fan made from palm leaf. The dewlap of this species resembles a local palm leaf fan.

Suggested English name. Palm leaf fan-throated lizard.

Distribution. Sitana visiri sp. nov. is found in Tuticorin and Kovilpatti, Thoothukudi District, Batlagundu, Dindigul District, Aruppukottai, Virudhunagar District in Tamil Nadu state. Sitana visiri sp. nov. is a wide spread species in the southern plains of Tamil Nadu south of the Cauvery River (Fig. 8). The altitudinal distribution is between 2 and 233 m.a.s.l.

Habitat and natural history. Sitana visiri sp. nov. is found on the coastal sand dunes, grassland habitats, Prosopis juliflora dominated areas, and grassland plains in the southern Tamil Nadu. Other diurnal lizard species found in these habitats include Eutropis carinata, Eutropis bibroni, and Calotes versicolor. Breeding males were observed during the month of September and October. Hatchlings were recorded during the month of January.
Sitana spinaecephalus Deepak, Vyas and Giri sp. nov.

(Figs 9G, 12A-D; Table 3, 5, 7, 8)

Holotype. NCBS-AQ055, an adult male. Halol, georeferenced latitude $\mathrm{N} 22.43163^{\circ}$, longitude E73.62966 ${ }^{\circ}$, Panchmahal District, Gujarat State, collected by Kartik Upadhay and V. Deepak on 10 May 2013.

Paratypes. BNHS 2320, adult female. Mandan, georeferenced latitude E73.4958 ${ }^{\circ}$, longitude N21.76298, Rajpipala, Narmada District, Gujarat State, collected by Raju Vyas, Kartik Upadhay and V. Deepak on 11 May 2013. CES 141164, adult male. Badlapur, georeferenced latitude $\mathrm{N} 19.17234^{\circ}$, longitude E73.26338, Thane District, Maharashtra State, collected by Saunak Pal on 30 April 2013.

Referred specimens. CES 13521 (1 adult male), Pavagadh, Panchmal District, Gujarat State, collected by Kartik Upadhay and V. Deepak on 9 May 2013. CES 13522-13524 (1 adult male, 2 adult females) Halol, Panchmal District, Gujarat State, collected by Kartik Upadhay and V. Deepak on 10 May 2013. CES 1352513526 (3 adult males, 3 adult females) Dariapura, Vadodara District, Gujarat State, collected by Raju Vyas, Kartik Upadhay and V. Deepak on 11 May 2013. CES 13530-13531 (2 adult females) Madan, Karjan reservoir, Bharuch District, Gujarat State, collected by Raju Vyas, Kartik Upadhay and V. Deepak on 11 May 2013. CES 13532 (1 adult male), Kunathia village, Kutch District, Gujarat State, collected by V. Deepak on 13 May 2013. CES 13533-13538 (3 adult males, 3 adult females) outside Saurashtra University campus, Rajkot District, collected by V. Deepak and Dhawal Mehta on 14 May 2013. CES 13539-13540 (2 adult males), near Wilson Hill, Valsad District, collected by V. Deepak and Harshil Patel on 15 May 2013. CES 13541-13542 (2 adult males), Dunguda village, Waghai, Valsad District, collected by V. Deepak and Harshil Patel on 16 May 2013. ZSIK 6334 (1 adult male) and ZSIK 6333, ZSIK 6336 (2 adult females), Kutch District, Gujarat State, collected by F. Stoliczka in 1872. CES G334 (1 adult male) Deviparbada, Toranmal, Nandurbar District, Maharashtra State, collected by Ishan Agarwal on 23 April 2012. CES 13543 (1 adult male), Badlapur, Thane District, Maharashtra State, collected by Saunak Pal on 30 April 2013. CES 14594-14597 (2 subadult males, 2 subadult females), Marda, Chandrapur District, collected by V. Deepak and Sanjay Karkare on 11 April 2014. CES 14598-14601 (3 subadult males, 1 subadult female) Umred road, Nagpur District, collected by V. Deepak and Sanjay Karkare on 12 April 
2014. ZSIK 5051-5055 (3 subadult males, 2 subadult females) SE of Berar and Chanda, collected by W.J. Blanford on 15 February 1870. CES 14651-14652 (1 adult male, 1 adult female) Abu Road, Sirohi District, Rajasthan State, collected by V. Deepak on 8 May 2014. CES 14653-14656 (3 adult males, 1 adult female) Kiranipura, Ajmer District, Rajasthan State, collected by V. Deepak and Hemant Singh on 17 May 2014.

Comments. We identified five specimens considered invalid syntypes of Sitana deccanensis housed in ZSI, Kolkata as Sitana spinaecephalus sp. nov. These five specimens were collected from southeast of Berar and Chanda. Amarasinghe et al. (2015) erroneously reported that Berar and Chanda are in Bihar without reference. Maps published before 1870 (Johnson, 1867; Colton and Colton, 1855) suggest that these locations were in the central province of British India (Fig. 8). Chanda now Chandrapur is in eastern Maharashtra and Berar was a vast area in the central province, which included Nagpur (Maharashtra) in the west and Sambalpur (Odisha) in the East (Fig. 8).

Diagnosis. Sitana spinaecephalus sp. nov. can be distinguished from all the members of S. ponticeriana clade in having a weakly-serrated dewlap with only a single blue line and white or yellowish color on the dewlap. Sitana spinaecephalus sp. nov. can be easily distinguished from the members of $S$. sivalensis complex by having a dewlap extending posteriorly beyond the forearm insertion. Sitana spinaecephalus sp. nov. can be distinguished from Sitana laticeps sp. nov. in having a proportionally larger dewlap (extending posteriorly $45 \%$ of the trunk length vs $29 \%$ ). Additionally S. spinaecephalus sp. nov. can be distinguished from S. laticeps sp. nov. in having four prominent and distinguishable spines on the back of the head (vs having four less prominent and indistinguishable spines) (compare Fig. 12C and Fig. 13C) and their larger body size (Table 3). Sitana spinaecephalus $\mathrm{sp}$. nov. are medium sized lizards; males $(48.5 \pm 2.9)$, females $(44.8 \pm$ 4.2). Details on morphometric data, scale counts and body ratios of select characters for multiple samples are given in Table 3,7 and 8 .

Genetic divergence. Genetic divergences between populations of Sitana spinaecephalus sp. nov. were 0-1\%. Sitana spinaecephalus sp. nov. are 6-8\% genetically divergent from Sitana laticeps sp. nov. (S4).

Description of holotype NCBS-AQ055, (Fig. 12A$\mathrm{D}$; Table 7). The holotype is in good condition, with the hemipenes exposed and visible on the left and right sides when viewed dorsally; tail entire, bent towards right side; forelimbs slightly adpressed to the body, ar- tifact of preservation. An adult male, SVL $48.13 \mathrm{~mm}$. Head relatively long (HL/SVL ratio 0.29 ), wide (HW/ HL ratio 0.66 ), not depressed (HH/HL ratio 0.50 ), distinct from neck. Snout short (SE/HL ratio 0.38), pointed; longer than eye diameter (OD/SE ratio 0.75). Eye large $(\mathrm{ED} / \mathrm{HL}$ ratio 0.24$)$; pupil round, eyelids covered with small pentagonal scales, supraciliaries short. Snout obtusely pointed in profile when viewed dorsally, rostral much wider than deep, contacted laterally by first supralabials, a large prenasal and three small scales dorsally. Canthus rostralis and supraciliary edge sharp. Nostril subcircular, laterally positioned and placed in the centre of a large, undivided and roughly pentagonal nasal plate, which is bordered by seven scales (right side), including one prenasal, two postnasals, one supranasal and the first supralabial, separated from rostral by prenasal. Ten (right) and 11 (left) rectangular, strongly keeled supralabials, bordered above by a single row of smaller (less than half the size of supralabials), equal sized, rectangular, keeled scales, which terminate above ninth supralabial; infralabials 10 (right) and 9 (left), strongly keeled, rectangular. Loreal region concave, scales of the loreal region heterogenous in size and shape, flat, keeled, some roughly hexagonal, also composed of a single row of rectangular, keeled scale, which begins behind postnasal and terminating with a large scale along with a row of scales above supralabial. Scales on postorbital and temporal region heterogenous, juxtaposed, strongly keeled, bottom two to three rows directed backward and upwards. Orbital scales small, flat, juxtaposed, not granular. Tympanum naked. Canthals enlarged, overlapping, becoming slightly smaller along subimbricate supraciliaries, protrude slightly laterally on supraorbital ridge. Scales on dorsal surface of snout, forehead, interorbital and occipital region heterogenous in size, shape; mostly elongate, imbricate, strongly keeled longitudinally, irregularly arranged throughout; supraorbital scales thin, elongate, increase in size from the supraciliaries to the inner edges of the orbits; occipital scales heterogenous in size, shape, very irregularly arranged; four distinct, spine-like, strongly pointed, conical scales, arranged in a single row bordering occipital region. Parietal plate distinct from rest, with pineal eye, slightly larger than adjacent scales. Mental shield narrower than rostral; scales on gular region keeled. Dewlap large, extends $45 \%$ of the length of the trunk, with posterior scales extending slightly beyond axila, not extending to mid-venter, dewlap scales slightly elongate, seven to eight anterior rows pointed, all keeled, gradually increasing in size 
towards margin and bluntly pointed, marginal row approximately equal in size as adjacent scales, 21 enlarged rows of scales on dewlap. Nuchal and dorsal crest absent. Scales on nuchal region smaller, regularly arranged, imbricate and strongly keeled. Body slender, 54 rows of scales at midbody, of these about 10 to 12 rows of scales on back, starting from back of neck to pectoral region homogenous in size, shape, slightly larger than those on neck, imbricate, pointed and keeled, these scales directed backwards forming regularly arranged longitudinal rows; those on flanks heterogenous in size, shape, smaller than those on back, obtusely pointed and keeled, with irregularly scattered, slightly larger, pointed and keeled scales, upper rows appear to be directed backwards and upwards and lower rows backwards and downwards; ventral scales subimbricate, keeled, homogenous in size and shape, arranged in 76 rows; no precloacal or femoral pores.

Fore and hindlimbs relatively slender; tibia short (CL/SVL ratio 0.31); digits moderately long, ending in strong, elongate, slightly recurved claws; inter-digital webbing absent; subdigital lamellae entire and bimucronate, 23 subdigital lamellae on toe IV; relative length of fingers $3>4>2>5>1$ and toes $4>3>2>1$. Fore and hindlimbs covered above and below with regularly arranged, enlarged, pointed, strongly keeled, scales.

Tail entire; tail base swollen; tail uniformly covered with similar sized, keeled, weakly pointed, regularly arranged, backwardly directed imbricate scales, no enlarged subcaudal row.

Colour in life. Dorsum light to dark brown with a black patch on the neck, three brown rhomboidal markings on the trunk. A dark to light (centre dark) brown patch on top of the head between the eyes. A cream coloured streak starts below the eye and behind the nostril, extending onto the flank region. Belly pale white (iridescent) in color. Forelimbs, hind limbs, and tail have dark brown bars of variable width. Dewlap with a single blue streak on the mental extending to the middle of the dewlap with brown patches or spots on the individual scales of the dewlap; parallel to the blue line are multiple dark brown lines on the throat.

Colour in preservation. Dorsum buff to light brown with a dark brown patch on neck, three indistinct rhomboid markings on the back. Flank with much darker marking with orange coloured markings mostly on enlarged scales. Dark brown bars on limbs and tail faintly visible. Dewlap colouration is faint.

Variation in paratypes. The paratype male agrees with the holotype in overall pholidosis except CES
141164 has 15 enlarged scale rows on the dewlap and 78 ventral scales. BNHS 2320 has 59 scales around the body and 77 ventrals (mental to vent). Morphometric data for the paratypes are summarized in S5.

Hemipenial morphology. We examined hemipenis of seven specimens of Sitana spinaecephalus sp. nov. from various locations in Gujarat and Maharashtra (CES 13525, CES 13536, CES 13539, CES 13540, CES 13541, CES 13542, NCBS-AQ055). The hemipenis is bilobed, relatively small, longer than wide and shallowly-forked (Fig. 4C and S3). The sulcus spermaticus originates from the center of the base, bifurcates, and continues to the apex of each lobe. Sulcal lips raised and papillate, sulcus smooth. Apex with small deep polygonal calyces and the sulcal region of the apex unornamented, a medial projection absent. Ornamentation is a combination of flounces and calyces. Papillae are present between the apical lobes. Calyculate ornamentation present on each lobe except proximal half of medial side of inner lobe, similarly on lateral side of outer lobe calyces are deep, irregular, polygonal pits that become shallow proximally. Proximal regions of the lobes have smaller calyces than apical region. Ridges between the calyces are thin and show scalloped micro-ornamentation. A groove is seen on the asulcal surface of each lobe with a division at the apical openings (S3). Four flounces are present but are not pronounced, the base unornamented.

Etymology. The species epithet is named as 'spinae', Latin for spine, and 'cephalus', Greek for head, referring to the row of four spine-like enlarged scales bordering occipital region.

Suggested English name. Spiny-headed fan-throated lizard

Distribution. Sitana spinaecephalus sp. nov. is recorded from Pavagadh and Halol, Panchmal District, Dariapura, Vadodara District, Madan, Karjan Reservoir, Bharuch District, Kunathia village, Kutch District, Outside Saurashtra University campus, Rajkot District, and near Wilson Hill and Dunguda village, Waghai, Valsad District in Gujarat state, Deviparbada, Toranmal, Nandurbar District, Badlapur, Thane District, Marda, Chandrapur District, and Umred Road, Nagpur District in Maharashtra state, Abu Road, Sirohi District and Kiranipura, Ajmer District in Rajasthan state (Fig. 8). The altitudinal distribution is between 40 and 1038 m.a.s.l. Sitana spinaecephalus sp. nov. is one of the most widely distributed lizards of the Sitana genus in India, with a distribution extending approximately $1000 \mathrm{~km}$ east to west and $800 \mathrm{~km}$ north to south. Large rivers including the Narmada and Tapi do 

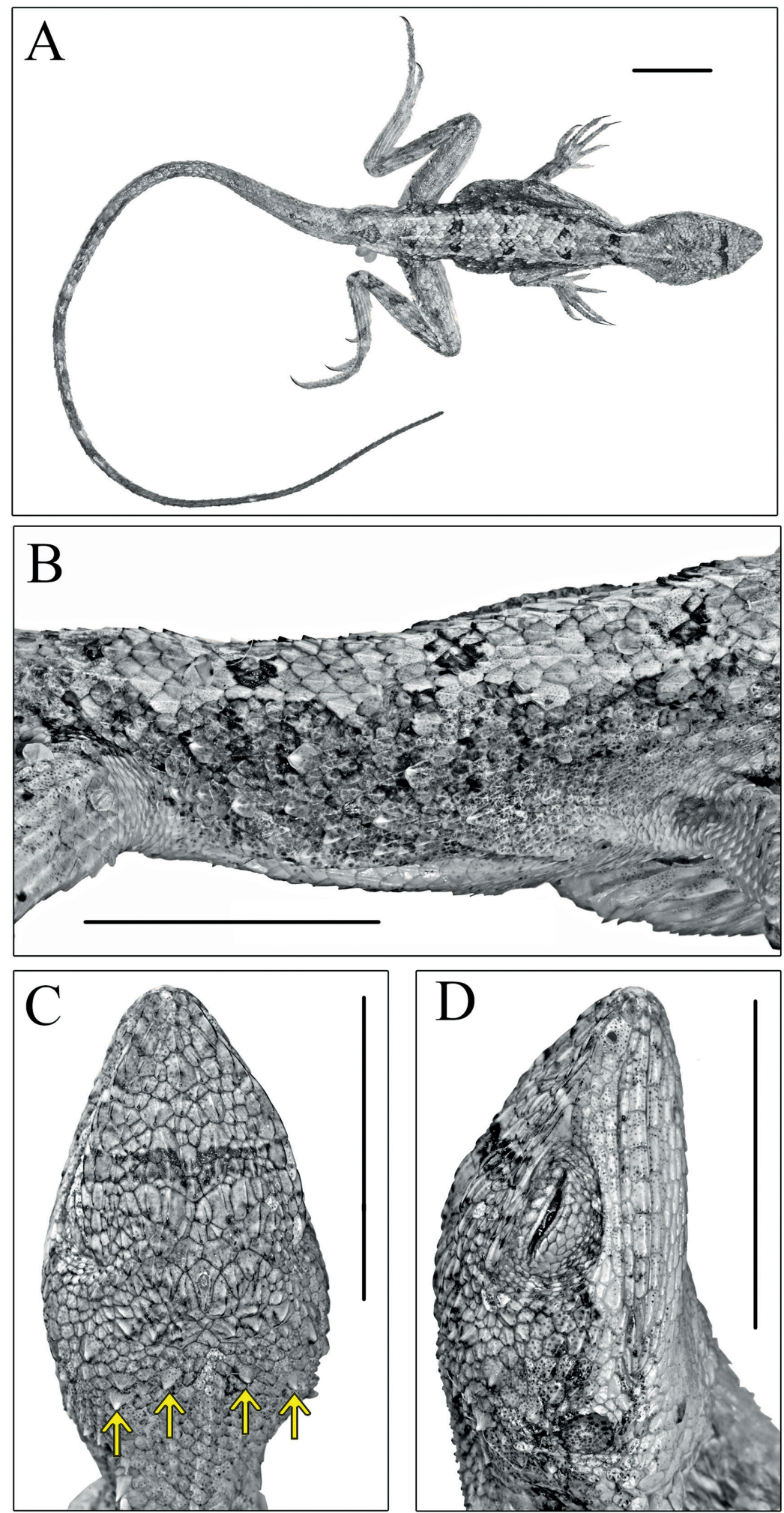

Fig. 12. Holotype of Sitana spinaecephalus sp. nov. from Halol, Gujarat. (A) full body dorsal (B) flank region (C) dorsal view of head (D) lateral view of head. Scale bar is equal to $10 \mathrm{~mm}$. Note: The enlarged scales on the back of the head are pointed with an arrow. 
not act as a barrier for the distribution of this species. All the invalid syntypes of Sitana deccanensis (ZSI 5051-5055) collected from south of Chanda and Berar are Sitana spinaecephalus sp. nov.

Habitat and natural history. Sitana spinaecephalus sp. nov. was collected across various habitats from $\mathrm{Gu}-$ jarat and Maharashtra. The natural vegetation around the type locality is grassland with abundant grass interspersed with thorny scrub. Other habitat types include rocky river beds, and scrub dominated by Prosopis $\mathrm{sp}$. Sitana spinaecephalus sp. nov. is a terrestrial lizard, and we observed them basking on rocks as well as on twigs. This species is sympatric with Sarada deccanensis comb. nov. in a few locations across the southern portion of its range (Fig. 8). Brachysaura minor, Acanthodactylus cantoris, Calotes versicolor, Ophisops sp. and Uromastyx hardwikii are some of the diurnal lizards found in similar habitats in some locations. Breeding males were found during May until the first week of June. Gravid females were found between the second and last week of June.

\section{Sitana laticeps Deepak and Giri sp. nov.}

(Figs 9C, 13A-D; Table 3, 5, 7, 8)

Holotype. NCBS-AQ056, adult male, Bopdev Ghat, georeferenced latitude N18.372818 ${ }^{\circ}$, longitude E73.9128 ${ }^{\circ}$, Pune District, Maharashtra State, collected by V. Deepak and Amod Zambre on 21 August 2013.

Paratypes. CES 141165, adult male and BNHS 2312, adult female, Saswad, georeferenced latitude N18.347139 ${ }^{\circ}$, longitude E73.898489 ${ }^{\circ}$, Pune District, Maharashtra state, collected by V. Deepak and Amod Zambre on 21 August 2013.

Referred specimens. CES 13521 (1 adult male), Pavagadh, Panchmal District, Gujarat State, collected by Kartik Upadhay and V. Deepak on 9 May 2013. ZSIP R/548 (1 adult male, 1 adult female), Sinhagad, Pune District, Maharashtra state, collected by S.S. Kamble on 28 May 1982. ZSIP R/564 (1 adult male), Uralikanchan, Pune District, Maharashtra state, collected by R.N. Chopra on 18 September 1968. ZSIP R/701 (1 adult female), Bhosari, Pune District, Maharashtra State, collected by R.N. Chopra on 31 July 1970; ZSIP R/958 (1 male, 1 female), Wagholi, Pune District, Maharashtra State, collected by B.S. Lamba on 8 July 1967. ZSIP R/549 (1 male, 1 female) Wagholi, Pune District, Maharashtra State, collected by D.N. Tiwari on 29 June 1967. ZSIP R/616 (1 adult male), Vettal Hill, Pune District, Maharashtra State, collected by
R.N. Chopra on 29 September 1962. ZSIP R/900 (1 adult male, 1 adult female) Chakan, Pune District, Maharashtra State, collected by K. Reddiah on 3 July 1976. ZSIK 21571 (6 adult males, 5 adult females), Indapur Town 31 miles NE of Baramati, Pune District, Maharashtra State, collected by R.C. Sharma on 6 June 1964. ZSI 21573 (4 adult males, 6 adult females), Dhond and vicinity, Pune District, Maharashtra State, collected by R.C. Sharma on 8 June 1964. ZSI 21581 (1 adult male), Manchar village, $13 \mathrm{~km}$ off Narayangaon, Pune District, Maharashtra State, collected by R.C. Sharma on 17 June 1964. ZSI 21578 (1 adult male, 1 adult female), Patas village, Pune District, Maharashtra State, collected by R.C. Sharma on 13 June 1964. ZSI 21585 (1 adult male), Pimpalvandi, Pune District, Maharashtra State, collected by R.C. Sharma on 22 June 1964.ZSIK 21584 (1 adult female) Nagapur, Pune District, Maharashtra State, collected by R.C. Sharma on 21 June 1964. ZSI 21579 (3 adult females) Bhigwan, Pune District, Maharashtra State, collected by R.C. Sharma on 14 June 1964. CES 14628 - CES 14629 (2 adult males) Saswad, Pune District, Maharashtra State, collected by V. Deepak and Amod Zambre on 17 April 2014. CES 14625 - CES 14627 (3 adult males) Kanifnath, Pune District, Maharashtra State, collected by V. Deepak and Amod Zambre on 17 April 2014. CES 13626 (1 subadult female), Nannaj, Solapur District, Maharashtra State collected by V. Deepak, Aparna Lajmi and Aniruddha Datta-Roy on 6 November 2013.

Diagnosis. Sitana laticeps sp. nov. can be distinguished from all the members of Sitana ponticeriana clade in having a weakly-serrated dewlap with only a single blue median line and with white or yellowish color on the dewlap (Fig. 3D and E). Sitana laticeps sp. nov. can be distinguished from Sitana spinaecephalus sp. nov. in having a proportionally smaller dewlap (29\% of the length of the trunk vs 36\%). Additionally, Sitana laticeps sp. nov. can be differentiated from Sitana spinaecephalus sp. nov. in having less prominent spines on the back of the head. Sitana laticeps sp. nov. are one of the small sized Sitana; males (44.7 \pm 2.0 ), females $(46.1 \pm 3.0)$. Details on morphometric data, scale counts and body ratios of select characters for multiple samples are given in Table 3, 7 and 8.

Description of holotype NCBS-AQ056 (Fig 13A-D; Table 7). The holotype is in a good condition. The hemipenes are everted and barely visible on the right and left sides when viewed dorsally; tail entire, slightly bent towards the right side; forelimbs are slightly adpressed to the body and right hind limb is slightly bent upwards, an artifact of preservation. An adult male, 

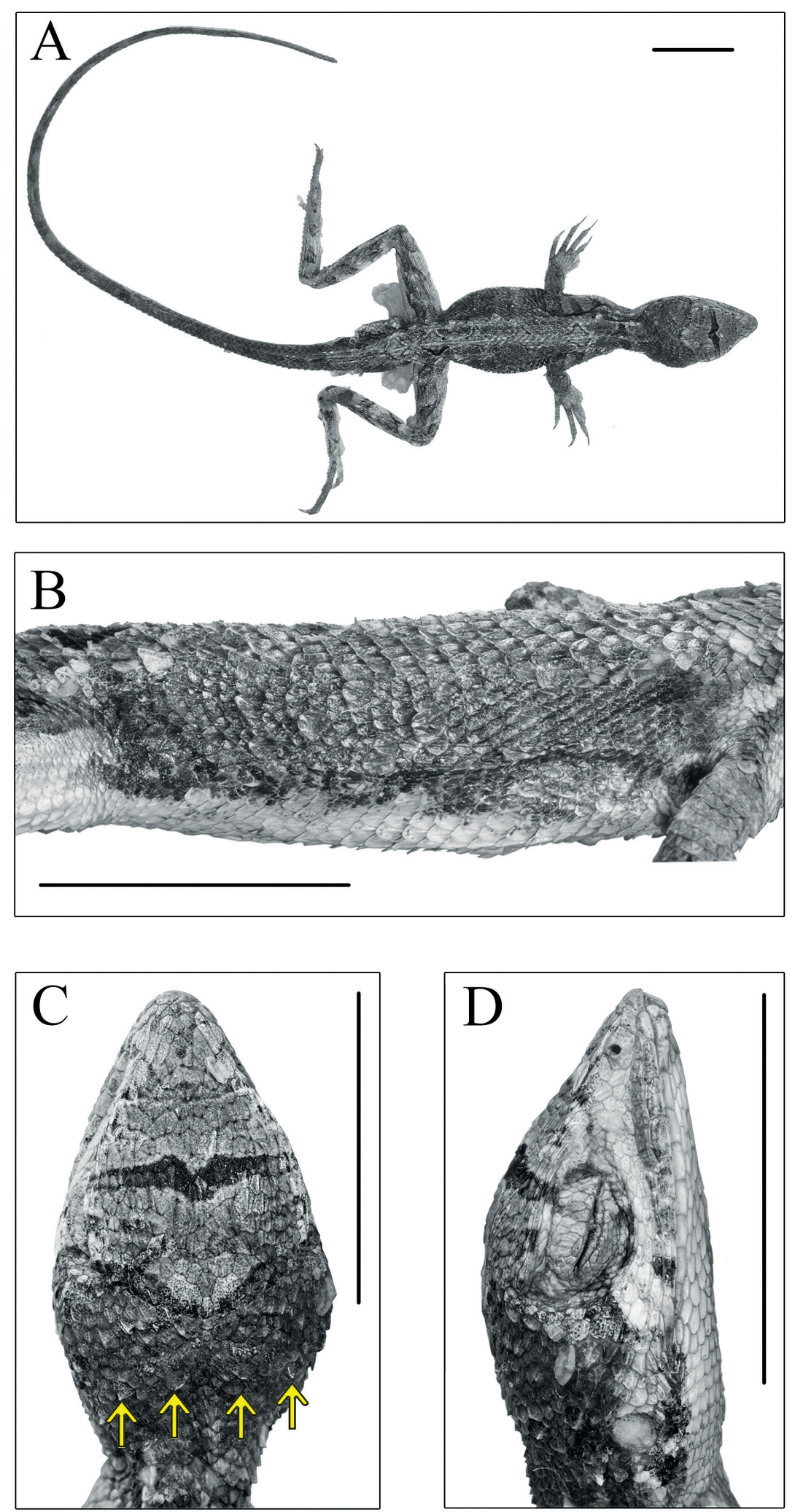

Fig. 13. Holotype of Sitana laticeps sp. nov. from Bopdev Ghat, Maharashtra. (A) full body dorsal (B) flank region (C) dorsal view of head (D) lateral view of head. Scale bar is equal to $10 \mathrm{~mm}$. Note: The enlarged scales on the back of the head are pointed with an arrow. 
SVL $43.05 \mathrm{~mm}$. Head relatively long (HL/SVL ratio 0.30 ), broad (HW/HL ratio 0.69), not depressed $(\mathrm{HH} /$ HL ratio 0.50), distinct from neck. Snout short (SE/HL ratio 0.42$)$, pointed; longer than eye diameter (OD/SE ratio 0.58$)$. Eye large $(\mathrm{ED} / \mathrm{HL}$ ratio 0.25$)$; pupil round, eyelids covered with small pentagonal scales, supraciliaries short. Snout obtusely pointed when viewed dorsally; rostral much wider than deep, contacted laterally by first supralabials, and dorsally by smaller prenasals and three anterior most scales on the snout. Canthus rostralis and supraciliary edge sharp. Nostril subcircular, laterally positioned and placed slightly behind the centre of a large, undivided and roughly pentagonal nasal plate, which is bordered by six scales (right side), including one prenasal, two postnasals and one supranasal, separated from rostral by prenasal; first supralabial barely touching nasal plate. 8 roughly rectangular, strongly keeled supralabials, bordered above by a single row of smaller (less than half the size of supralabials), unequal sized, roughly rectangular, keeled scales, which terminate above last supralabial; infralabials 7 , strongly keeled, rectangular. Loreal region concave, scales of the loreal region heterogenous in size and shape, flat, keeled, composed of a single row of rectangular, keeled scales, which begin behind the postnasal and terminate with a large scale along with a row of scales above supralabial. Scales on postorbital and temporal region slightly heterogeneous, subimbricate, strongly keeled and mostly directed backward and upwards. Orbital scales small, flat, juxtaposed, not granular. Tympanum naked. Canthals enlarged, overlapping, becoming slightly smaller along supraciliaries that are subimbricate, protrude slightly laterally on supraorbital ridge. Scales on dorsal surface of snout, forehead, interorbital and occipital region are heterogeneous in size and shape, smallest on snout, two large scales on forehead and a pair of much larger, slightly incurved scales at frontal position; most of the remaining scales are elongate, imbricate, strongly keeled longitudinally, fairly regularly arranged throughout; supraorbital and interorbital scales more or less similar except a single row of scales at midorbital position which is slightly larger than adjacent scales and appear regularly arranged; occipital scales heterogeneous in size and shape, weakly pointed, keeled and irregularly arranged. Parietal plate indistinct from remaining head scales, with small pineal eye. Mental shield narrower than rostral; scales on the gular region not keeled. Dewlap medium, extends posteriorly over $12 \%$ of the trunk, with posterior scales extending slightly beyond axila, not extending to mid-venter, dewlap scales slightly elongate, gradually increasing in size towards margin and bluntly pointed, marginal row similar in size as adjacent scales, 12 enlarged rows of scale on dewlap. Nuchal and dorsal crest absent. Nuchal scales slightly larger than those of occipital region, regularly arranged, imbricate, strongly keeled. Body slender, 51 rows of scales at midbody, of these about 10 rows of scales on back, starting from back of neck to pectoral region homogeneous in size and shape, slightly larger than those on neck, imbricate, pointed and keeled, these scales directed posteriorly forming regularly arranged longitudinal rows; those on flanks heterogeneous in size and shape, smaller than those on back, obtusely pointed and keeled, with irregularly scattered, slightly larger, pointed and keeled scales, upper rows appear to be directed posterodorsally, lower rows posteroventrally; ventral scales subimbricate, keeled, homogeneous in size and shape, arranged in 75 rows; no precloacal or femoral pores.

Fore and hind limbs relatively slender; tibia short (CL/SVL ratio 0.32 ); digits moderately long, ending in strong, elongate, slightly recurved claws; inter-digital webbing absent; subdigital lamellae entire and bimucronate, 25 subdigital lamellae on toe IV; relative length of fingers $3>4>2>5>1$ and toes $4>3>2>1$. Fore and hind limbs are covered above and below with regularly arranged, enlarged, pointed and strongly keeled scales.

Tail entire; tail base swollen; tail uniformly covered with similar sized, keeled, weakly pointed, regularly arranged, posteriorly-directed imbricate scales, no enlarged subcaudal row.

Hemipenial morphology. The hemipenes of six specimens of Sitana laticeps sp. nov. were examined (CES 141165, NCBS-AQ056, CES 14625, CES 14626, CES 14627, CES 14628). Hemipenis single lobed without any division on the asulcal side, clavate, a medial projection present on top of the hemipenis (Fig. 4D, S3). Sulcus spermaticus in the form of a single broad channel. Apex capitate, asulcal surface has calyces forming shallow polygonal pits, ridges between the calyces thin and without micro-ornamentation. Sulcal surface differentiated, medial region has smooth calyces, lateral region has thick fleshy protuberances or flounces, 6-7 in number, the three distalmost protuberances are most pronounced. Papillae present near the sulcus spermaticus, the base unornamented.

Colour in life. Dorsum light to dark brown with a black patch on the neck, three brown rhomboidal markings on the trunk, one each on sacral region and on the base of tail, all relatively lighter than the one on 

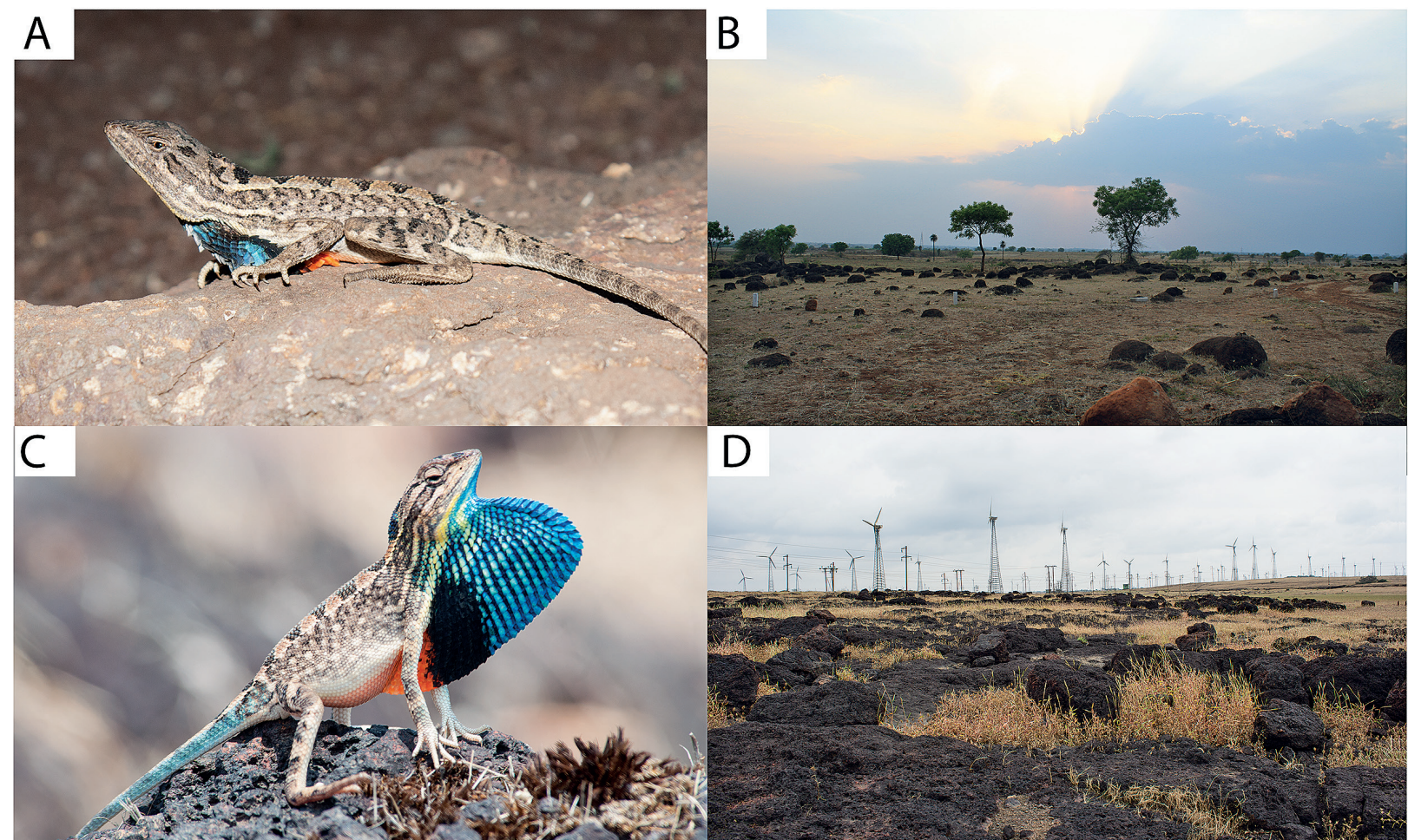

D

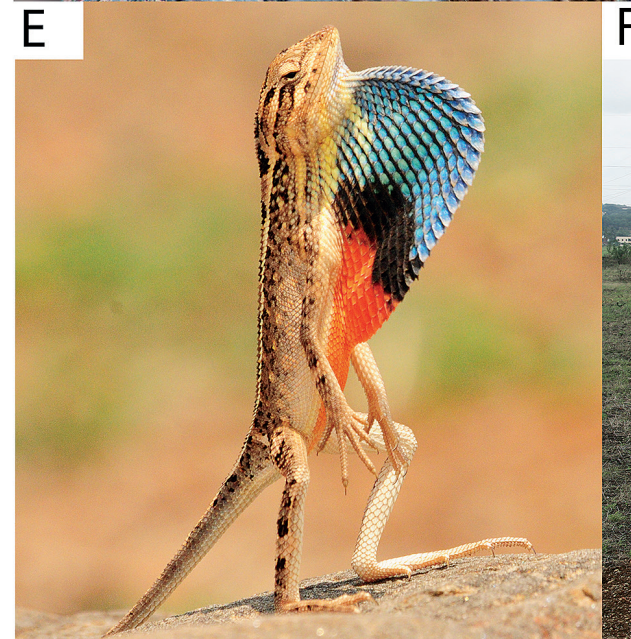

$\mathrm{F}$

Fig. 14. Images of Sarada in life with photos of their habitat: A. Adult male Sarada deccanensis comb. nov. B. Habitat at Jalna, the type locality of S. deccanensis. C. Adult male $S$. superba sp. nov. in breeding display. D. Habitat at Chalkewadi, the type locality of $S$. superba sp. nov. E. Adult male $S$. darwini sp. nov. in breeding display. F. Habitat at Bidnal, the type locality of $S$. darwini sp. nov.

the neck. A black line is present between the eyes. A cream-coloured streak begins below the eye, extending from the nostril to the tympanum, beyond which there are patches of the same colour. The flanks have a mixture of cream, brown, and dark brown scales (enlarged scales were burnt amber coloured). Belly pale white (iridescent) in color. The forelimbs, hind limbs, and tail have dark brown bars of variable width. The dewlap has a single blue streak on the mentum extending to the middle with brown patches or spots on the individual scales of the dewlap.

Colour in preservation. The colouration in preservative closely approximates color in life. Rhomboidal markings and dark brown bars on limbs and tail faint- 
ly visible. Colouration on flanks is slightly darker than back. Dewlap colouration is faint.

Variation in paratypes. The paratype male CES 141165 is similar to the holotype in general morphology, scalation and colour, except for the number of enlarged scale rows on the dewlap (13) and the number of ventrals (76). The paratype female BNHS 2312 differs from the type in having 58 scales around the body and 70 ventrals (below mentum to vent). Morphometric data for the paratypes are summarized in S5.

Etymology. The new species is named for its broad head, laticeps, derived from the Latin word latus meaning broad and Latin suffix ceps referring to its head.

Suggested English name. Broad-headed fan-throated lizard.

Distribution. Sitana laticeps sp. nov. is recorded from Sinhagad, Uralikanchan, Bhosari, Wagholi, Vettal Hill, Chakan, Indapur, Dhond, Manchar, Patas village, Pimpalvandi, Nagapur, Bhigwan, Saswad, Kanifnath in Pune District, and Nannaj, Solapur District in Maharashtra State (Fig. 8). The altitudinal distribution is between 513 and 930 m.a.s.l. This is one of the Sitana species with a restricted range in the Balaghat Hill Range (hills around Pune) (see hill range map in Smith, 1935). This hill range is located south of the Godavari River and north of the Bhima River in Maharashtra.

Habitat and natural history. Sitana laticeps sp. nov. is found in rocky terrain with low grass and sparse scrub. The males were found displaying on the rocks. Calotes versicolor and Sarada deccanensis comb. nov. are the sympatric agamid species found in similar habitats. Breeding males are found during the months of May, June and August.

\section{Sarada Deepak, Karanth and Giri, gen. nov.}

Suggested English name. Large fan-throated lizards.

Type species. Sitana deccanensis Jerdon, 1870.

Content. Sarada deccanensis (Jerdon, 1870) comb. nov., Sarada darwini sp. nov., Sarada superba sp. nov.

Etymology. The generic epithet is derived from the word 'Sarada,' which is the Marathi word for agamid lizards in Maharashtra and some parts of Karnataka, where this genus is endemic.

Diagnosis. Sarada gen. nov. can be easily diagnosed from all other agamid lizards from the Indian subcontinent except Sitana in having five fingers and four toes. Sarada gen. nov. is closely related to two genera from Indian subcontinent, Otocryptis Wagler 1830 and Sitana Cuvier (1829). Sarada gen. nov. can be easily differentiated from Otocryptis by the absence of fifth toe and exposed tympanum. Sarada gen. nov. can be diagnosed from Sitana by following unique combination of characters: breeding males with iridescent blue, orange and black colour with yellow stripes, the orange colour in some individuals extending all the way to the vent; absence of enlarged scale on the thigh; scales on flanks homogeneous, absence of enlarged scales on the lateral side of the body, absence of enlarged, strongly keeled scales around the tympanum; additionally Sara$d a$ gen. nov. can be distinguished from the Sitana sivalensis complex by the following set of characters: large body size (range 52.9-74.4 mm SVL males; range 43.6$64.3 \mathrm{~mm}$ SVL females); very large dewlap with enlarged overlapping scales extending all the way to middle of the abdomen (mean 51\% up to $73 \%$ of TRL). Osteologically, Sarada gen. nov. can be distinguished from Sitana ponticeriana and Sitana spinaecephalus clades by the additional phalange on the fourth finger and in having one less trunk vertebra (Fig. 7 and Table 6). Dorsum pale brown to dark brown with four black brown-edged rhomboidal markings, the one on the nuchal region is darker than the remainder, and the back is bordered on each side with a thin cream coloured band. One prominent buff coloured line begins below the eye extending to the forearam, and another is comparatively broad and extends from behind the eye to the neck; a prominent dark brown interorbital patch is present but does not reach the eyes. Limbs and tail with dark brown or black bands of variable widths.

Distribution. Restricted distribution in Maharshtra and north Karnataka, the northern most records are from Nashik in Maharashtra, and the southernmost are in Bellary and Bidnal in north Karnataka. The easternmost records are from Chanda (Chandrapur) (Blanford, 1870; Amarasinghe et al., 2015). Based on the available records, it appears that they are not found in the lowlands and coastal plateaus on the western part of the distribution of the genus.

Sarada deccanensis (Jerdon, 1870) comb. nov. (Figs 14A, 15A-D; Table 2, 4, 7, 8)

Sitana deccanensis Jerdon, 1870

Sitana ponticeriana deccanensis Deraniyagala, 1953

Sitana deccanensis Amarsinghe, Ineich, Karunarathna, Botejue and Campbell, 2015

Syntypes. Male, BMNH 1946.8.27.39, SVL $67.6 \mathrm{~mm}$, India, presented by J.E. Gray; male, BMNH 1946.8 . 27.40, SVL $60.0 \mathrm{~mm}$, India, presented by J.E. Gray. 

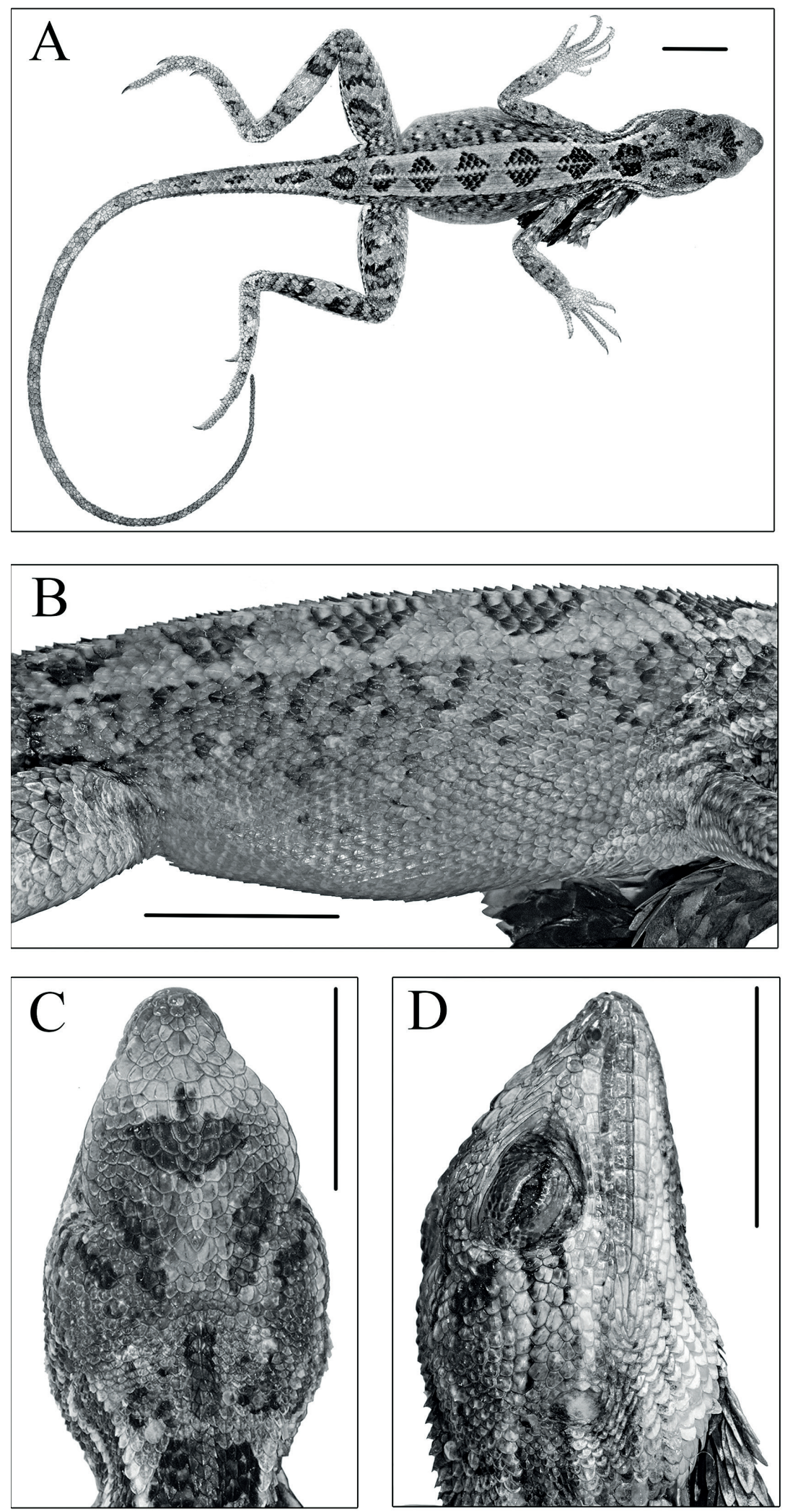

Fig. 15. Sarada deccanensis comb. nov. collected from Jalna, Maharashtra. (A) full body dorsal (B) flank region (C) head dorsal (D) head lateral. Scale bar is equal to $10 \mathrm{~mm}$. 
Referred specimens. CES 14608-14609 (2 adult females), CES 14611-14623 (9 males, 2 females), NCBSAQ050 (1 adult male )BNHS-2307 (1 adult female) all individuals collected near Indewadi, Jalna District, Maharashtra State, georeferenced latitude N19.79636 ${ }^{\circ}$, longitude E75.85397 ${ }^{\circ}$, collected by V. Deepak, Raman Upadhye, and Durgesh Pangarkar on 16 April 2014. ZSIK 6331 (1 adult female) collected by Major Houghton on 12 July 1871 from Nashik. BMNH 1946.8.27.39 and BMNH 1946.8.27.40 collected by Gray, India, measurements and counts of BMNH syntypes are referred from Amarasinghe et al. (2015).

Comments. This species has been the subject of substantial taxonomic confusion because of vague type locality information, as well as the description by Günther, 1864 of Sitana minor based on a mixture of specimens that included both Sitana deccanensis and S. ponticeriana (see Amarasinghe et al., 2015). Sitana minor is now a synonym of Sitana ponticeriana (Amarasinghe et al., 2015). The original syntypes of Sarada deccanensis presented by Gray are currently in the British Museum of Natural History (Amarasinghe et al., 2015). We assume that the original description by T.C. Jerdon was based on samples from Jalna, Maharashtra. As he wasposted in Jalna (Jalnah) in Maharashtra (Elliot, 1873). Many of his herpetological collections were obtained in and around Jalna, including Psammophis condanarus (as Leptophis bellii), Calliophis melanurus (as Elaps melanurus), and Eutropis trivittata (as Tiliqua trivittata) (Theobald, 1876). Although Jerdon (1870) did not specify exactly where in Deccan he had collected Sarada deccanensis, considering he was collecting in Jalna, it is likely the specimens were collected in or near Jalna. Therefore, we fix Jalna as the type locality of Sarada deccanensis comb. nov. Because the syntype descriptions are based on two specimens with vague locality information ("India"), we provide a complete description based on new topotypic material from Jalna, Maharashtra.

The body scale counts of the syntypes at the BMNH match those of our newly collected specimens from the type locality but these characters overlap with other two species in the genus Sarada gen. nov. The extent that the dewlap extends onto the trunk region for the syntypes is $55.6 \%$ and $54.5 \%$, which is consistent with some of the specimens collected from the type locality.

Diagnosis. Sarada deccanensis comb. nov. is closed related to the congeners $S$. superba sp. nov. and $S$. darwini sp. nov. due to similar colour and body size. Sarada deccanensis comb. nov. can be distinguished from
S. superba sp. nov. and S. darwini sp. nov. in having proportionally longer hind limbs (exceeding the SVL). Sarada deccanensis comb. nov. are large in size, males $(62.2 \pm 3.8)$ and females $(52.2 \pm 4.2)$. Details on morphometric data and body ratios of select characters for multiple samples are given in Tables 2 and 8. Furthermore, Sarada deccanensis comb. nov. is a species inhabiting northern parts of Maharashtra, whereas the other two species are found only in southern Maharashtra.

Genetic divergence. The differences shown here are for all the three species in the new genus Sarada gen. nov. Sarada deccanensis comb. nov. exhibits only $0-1 \%$ intraspecific genetic divergence in the ND2 gene. Sarada deccanensis comb. nov. is $11 \%$ divergent from Sarada darwini sp. nov. and 11-12\% divergent from Sarada superba sp. nov. (S4).

Description of topotype. NCBS-AQ050 (Figs 14A, 15A-D; Table 7). The holotype is in a good condition. The tail is entire, bent to the right side, the dewlap is slightly exposed on the right side and can be seen from above. An adult male, SVL $65.7 \mathrm{~mm}$. Head relatively long (HL/SVL 0.28), broad (HW/HL ratio 0.70), not depressed (HH/HL ratio 0.61), distinct from neck. Snout short (SE/HL ratio 0.39), pointed, longer than eye diameter (OD/SE ratio 0.75). Eye large (ED/HL ratio 0.29); pupil round, eyelids covered with small pentagonal scales, supraciliaries short. Snout obtusely pointed when viewed from above, rostral wider than deep, contacted laterally by first supralabials, a smaller prenasal and three small scales dorsally. Canthus rostralis and supraciliary edge sharp. Nostril subcircular, laterally positioned, placed at centre of a large, undivided and roughly pentagonal nasal plate, which is bordered by six scales (right side), including one prenasal, two postnasals and one supranasal, separated from rostral by prenasal and from first supralabial by two enlarged scales. 13 (right) - 14 (left) rectangular, equal sized, strongly keeled supralabials, bordered above by a single row of roughly rectangular, keeled scales, becoming smaller in size posteriorly, terminates above 10th supralabial; infralabials 13 (right) 14 (left), strongly keeled, equal sized, rectangular. Loreal region concave, scales of the loreal region heterogeneous in size and shape, flat, keeled, a single row of rectangular, keeled scales beginning behind postnasal and terminating below eye. Scales on postorbital and temporal region vaguely heterogeneous, subimbricate, strongly keeled, obtusely pointed and mostly directed posterodorsally. Orbital scales small, flat, juxtaposed, not granular. Tympanum naked. Canthals enlarged, 
overlapping, becoming slightly larger along supraciliaries that are subimbricate, protrude slightly laterally on supraorbital ridge. Scales on dorsal surface of snout, forehead, interorbital and occipital region are barely heterogeneous in size and shape, smallest on snout, a few large scales on forehead and interorbital position, obtusely pointed, subimbricate, strongly keeled longitudinally, fairly regularly arranged throughout; supraorbital and interorbital scales more or less similar except a few enlarged scales; occipital scales much smaller in size, barely heterogeneous in size and shape, weakly pointed, keeled and irregularly arranged. Parietal plate indistinct from remainder, with small pineal eye, surrounded on either side by two enlarged scales. Mental shield narrower than rostral; scales on the gular region smooth. Dewlap large, extends to $51 \%$ of the trunk, with posterior scales extending beyond axila, dewlap scales elongate, pointed, keeled, gradually increasing in size towards margin and trunk, marginal row is similar in size as adjacent scales, 24 enlarged rows of scale on dewlap. Nuchal and dorsal crest very weak. Scales on nuchal region slightly larger than those of occipital region, regularly arranged, imbricate, strongly keeled. Body slender, 69 rows of scales at mid-body, of these about 11 rows of scales on back, starting from back of neck to pectoral region homogeneous in size and shape, slightly larger than those on neck, imbricate, pointed and keeled, these scales directed posteriorly forming regularly arranged longitudinal rows; those on flanks homogeneous in size, shape, smaller than those on back, obtusely pointed and keeled, upper rows appear to be directed posterodorsally and lower rows posteroventrally; ventral scales subimbricate, keeled, homogeneous in size and shape, arranged in 95 rows; no precloacal or femoral pores.

Fore and hindlimbs relatively slender; tibia short (CL/SVL ratio 0.33 ); digits moderately long, ending in strong, elongate, slightly recurved claw; inter-digital webbing absent; subdigital lamellae entire and bimucronate, subdigital lamellae on toe IV, 24 ; relative length of fingers $4=3>5>2>1$ and toes $4>3>2>1$. Fore- and hind limbs covered above and below with regularly arranged, enlarged, pointed and strongly keeled scales.

Tail entire; tail base swollen; tail uniformly covered with similar sized, keeled, weakly pointed, regularly arranged, posteriorly directed imbricate scales, no enlarged subcaudal row.

Colour in life. Dorsum pale to dark brown with a black patch on the neck, four rhomboidal markings on the trunk dark brown edged with black. Dorsum bor- dered on each side with a cream line. One prominent cream line begins below the eye extending to the forearm, one cream line extending behind the eye to the dorsal line and another behind the labials which terminates before the forearm insertion. A black patch present between the eyes, five medium to large black patches on top of the head, several small black patches on the occiput region. Two short black lines behind the eye. Belly mostly orange but near the vent pale white (iridescent) in color. Forelimbs, hind limbs, and tail have dark brown bars of variable width. Dewlap with yellow lines on the side of the throat, from the iridescent blue colour of the mental, followed by black and then dark orange, which extends to the vent.

Colour in preservation. Colouration is similar to that of live specimens. Rhomboidal markings and dark brown bars on limbs and tail faintly visible. Colouration on flanks is slightly darker than that of the back. Dewlap colouration is faint.

Variation in paratypes. NCBS-AQ050 matches well with the syntypes of Sitana deccanensis (BMNH 1946.8.27.30 and 40) in the number of scales around the trunk. NCBS-AQ050 has one additional ventral scale and one additional fourth toe lamella compared to the syntypes. The female BNHS 2307 agrees with the male in all the characters except absence of a dewlap, 66 scales around the body, and 23 subdigital lamellae under the fourth toe. BNHS 2307 has 77 ventral scales. Live body coloration varies from dark to light brown, there is a black roughly diamond shaped blotch between the eyes, and six black blotches (diamond or triangular shaped) from neck to hind limb. Morphometric data for the topotypes are summarized in S5.

Suggested English name. Deccan large fan-throated lizard.

Distribution. Sarada deccanensis comb. nov. is recorded from Vaijapur in Aurangabad District, Gangapur in Nashik District, Indewadi in Jalna District and Pallam in Nanded District of Maharashtra State (Fig. 8). Blandford (1870) noted the occurrence of this species in Chanda (now Chandrapur), but we did not find any individuals during our surveys of this region. The altitudinal distribution is between 357 and 639 m.a.s.l.

Habitat and natural history. Sarada deccanensis comb. nov. is a terrestrial agamid found in the grasslands, agriculture fields, and on lateritic terrain in the northern hill ranges and north eastern plains of the Deccan (Fig. 14F). One of the first mentions of the breeding color and season of this species was by Blanford (1870), who observed them breeding during April 
and May. We also observed breeding males in May. Near Gangapur Dam, Nashik District, this species was seen using cracks in the black soil as temporary refuges (Kiran Rahalkar pers. obs.). Sitana spinaecephalus sp. nov. and Calotes versicolor are the other agamids found in the same habitat.

\section{Sarada darwini Deepak, Karanth, Dutta and Giri sp. nov.}

(Figs 14E, 16A-D; Table 2, 4, 7, 8)

Holotype. NCBS-AQ051, Adult male. Bidnal, georeferenced latitude $\mathrm{N} 15.32724^{\circ}$, longitude E75.15823 ${ }^{\circ}$, Dharwad District, Karnataka State, collected by V. Deepak, P. Saunak, and K. Arekar on 9 June 2013.

Paratypes. BNHS 2308, adult female, CES 141161, adult male, Girgaon, georeferenced latitude N16.61069 ${ }^{\circ}$, longitude E74.21253 ${ }^{\circ}$, Kolhapur District, Maharashtra State, collected by V. Deepak on 3 May 2013.

Referred specimens. ZSIP R/613 (2 adult males, 2 adult females), Terawad village, Kolhapur District by M.S. Pradhan on 7 June 1978. ZSIP R/644 (1 adult female) Awalikhind, Malkapur, Kolhapur District by M.S. Pradhan on 7 June 1978; CES 13512-13515 (3 adult males, 1 adult female) Giragaon, Kolhapur District, Maharashtra State collected by V. Deepak on 3 May 2013. CES 13519 (1 adult female) Kagal, Kolhapur District, Maharashtra state collected by V. Deepak on 12 June 2013. CES 13544-13549 (2 adult males, 4 adult females), Bidnal, Dharwad District, Karnataka state collected by V. Deepak, P. Saunak, and K. Arekar on 9 June 2013.

Diagnosis. Sarada darwini sp. nov. can be distinguished from Sarada superba sp. nov. in having proportionally longer feet (Table 8). Sarada darwini sp. nov. can be distinguished from Sarada deccanensis comb. nov. by its proportionally shorter hind limb (not exceeding the SVL) (Table 8). Sarada darwini sp. nov. are large lizards (males: average $58.0 \pm 3.3 \mathrm{SD}$; females: average $54.5 \pm 5.4 \mathrm{SD}$ ). Details on morphometric data and body ratios of select characters for multiple samples are given in Table 2 and Table 8. Furthermore, Sarada darwini sp. nov. inhabits the southern parts of Maharashtra State and northern parts of Karnataka State, whereas Sarada superba sp. nov. is found only in the south on plateaus $>1000 \mathrm{~m}$ in elevation in South Maharashtra.

Genetic divergence. Sarada darwini sp. nov. exhibits only $1 \%$ intraspecific genetic divergence in the mi- tochondrial ND2 gene. The species is 5\% divergent from Sarada superba sp. nov. (S4).

Description of holotype. NCBS-AQ051 (Figs 16A$\mathrm{D}$, Table 7). The holotype is in a good condition. Part of the dewlap is visible on the right when viewed from above, hemipenis exposed and visible on both sides, tail slightly bent toward right, tail tip broken, left manus slightly bent and not properly extended, an artifact of preservation. An adult male, SVL $59.8 \mathrm{~mm}$. Head relatively long (HL/SVL 0.29), broad (HW/HL ratio 0.61 ), not depressed (HH/HL ratio 0.53 ), distinct from neck. Snout short (SE/HL ratio 0.36), longer than eye diameter (OD/SE ratio 0.71). Eye large (ED/HL ratio 0.26); pupil round, eyelids covered with small pentagonal scales, supraciliaries short. Snout obtusely pointed when viewed dorsally, rostral wider than deep, contacted laterally by first supralabial, a smaller prenasal and three small scales dorsally. Canthus rostralis and supraciliary edge sharp. Nostril subcircular, laterally positioned and placed at centre of a large, undivided and roughly pentagonal nasal plate, which is bordered by six scales (right side), including one prenasal, two postnasals and one supranasal, separated from rostral by prenasal and from first supralabial by two enlarged scales. 12 rectangular, equal sized, strongly keeled supralabials, bordered above by a single row of, roughly rectangular, keeled scales, becoming smaller in size posteriorly, terminates above 9th supralabial; infralabials 11, strongly keeled, equal in size, rectangular. Loreal region concave, scales of the loreal region heterogeneous in size and shape, flat, keeled, single row of rectangular, keeled scale, which begins behind the postnasal and terminates below eye. Scales on postorbital and temporal region slightly heterogeneous, subimbricate, strongly keeled, obtusely pointed and mostly directed posterodorsally. Orbital scales small, flat, juxtaposed, not granular. Tympanum naked. Canthals enlarged, overlapping, becoming slightly larger along supraciliaries that are subimbricate, protrude slightly laterally on supraorbital ridge. Scales on dorsal surface of snout, forehead, interorbital and occipital region are weakly heterogeneous in size and shape, smallest on snout, a few large scales on forehead and interorbital position, obtusely pointed, subimbricate, strongly keeled longitudinally, fairly regularly arranged throughout; supraorbital and interorbital scales similar except for a few enlarged scales; occipital scales, much smaller in size, weakly heterogeneous in size and shape, weakly pointed, keeled and irregularly arranged. Parietal plate indistinct from remainder, with small pineal eye, surrounded laterally 

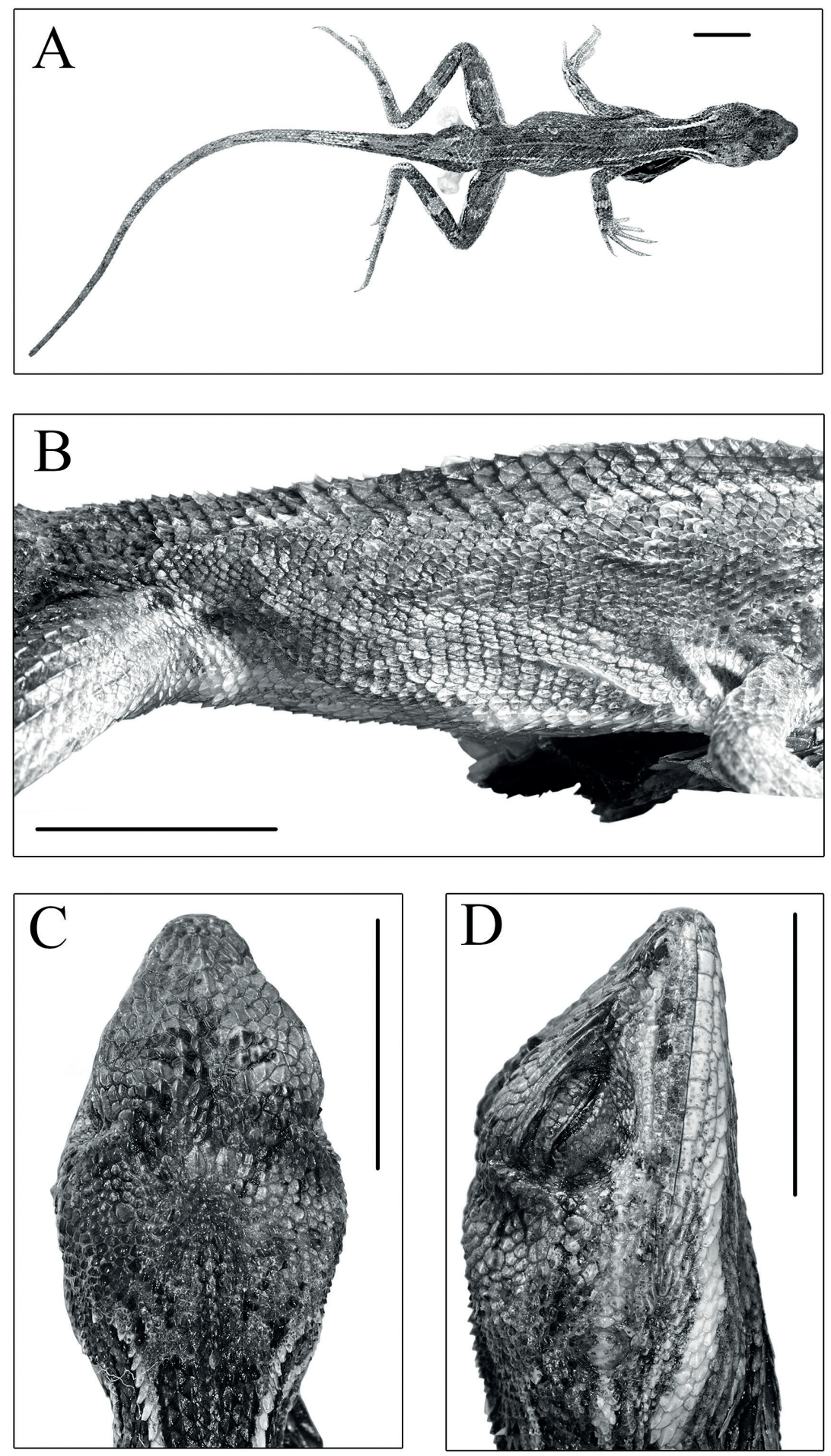

Fig. 16. Holotype of Sarada darwini sp. nov. from Bidnal, Karnataka. (A) full body dorsal (B) flank region (C) dorsal view of head (D) lateral view of head. Scale bar is equal to $10 \mathrm{~mm}$. 
by two enlarged scales. Mental shield narrower than rostral; scales on the gular region not keeled. Dewlap much larger, extends up to $52 \%$ of the trunk, with posterior scales extending beyond axila, dewlap scales elongate, pointed, keeled, gradually increasing in size towards margin and trunk, marginal row is similar in size with adjacent scales, 23 enlarged rows of scales on dewlap. Nuchal and dorsal crest absent. Scales on nuchal region slightly larger than occipital region, regularly arranged, imbricate and strongly keeled. Body slender, 66 rows of scales at midbody, of these about 11 rows of scales on back, starting from back of neck to pectoral region, homogeneous in size and shape, slightly larger than those on neck, imbricate, pointed and keeled, these scales directed posteriorly forming regularly arranged longitudinal rows; those on flanks homogenous in size and shape, smaller than those on back, obtusely pointed and keeled, upper rows directed posterodorsally and lower rows posteroventrally; ventral scales subimbricate, keeled, homogeneous in size and shape, arranged in 83 rows; no precloacal or femoral pores.

Fore and hind limbs relatively slender; tibia short (CL/SVL ratio 0.31); digits moderately long, ending in strong, elongate, slightly recurved claws; inter-digital webbing absent; subdigital lamellae entire and bimucronate, 24 subdigital lamellae on toe IV; relative length of fingers $4>3>2>5>1$ and toes $4>3>2>1$. Fore and hind limbs are covered above and below with regularly arranged, enlarged, pointed and strongly keeled scales.

Tail entire, small portion is broken; tail base swollen; tail uniformly covered with similar sized, keeled, weakly pointed, regularly arranged, posteriorly directed imbricate scales, no enlarged subcaudal row.

Colour in life. Dorsum pale to dark brown with a black patch on the neck, four dark brown rhomboidal markings edged with black on the trunk. Dorsum bordered on each side with a cream line. One prominent cream line begins below the eye, extending to the forearm, another begins behind the eye extending to the dorsal line, and another begins behind the labials ending before the forearm insertion. A black patch present between the eyes, and five medium to large black patches on top of the head, several small black patches on the occiput region. Two short black lines behind the eye. Belly mostly orange but near the vent pale white (iridescent) in color. Forelimbs, hind limbs, and tail have dark brown bars of variable width. Dewlap with yellow lines on the side of the throat, from the iridescent blue colour of the mentum, followed by black, followed by dark orange that extends to the vent.
Colour in preservation. Colouration is similar to that of live specimens. Rhomboidal markings and dark brown bars on limbs and tail faintly visible. Colouration on flanks is slightly darker than on the back. Dewlap colouration faint.

Variation in paratypes. The two paratypes agree with the holotype in general morphology and scalation with some exceptions. CES 141161 has 12/12 supralabials, 13/13 infralabials. two large but not elongated scales present in the center of the head flanking the parietal/pineal eye, 21 enlarged scale rows on the dewlap, and 81 ventral scales. BNHS 2308 (a female) has $11 / 12 \mathrm{SL}, 12 / 12 \mathrm{IL} .73$ ventrals, $234^{\text {th }}$ toe lamellae, and scales on the dewlap larger than those of the abdomen. Morphometric data for the paratypes are summarized in S5.

Hemipenial morphology. The hemipenes of two specimen were examined (NCBS-AQ051 and CES 13549). Each hemipenis has a single lobe, clavate, longer than wide and relatively small. A peculiar medial projection is present on top of the hemipenis, which deflates in older specimens. Sulcus spermaticus single, oblique, and ends at the base of the medial projection, which has groove on either side that leads to apex. Apex capitate, asulcal surface without any division, calyces present forming shallow polygonal and rhomboidal pits, ridges between the calyces thin and without micro-ornamentation or smooth. Sulcal surface is differentiated and has smooth calyces forming deep polygonal pit on lateral side and papillated near the sulcus spermaticus. Flounces present but not prominent and base unornamented (Fig. 4A, S3).

Etymology. The species epithet is in honour of Charles Darwin. Darwin used Sitana as an example of secondary sexual characteristics in his book "The Descent of Man, and Selection in Relation to Sex".

Suggested English name. Darwin's large fan-throated lizard.

Distribution. Sarada darwini sp. nov. is recorded from Nipani, Belgaum District and Bidnal, Dharwad District in Karnataka State and Giragaon, Kagal, Terawad, Atigre and Malkapur in Kolhapur District, Sangli, Atpadi and Dongarwadi in Sangli District of Maharashtra State (Fig. 8). The altitudinal distribution is between 550 and 680 m.a.s.l.

Habitat and natural history. Sarada darwini sp. nov. is found in the grasslands, and agricultural (cotton) fields on the plains of the Karnataka and in southern Maharashtra (Fig. 14F). In Bidnal and Sangli, Sarada darwini sp. nov. is found in cotton fields where it lives inside deep underground cracks. We observed 

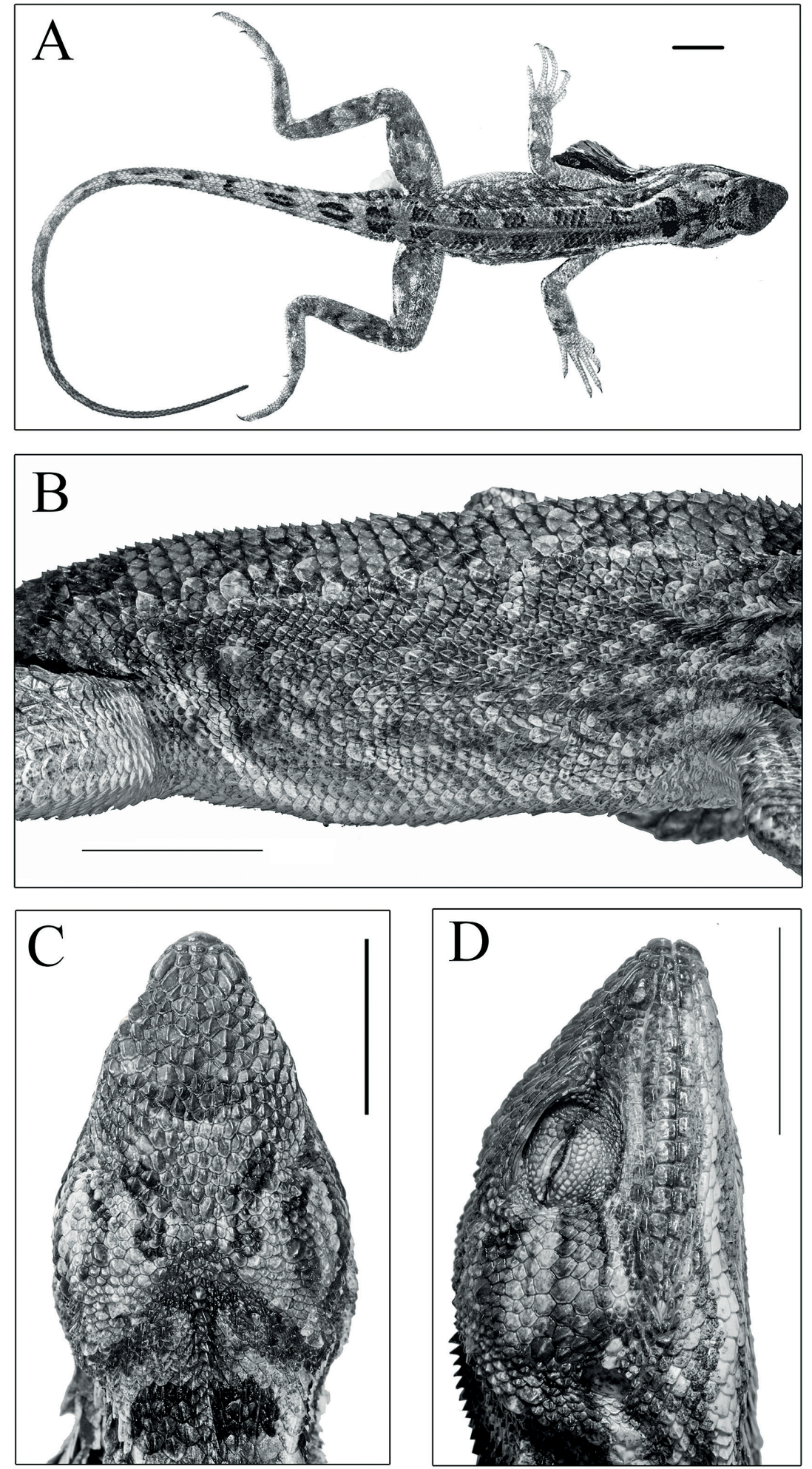

Fig. 17. Holotype of Sarada superba sp. nov. from Chalkewadi, Maharashtra. (A) full body dorsal (B) flank region (C) dorsal view of head (D) lateral view of head. Scale bar is equal to $10 \mathrm{~mm}$. 
them perching on rocks, grass, soil mounds, and twigs. In Giragaon, between $9.30 \mathrm{hrs}$ and $12.00 \mathrm{hrs,} \mathrm{we} \mathrm{ob-}$ served twelve males and six females in an area approximately $1000 \mathrm{~m} \times 25 \mathrm{~m}$. Out of these 18 individuals, eight were observed perching in pairs, while two pairs perched on rocks and the other two were on a tuft of grass. Calotes versicolor is the only other agamid observed in the same habitat. Breeding males are found during the month of May in Kolhapur, Sangli and Bidnal. Gravid females were recorded on $9^{\text {th }}$ of June 2013. Hatchlings were recorded from Sangli on $22^{\text {nd }}$ October 2013.

\section{Sarada superba Deepak, Zambre, Bhosale and Giri sp. nov.}

(Figs 14C, 17A-D; Table 2, 4, 7, 8)

Holotype. NCBS-AQ052, adult male, Chalkewadi, georeferenced latitude $\mathrm{N} 17.57635^{\circ}$, longitude E73.82430, Satara District, Maharashtra State. Collected by V. Deepak and H. Bhosale on 19 April 2014.

Paratypes. CES 141162, adult male, BNHS 2309, adult female. Chalkewadi, georeferenced latitude N17.57635 ${ }^{\circ}$, longitude E73.82430 ${ }^{\circ}$, Satara District, Maharashtra State. Collected by H. Bhosale male on 10 June, 2013 and female on 16 October 2013.

Referred specimens. CES 13566-13576 (9 adult males, 2 adult females) Chalkewadi, Satara District, Maharashtra State, collected by H. Bhosale and A. Zambre on 10 June, 2013; CES 14631, CES 1463314635 ( 1 adult male, 3 adult females) Chalkewadi, Satara District, Maharashtra state, collected by V. Deepak and H. Bhosale on 19 April 2014.

Diagnosis. Sarada superba sp. nov. can be distinguished from Sarada deccanensis comb. nov. and Sarada darwini sp. nov. in having relatively short feet (Table 8). Sarada superba sp. nov. is the largest species of Sarada: males (67.9 \pm 5.9$)$ and females (58.0 \pm 3.5). Details on morphometric data and body ratios of select characters for multiple samples are given in Tables 3 and 8. Furthermore, Sarada superba sp. nov. inhabits high elevation $(>1000 \mathrm{~m})$ plateaus of South Maharashtra, whereas Sarada darwini sp. nov. is found in the southern parts of Maharashtra and usually found on plains and on low elevation hills $(<700 \mathrm{~m})$.

Genetic divergence. We only studied one population of Sarada superba sp. nov. and the genetic divergence between the two specimens we compared was $0 \%$.

Description of holotype NCBS-AQ052 (Figs 17A-
D, Table 7). The holotype is in a good condition. Part of the dewlap is visible on the left when viewed from above; the hemipenes are exposed and visible on the left side, the tail is bent toward the right, forelimbs slightly adpressed and not properly extended, an artifact of preservation. An adult male, SVL $75.7 \mathrm{~mm}$. Head relatively long (HL/SVL ratio 0.29), broad (HW/ HL ratio 0.72 ), not depressed (HH/HL ratio 0.64$)$, distinct from neck. Snout short (SE/HL ratio 0.36), longer than eye diameter (OD/SE ratio 0.68). Eye large (ED/ HL ratio 0.25); pupil round, eyelids covered with small pentagonal scales, supraciliaries short. Snout obtusely pointed when viewed from above, rostral wider than deep, contacted laterally by first supralabial, a smaller prenasal and three small scales dorsally. Canthus rostralis and supraciliary edges sharp. Nostril subcircular, laterally positioned and placed at centre of a large, undivided and roughly pentagonal nasal plate, which is bordered by eight scales (right side), including one prenasal, three postnasals and one supranasal, separated from rostral by prenasal and from first supralabial by single scales. 14 (left), 13 (left) rectangular, equal sized, strongly keeled supralabials, bordered above by a single row of, roughly rectangular, keeled scales, becoming smaller in size posteriorly, terminates above 12th supralabial; infralabials 14, strongly keeled, equal sized, rectangular. Loreal region concave, scales of the loreal region heterogeneous in size and shape, flat, keeled, single row of rectangular, keeled scale, which begins behind the postnasal and terminates below the eye. Scales on postorbital and temporal region vaguely heterogeneous, subimbricate, strongly keeled, obtusely pointed and mostly directed posterodorsally. Orbital scales small, flat, juxtaposed, not granular. Tympanum naked. Canthals enlarged, overlapping, becoming slightly larger along supraciliaries that are subimbricate, slightly protrude laterally on supraorbital ridge. Scales on dorsal surface of snout, forehead, interorbital and occipital region weakly heterogeneous in size and shape, smallest on snout, forehead mostly with large scales and slightly smaller scales in the interorbital position, all obtusely pointed, subimbricate, strongly keeled longitudinally, fairly regularly arranged throughout; supraorbital and interorbital scales similar except for a few enlarged scales; occipital scales much smaller in size, weakly heterogeneous in size and shape, weakly pointed, keeled and irregularly arranged. Parietal plate indistinct from surrounding scales, with small pineal eye. Mental shield narrower than rostral; scales on the gular region not keeled. Dewlap large, extends posteriorly over $59 \%$ of 
the trunk, with posterior scales extending beyond axila, dewlap scales elongate, pointed, keeled, gradually increasing in size towards margin and trunk, marginal row is similar in size as adjacent scales, 23 enlarged rows of scales on dewlap. Nuchal and dorsal crest very weak. Scales on nuchal region slightly larger than those of occipital region, regularly arranged, imbricate and strongly keeled. Body slender, 68 rows of scales at midbody, of these about 12 rows of scales on back, starting from back of neck to pectoral region homogeneous in size and shape, slightly larger than those on neck, imbricate, pointed and keeled, these scales directed backwards forming regularly arranged longitudinal rows; those on flanks homogeneous in size and shape, smaller than those on back, obtusely pointed and keeled, upper rows appear to be directed posterodorsally and lower rows posteroventrally; ventral scales subimbricate, keeled, homogeneous in size and shape, arranged in 93 rows; no precloacal or femoral pores.

Fore and hind limbs relatively slender; tibia short (CL/SVL ratio 0.31 ); digits moderately long, ending in strong, elongate, slightly recurved claws; inter-digital webbing absent; subdigital lamellae entire and bimucronate, 21 subdigital lamellae on toe IV; relative length of fingers $4=3>5>2>1$ and toes $4>3>2>1$. Fore and hind limbs are covered above and below with regularly arranged, enlarged, pointed, and strongly keeled scales.

Tail entire, small portion is broken; tail base swollen; tail uniformly covered with similar sized, keeled, weakly pointed, regularly arranged, backwardly directed imbricate scales, no enlarged subcaudal row.

Colour in life. Dorsum pale to dark brown with a black patch on the neck, four dark brown rhomboidal markings edged with black on the trunk. Dorsum bordered on each side with a cream line. One prominent cream line starts from below the eye and extends to the forearm, one begins behind the eye and extends to the dorsal line. Another cream line begins behind the labials and ends anterior to the forearm insertion. Blue spots present on the neck region. A black patch is present between the eyes, five medium to large black patches on the top of the head, several small black patches on the occiput region. Two short black lines behind the eye. Belly mostly orange but near the vent pale white (iridescent) in color. The forelimbs, hind limbs, and tail with dark brown/black bars of variable width. Tail light brown in color. Dewlap with yellow lines on the side of the throat, extending from the iridescent blue mentum, followed by a black patch, and then by dark orange that extends all the way to the vent.

Colour in preservation. Colouration similar to that of live specimens. Rhomboidal markings and dark brown bars on limbs and tail only faintly visible. Blue spots on the neck region not visible. Colouration on flanks is slightly darker than on the back. Dewlap colouration is faint.

Variation in paratypes. The paratypes male agrees with the type in overall scalation except CES 141162 which has 20 enlarged scale rows on the dewlap, 83 scales on the ventrals, and a smaller hindlimb that only extends $89 \%$ of SVL. Apart from the absence of a dewlap, the other scale pholidosis matches with BNHS 2309. The paratype female has 77 scales around the body and 22 lamellae on the fourth toe. The paratype female has 81 ventral scales. Morphometric data for the paratypes are summarized in S5.

Hemipenial morphology. The hemipenes of the type (NCBS-AQ052) were studied. Each hemipenis is bilobed, divided for more than half its length (Fig. 4B, S3), longer than wide, and with a naked base. Sulcus spermaticus single, lips smooth and widely open at the apex. Calyculate ornamentation present on each lobe except for the proximal half of the sulcus. Medial side of inner lobes with 6-7 flounces. Thin walled, large, smooth calyces present on proximal half of dorsal and ventral sides of each lobe forming shallow polygonal calyces. Thick walled small, smooth calyces present on the distal half. Apex naked.

Etymology. The species epithet is after the Latin word superbus, meaning magnificent, a reference to the dramatic display of the large dewlap with brilliant breeding colours.

Suggested English name. Superb large fan-throated lizard.

Distribution. Sarada superba sp. nov. is presently only known from its type locality Chalkewadi, Satara District, Maharashtra state (Fig. 8). The altitudinal distribution of this species is $1100 \mathrm{~m}$ to $1300 \mathrm{~m}$ m a.s.l.

Habitat and natural history. The type locality is a high elevation lateritic plateau in the northern Western Ghats (Fig. 14D). Calotes versicolor and Ophisops sp. are other diurnal lizards found in this habitat. Hatchlings (23-30 mm SVL, 34-52 mm TL ( $\mathrm{n}=4)$ ) were seen on 25 October 2013 at the type locality. Fifteen welldeveloped eggs were inside CES 13567. At the type locality, these lizards are known to hide under lateritic rocks and cracks in the lateritic substrate. 
Key to species of Sitana Cuvier, 1829

(based on adult males)

1a. Dewlap colouration in breeding males blue, iridescent white and orange ……............................................................. 2

1b. Dewlap in breeding male yellowish white with only a single blue line .................................................................. 3

2a. Dewlap very large (extending over up to $56 \%$ of the trunk), with enlarged scales and strongly serrated margins; average SVL $50 \mathrm{~mm}$; 65-69 ventral scales Sitana visiri sp. nov.

2b. Dewlap large (extending over up to $46 \%$ of the trunk), with strongly serrated margins, average SVL $40.5 \mathrm{~mm}$, 64-76 ventral scales

Sitana ponticeriana

2c. Dewlap large (extending over up to 33\% of trunk), with enlarged scales and strongly serrated margins, average SVL 35 mm, 100-108 ventral scales Sitana devakai

2d. Dewlap of medium size (extending over up to $29 \%$ of trunk), with enlarged scales and strongly serrated margins, average SVL $34 \mathrm{~mm}, 86-89$ ventral scales Sitana bahiri

3a. Dewlap small, weakly serrated, not reaching axilla Sitana sivalensis complex

3b. Dewlap medium to large, weakly serrated, extending beyond axilla 4

4a. Dewlap medium (extending over up to $29 \%$ of trunk), four small yet enlarged spine-like scales bordering occipital region Sitana laticeps sp. nov.

4b. Dewlap large (extending over up to $45 \%$ of trunk), four prominent enlarged spine-like scales bordering occipital region. Sitana spinaecephalus $\mathrm{sp}$. nov.

Key to species of Sarada Deepak, Karanth and Giri gen. nov. (based on adult males)

1a. Hind limb length exceeds SVL, dewlap large (extending over up to 55\% of trunk), average SVL $62.2 \mathrm{~mm}$, relatively large feet $(0.42 \mathrm{HFL} / \mathrm{SVL})$ Sarada deccanensis comb. nov.

1b. Hind limb length not exceeding SVL

2a. Dewlap very large (extending over up to $52 \%$ of trunk), average SVL $54.5 \mathrm{~mm}$, relatively large feet $(0.40 \mathrm{HFL} /$ SVL) Sarada darwini sp. nov.

2b. Dewlap very large (extending over up to 59\% of trunk), average SVL $67.9 \mathrm{~mm}$, relatively small feet $(0.37 \mathrm{HFL} /$ SVL) Sarada superba sp. nov. 